\title{
Reconstrucción, representación gráfica y análisis de las redes de poder en la alta edad media. Aproximación a las prácticas sociales de la aristocracia a partir del ejemplo de Odón de Cluny $(+942)^{12}$
}

Isabelle Rosé- Université de Rennes 2 - Cerhio, UMR 6258 - Université

Européenne de Bretagne (UEB) ${ }^{3}$

\begin{abstract}
Resumen
Este texto pretende mostrar cómo la utilización de métodos, de conceptos y de análisis sobre las redes sociales pueden ser útiles en el estudio del principio de la Edad Media. Para reconstruir una « red personal » en este periodo, este artículo pone de manifiesto primero varias dificultades : la falta de fuentes, la selección y uso de documentos adecuados, la identifiacion clara de redes aristocráticas así como consideraciones sobre la construcción de redes que evolucionan en el tiempo. Se propone utilizar teorías y métodos tomados prestados de la sociología y se muestra un estudio de caso: la red personal de Odon de Cluny, un miembro importante de la aristocracia que también era abad del monasterio francés de Cluny entre 926 y 942 . Ese caso sirve de ejemplo significativo para ilustrar como funcionaban las redes sociales en la sociedad de la Alta Edad Media.
\end{abstract}

Palabras clave: Haut Moyen Âge, aristocratie, Odon de Cluny, réseaux, Xe siècle.

\begin{abstract}
This paper intends to show how the use of methods, concepts and analysis pertaining to social networks may be relevant to the study of early Middle Ages. In order to retrace a "personal network" for this period, the study first points out several difficulties: the lack of sources, the selection and use of proper documents, the sole identification of aristocratic networks, and the long-term considerations of the networks' construction. The paper then uses sociological theories and methods in a case study, that of the personal network of Odo of Cluny, an important member of the aristocracy who was also abbot of the French monastery of Cluny, between 926 and 942 . This case serves as a perfect example of how social networks worked in the early medieval society.
\end{abstract}

Key words: Early middle age, aristocracy, Odo of Cluny, networks, 10th Century.

\footnotetext{
${ }^{1}$ Artículo traducido por Lola de la Rúa y Ainhoa de Federico

2 Este artículo es la prolongación de una reflexión que aparecerá en portugués en el volumen colectivo, dirigido por Marcelo Candido Da Silva, Os medievalistas e suas fontes. Leituras cruzadas sobre a Alta Idade Média, escrito antes de que yo utilizara el programa Netdraw. Quiero agradecer ante todo a Claire Lemercier por la energía excepcional que ha puesto en las lecturas de este artículo; también me ha ayudado mucho a familiarizarme con Netdraw, a diseñar las hojas de datos y a afinar y enriquecer mis reflexiones; le agradezco igualmente el haberme permitido publicar este artículo en la Revista Redes. Karine Karila-Cohen y Michel Lauwers me han permitido precisar, por otra parte, con sus comentarios, algunos puntos. Mi gratitud va también para los tres reviewers anónimos que han aceptado releer este artículo para la Revista Redes y cuyos comentarios, particularmente estimulantes, me han sido de una gran utilidad para profundizar en algunos puntos.

${ }^{3}$ Enviar correspondencia a: Isabelle Rosé: rosisa@wanadoo.fr
} 


\section{Introducción}

Desde los años 1970, la noción de « red » está en el centro de numerosos trabajos en ciencias sociales. El concepto de « red social » (social Network) fue desarrollada por primera vez por un etnólogo británico, John Barnes, en 1954 y designa "conjuntos de relaciones entre personas o grupos sociales" ${ }^{4}$. Para los sociólogos la reflexión sobre las redes, el análisis informático y la representación gráfica de estos últimos deben permitir delimitar cómo un comportamiento individual se modela por la pertenencia a diferentes conjuntos reticulares, y ver, en cambio, cómo estos comportamientos contribuyen a modificar las estructuras sociales. ${ }^{5}$

Influidos por la evolución global de las ciencias sociales, los historiadores se han amparado en esta noción, empleada frecuentemente de modo metafórico. Desde los años 1990, principalmente en el campo de los estudios anglosajones, muchos investigadores se han dedicado sin embargo a adaptar las técnicas informáticas y las tablas de análisis sociológico de las redes de las sociedades del pasado ${ }^{6}$. Tal como subrayó Claire Lemercier, los trabajos históricos sobre las redes han adoptado globalmente dos tipos de aproximaciones que se distinguen por el objeto que estudian: algunas, mayoritariamente sobre historia contemporánea, se concentran en la estructura misma de la red puesta en evidencia (se habla entonces de "análisis estructural de redes"); otras, la mayor parte en historia moderna, se focalizan en un individuo de quien reconstruyen las relaciones sociales, analizando su naturaleza (se trata en este caso de "análisis egocéntricos de redes"77).

Estas iniciativas son mayoritariamente el caso de los especialistas de historia moderna y sobre todo contemporánea ${ }^{8}$. La adopción por parte de los investigadores

4 J. E. BARneS, « Class and Commities in a norwegian Island Parish », en Human Relations, VII/1, 1954, p. 39-58.

${ }^{5}$ Para un enfoque sociológico de las redes sociales, A. DEGENNE, M. Forsé, Les réseaux sociaux, Paris, 2004 [2ème édition].

6 Para una historiografía de los análisis de redes en historia, las perspectivas adoptadas y una bibliografía de los trabajos importantes. Ibid., p. 88-112. Cfr. también C. LEMERCIER, C. ZALC, Méthodes quantitatives pour I'historien, Paris, 2008, p. 80-102, con precisiones y una puesta a punto regular de la bibliografía y de los programas disponibles en la dirección de internet: http://www.quanti.ihmc.ens.fr/sommaire.php?id=52.

7 C. Lemercier, «Analyse de réseaux et histoire », loc. cit. n., p. 91-94. Para una historiografía de los análisis de redes en historia, las perspectivas adoptadas y una bibliografía de los trabajos importantes, Ibid., p. 88-112. Cfr. también C. Lemercier, C. Zalc, Méthodes quantitatives pour I'historien, Paris, 2008 , p. 80-102, con precisiones y una puesta al día regular de la bibliografía y de los programas disponibles en el sitio de internet: http://www.quanti.inmc.ens.fr/sommaire.php?id=52.

8 Para una bibliografía exhaustiva C. LEMERCIER, «Analyse de réseaux et histoire: une bibliographie. Support d'une intervention pour la préparation de l'agrégation de sciences sociales - mars $2006 »$, en http://www.quanti.ihmc.ens.fr/document.php?id=106. En Francia se pueden citar, en particular, los trabajos de C. LEMERCIER, Un si discret pouvoir. Aux origines de la chambre de commerce 
de estos períodos, de métodos propios de las encuestas sociológicas podría explicarse a primera vista por el carácter relativamente exhaustivo y homogéneo de su documentación, principalmente en relación con las de las épocas "altas" -antigua y medieval- desprovistas de series continuas y de fuentes utilizadas de forma clásica en historia serial, como los registros notariales o parroquiales (al menos hasta el siglo XII $)^{9}$. Más ampliamente, esta preferencia parece derivarse ante todo de una tradición historiográfica fuertemente marcada por el recurso de los métodos cuantitativos y por el impacto de la Nueva historia cuyo renacer, en historia moderna y contemporánea se apoyaba en la utilización de marcos de análisis de los sociólogos ${ }^{10}$.

Habiendo sido globalmente ajena a las técnicas cuantitativas - dada una menor abundancia documental- la medievalística se ha quedado al margen del interés compartido en las ciencias sociales por las redes. El concepto forma parte del vocabulario de los medievalistas, pero se utiliza frecuentemente de forma artificial para los modelos geográficos de "red urbana", "comercial" o "de carreteras"11, bien

de Paris, 1803-1853, Paris, 2003 ; EAD., «Les carrières des membres des institutions consulaires parisiennes au XIX siècle », en Histoire et mesure, 20/1-2, 2005, p. 59-95; EAD., «Liens privés et régulation de l'économie : la famille et l'institution (Paris, XIX ${ }^{\mathrm{e}}$ siècle) 》 en Revue d'histoire du XIX siècle, 33, 2006, p. 23-53.

9 En registros notariales, O. GuYOTJEAnNIn, J. PYCKE et B.-M. Tock, Diplomatique médiévale, Turnhout, Brepols, 2006 (L'atelier du médiéviste, 2), p. 242-245; R. FossIER, Sources de I'histoire économique et sociale du Moyen Âge occidental. Questions, sources et documents commentés, Turnhout, Brepols, 2006 (L'atelier du médiéviste, 6), p. 64-82.

10 Sobre los métodos cuantitativos, C. DELACROIX, F. DOSSE, P. GARCIA, Les courants historiques en France, $X I X^{e}-X X^{e}$ siècle, Paris, 2005, p. 302-357; sobre el impacto de la sociología en la Nouvelle Histoire para los especialistas de los períodos moderno y contemporáneo, p. 392-482.

11 Tomado prestado el modelo geográfico de las "redes urbanas" y "comerciales" en publicaciones recientes:

J. L. FRAY, Villes et bourgs de Lorraine : réseaux urbains et centralité au Moyen Âge, Clermont-Ferrand, 2006 (réseau urbain); L. BUCHHOLZER-RÉMY, Une ville en ses réseaux : Nuremberg à la fin du Moyen Âge, Paris, Belin, 2006 (red urbana); S. DiMMOcK, « Urban and commercial Networks in the Later Middle Ages : Chepstow, Severnside and the Ports of southern Wales », en Archaeologia Cambrensis, 152, 2005, p. 53-68 (redes urbanas y comerciales). E. JAMROZIAK, « Networks of Markets and Networks of Patronage in thirteenth-Century England », en M. PRESTWICH, R. BRITNELL, R. FrAME (éd.), Thirteenth Century England, X, Woodbridge, The Boydell Press, 2005, p. 41-49 (red urbana); P. STABEL, « Markets and Retail in the Cities of the late medieval Low Countries. Economic Networks and socio-cultural Display », en S. CAVACIOCCHI (éd.), Fiere e mercati nella integrazione delle economie europee, secc. XIII-XVIII, Florence, Le Monnier, 2001, p. 797-817 (réseaux commerciaux); M. ComBER, « Trade and Communication Networks in early historic Ireland », en Journal of Irish Archaeology, 10, 2001, p. 7392; J. M. MURRAY, « Of nodes and Networks: Bruges and the Infrastructure of Trade in FourteenthCentury Europe », en P. STABEL, B. BLondÉ, A. GReve (éd.), International Trade in the Low Countries (14th-16th Centuries): Merchants, Organisation, Infrastructure. Proceedings of the International Conference, Ghent-Antwerp, 12th-13th January 1997, Leuven, Garant, 2000, p. 1-14 (redes comerciales); F. BRECHON, «Le réseau urbain en Cévennes et Vivarais », en N. COULET, O. GUYOTJEANNIN (éd.), La Ville au Moyen Age. I : Ville et espace, Paris, Éditions du CTHS, 1998, p. 265-277 ; G. DAHL, Trade, Trust, and Networks : commercial Culture in late medieval Italy, Lund (Sweden), Nordic Academic Press, 1998 (redes comerciales de los comerciantes italianos). Red de carreteras: F. BRECHON, Réseau routier et organisation de l'espace en Vivarais et sur ses marges au Moyen Âge. Thèse de doctorat d'histoire sous la direction de M.-T. Lorcin, Université Lumière-Lyon II, 2000 ; O. BRUAND, Voyageurs et marchandises aux temps carolingiens. Les réseaux de communication entre Loire et Meuse aux VIII et IX siècles, Bruxelles, 2002 ; T. SzABó, « Der Übergang von der Antike zum Mittelalter am 
para designar un conjunto de casas monásticas dependientes de una misma institución ${ }^{12}$ o bien como un concepto impreciso y metafórico, que permite describir grupos informales que no tienen a menudo cimiento territorial y que encuentran una cierta cohesión gracias a lazos efímeros. Es esta última acepción la que ha invadido el campo de los estudios medievales donde últimamente se evocan fácilmente - pero sin reconstruirlas realmente - redes de influencia, de poder o de patrocinio ${ }^{13}$, redes de comerciantes y de clientela ${ }^{14}$, redes intelectuales $\mathrm{y} / \mathrm{o}$

Beispiel des Straßennetzes », en U. LIndgren (éd.), Europäische Technik im Mittelalter, 800 bis 1400 : Tradition und Innovation, Berlin, Gebr. Mann, 1996, p. 25-43.

12 Para las dependencias monásticas: N. Bouter (éd.), Naissance et fonctionnement des réseaux monastiques et canoniaux (Actes du premier colloque international du CERCOM, Saint-Étienne, 16-18 novembre 1985), Saint-Étienne, 1991 ; J. BURGTORF, H. NiCHOLSON (éd.), International Mobility in the Military Orders (Twelfth to Fifteenth Centuries): Travelling on Christ's Business, Cardiff, 2006 ; I. CARTRON, Les pérégrinations de Saint-Philibert. Genèse d'un réseau monastique dans la société carolingienne, Rennes, Presses Universitaires de Rennes, 2010. N. Deflou-LECA, Saint-Germain d'Auxerre et ses dépendances (Ve-VIIIe siècle), Saint-Étienne, Presses Universitaires de Saint-Étienne, 2010.

13 W. YSEBAERT, «The Power of personal Networks : Clerics as political Actors in the Conflict between Capetian France and the County of Flanders during the last Decade of the Twelfth Century », en B. Bolton, C. MeEk (éd.), Aspects of Power and Authority in the Middle Ages, Turnhout, 2007, p. 165-184. J. DUMOLYN, « Jan van den Driessche / Jehan de la Driesche, un fonctionnaire flamand au service de Louis XI », en Revue historique, 309/1, 2007, p. 71-90 (evocación del rol de las "redes políticas de los funcionarios burguiñones a partir de un ejemplo); mismo proceso en ID., « Les réseaux politiques locaux en Flandre sous la domination bourguignonne : les exemples de Gand et de Lille », en Revue du Nord, 88, 2006, p. 309-329 (estudio más prosopográfico que reticular de las "redes políticas", de los sistemas de patronazgo y de clientela que permiten la formación del Estado burguiñón en el siglo XV). J. BURTON, « Fundator noster : Roger de Mowbray as Founder and Patron of Monasteries », en E. JAMROZIAK, J. BURTON (éd.), Religious and Laity in Western Europe 1000-1400, Brepols, Turnhout, 2006 , p. 23-39. A. AYTON, "The Battle of Crécy : Context and Significance », en A. AYTON, P. PRESTON (éd.), The Battle of Crécy, 1346, Woodbridge, Boydell Press, 2005, p. 1-34 (análisis de las armadas de Crécy como "redes")A.-J. BIJSTERVELD, « Overqualified for their Jobs ? Rural Deans in the Diocese of Liège (Fifteenth and Sixteenth Centuries) », en K. GoudriaAN, J. VAN MOOLENBROEK, A. TerVoORT (éd.), Education and Learning in the Netherlands, 1400-1600, Leiden, Brill, 2004, p. 87-111 (evocación de las relaciones entre decanos rurales como una "red"). M. DAMEN, « Het Hof van Holland in de late Middeleeuwen », en Holland, 35/1, 2003, p. 1-8 (redes de relaciones entre funcionarios en la corte de Holanda, al final de la Edad Media). D. GrummitT, « Public Service, private Interest and Patronage in the fifteenth-century Exchequer », en L. CLARK (éd.), The Fifteenth Century, III, Woodbridge, Boydell \& Brewer, 2003, p. 149-162 (redes de influencia semi-privadas). H.-D. KAHL, « Feldkirchen und Dietrichstein zwischen den Mächtigen des zwölften Jahrhunderts. Ein Beitrag zu den Anfängen bambergischer Besitzungen in Kärnten », en Carinthia, 193, 2003, p. 225-251 (redes episcopales de poder alrededor de Bamberg). B. SAWYER, «The Civil Wars revisited », en Historisk tidsskrift (Oslo), $82 / 1,2003$, p. $43-73$ (redes de poder, principalmente femeninas, en la Europa del Norte en el siglo XIII). E. PASCUA, «South of the Pyrenees : Kings, Magnates and political Bargaining in Twelfth-Century Spain », en Journal of Medieval History, 27/2, 2001, p. 101-120 (redes aristocráticas y su juego en la puesta en funcionamiento del poder real ibérico en el siglo XII) C. M. CHATTAWAY, « Looking a medieval Gift Horse in the Mouth : the Role of the Giving of Gift Objects in the Definition and Maintenance of the Power Networks of Philip the Bold», en Bijdragen en mededelingen betreffende de geschiedenis der Nederlanden, 114/1, 1999, p. 1-14 (redes de poder burguiñonas al final de la Edad Media). M. BoonE, « Het falen van de netwerken », en W. Prevenier (éd.), Prinsen en Poorters : Beelden van de laatmiddeleeuwse samenleving in de Bourgondische Nederlanden, 1384-1530, Antwerpen, 1998, p. 344354 (redes de poder en Flandes al final de la Edad Media). M. Boone, « Netwerken in de steden », en W. Prevenier (éd.), Ibid., p. 232-257 (redes de poder intra-urbanas). C. RAPP, « Ritual Brotherhood in Byzantium », en Traditio, 52, 1997, p. 285-326 (prácticas de fraternidad ritual y su rol en tanto que red de poder). C. RICHMOND, «Ruling Classes and Agents of the State : formal and informal Networks of Power », en Historical Sociology, 10/1, 1997, p. 1-26 (redes de poder en la Inglaterra tardo-medieval). B. HiLL, «Alexios I Komnenos and the imperial Women», en M. MulletT, D. SMrthe (éd.) Alexios I Komnenos: Papers on the Second Belfast Byzantine International Colloquium, 14-16 April 1989, Belfast, Belfast Texts and Translations, 1996, p. 37-54 (redes de poder imperiales). L. BALLETTO, « Ethnic Groups, cross-social and cross-cultural Contacts on Fifteenth-Century Cyprus », en Mediterranean Historical Review, 10/1-2, 1995, p. 35-48 (redes de poder inter-comunitarias). W. PREVENIER, M. BOONE, 
religiosas ${ }^{15}$, redes de amistad $^{16}$ o redes de emigrantes ${ }^{17}$. Adornado con este significado, el concepto de red ha afectado especialmente a algunos actores de la investigación, mayoritariamente a bajo-medievalistas, especialistas de Europa del Norte (Flandes, Inglaterra y más parcialmente las regiones escandinavas), de Bizancio y de Italia septentrional. Más allá de estos usos metafóricos, algunos

«De steden van de Zuidelijke Nederlanden in de late middeleeuwen: stedelijke identiteit en corporatieve solidariteiten », en Tijdschrift van het Gemeentekrediet, 183, 1993, p. 25-45 (redes de poder urbano en Flandes al final de la Edad Media). S. L. Mooers, « Networks of Power in Anglo-Norman England », en Medieval Prosopography, 7/2, 1986, p. 25-54.

14 E. JAMROZIAK, « Networks of Markets and Networks of Patronage in Thirteenth-Century England », en M. PRestwich, R. BRITNelL, R. Frame (éd.), Thirteenth Century England, X, Woodbridge, The Boydell Press, 2005, p. 41-49. J. Rollo-Koster, «Amongst Brothers: Italians' Networks in Papal Avignon (1360s-80s) », en Medieval Prosopography, 21, 2000, p. 153-189. D. KuSMAN, « Entre noblesse, ville et clergé. Les financiers lombards dans les anciens Pays-Bas aux XIVe $-\mathrm{XV}^{\mathrm{e}}$ siècles: un état de la question », en Publications du Centre européen d'études bourguignonnes (XIVE-XVI $I^{e}$ s.), 39, 1999, p. 113-132. W. PreVenier, « De netwerken in actie », en W. PreVenier (éd.), Ibid., p. 294-319 (redes de clientela).

15 C. FABris, Étudier et vivre à Paris au Moyen Âge : le collège de Laon, Paris, Droz, 2005, p. 293-300 (análisis de un colegio universitario como lugar que favorece las relaciones entre personas que han estudiado allí). T. O'KEEFFE, « Wheels of Words, Networks of Knowledge: Romanesque Scholarship and Cormac's Chapel », en D. BRACKEN, D. Ó RIAIN-RAEDEL (éd.), Ireland and Europe in the Twelfth Century, Dublin, Four Courts Press, 2006, p. 257-269. R. A. O'SUlLIVAN, « The School of Love : Marguerite Porete's Mirror of Simple Souls », en Journal of Medieval History, 32/2, 2006, p. 143-162 (evocación de "redes" de monasterios para explicar su educación intelectual). M. JURKOWSKI, « Lollard Book Producers in London in 1414 », en H. BARR, A. M. HUTCHISON (éd.), Text and Controversy from Wyclif to Bale, Turnhout, Brepols, 2005, p. 201-226. D. ReVEnEY, «Middle English Writings for Women : Ancrene Wisse », en D. Johnson, E. TRehARne (éd.), Readings in Medieval Texts, Oxford, Oxford University Press, 2005, 198-212 (redes intelectuales femeninas resultantes de la lectura de manuscritos). D. YounGs, «Cultural Networks », en R. RAdulescu, A. TRuelove (éd.), Gentry Culture in Late Medieval England, Manchester, Manchester University Press, 2005, p. 119-133 (circulación de manuscritos y creación de redes intelectuales en el seno de la gentry inglesa al final de la Edad Media); W. SCHEEPSMA, « Mystical Networks in the Middle Ages ? On the first Women Writers in Dutch and their literary Contacts », en S. VAN DiJk, P. BRoomans, J. VAN DER MeUlen, P. VAN OOSTRUm (éd.), I Have Heard about You, Hilversum, Uitgeverij Verloren, 2004, p. 43-60 («redes intelectuales" de los primeros místicos que escribieron en holandés, a partir del siglo XIII). B. CARDON, B. DEKEYZER, «Dirk Bouts in de universiteitsstad : intellectuele netwerken », en K. VEELENTURF (éd.), Geen povere schoonheid: Laat-middeleeuwse kunst in verband met de Moderne Devotie, Nijmegen, Valkhof Pers, 2000, p. 195-221 (redes intelectuales en Flandes al final de la Edad Media, estudiados a través de obras de arte). H. SERVANT, Artistes et gens de Lettres à Valenciennes à la fin du Moyen Âge (vers 1440-1507), Klincsieck, 1998. M. HAINES, « Artisan family Strategies: Proposals for Research on the Families of Florentine Artists », en G. CIAPPELLI, P. L. RuBIN (éd.), Art, Memory, and Family in Renaissance Florence, Cambridge, Cambridge University Press, 29/1, 2000, p. 163-175. S. GoldiN, " "Companies of Disciples" and "Companies of Colleagues" : Communication in Jewish intellectual Circles », en S. MenACHE (éd.), Communication in the Jewish Diaspora: The Pre-Modern World, Leiden, Brill, 1996, p. 127-139 (redes de rabinos). M. MULLETT, Theophylact of Ochrid: Reading the Letters of a Byzantine Archbishop, Birmingham, 1996 (redes de corresponsales a finales del siglo XI y al principio del siglo XII). L. MARTINES, « Love and Hate in Renaissance Patronage : Italy », en The Italianist, 14, 1994, p. 5-31. K. ScotT, « Urban Spaces, Women's Networks, and the lay Apostolate in the Siena of Catherine Benincasa », en A. MATTER, J. COAKLEY (éd.), Creative Women in Medieval and Early Modern Italy: A Religious and Artistic Renaissance, Philadelphia, University of Pennsylvania Press, 1994, p. 105-119 (redes místicas en Italia).

16 E. ARTIFONI, «Segreti e amicizie nell'educazione civile dell'età dei comuni », en Micrologus, 14, 2006, p. 259-274. J. P. HASELDINE, « Thomas Becket : martyr, saint and friend ? », en R. GAMESON, H. LeYSER (éd.), Belief and Culture in the Middle Ages : Studies presented to Henry Mayr-Harting, Oxford, Oxford University Press, 2001, p. 305-317.

17 J. LAUGHTON, E. JONES, C. C. DYER, « The urban Hierarchy in the later Middle Ages : a study of the East Midlands », en Urban History, 28/3, 2001, p. 331-357. P. W. MCCRAY, «Creating Networks of Skill: Technology Transfer and the Glass Industry of Venice », en Journal of European Economic History, 28/2, 1999, p. 301-333. J. CASTAÑo GonZÁLEZ, « Social Networks in a Castilian Jewish Aljama and the Court Jews in the Fifteenth Century : a preliminary Survey (Madrid 1440-1475) », en En la España medieval, 20, 1997, p. 379-392 (redes de la diáspora judía en España). 
estudios han intentado inscribirse en las huellas abiertas por los modernistas y estudiosos de la edad contemporánea, intentando aproximaciones más sistemáticas y más sociológicas de las redes medievales. Estas iniciativas son poco numerosas especialmente en el campo de los estudios francófonos- y son siempre posteriores al siglo $\mathrm{XII}^{18}$. Los especialistas de la alta Edad Media han seguido estas tendencias globales, es decir que utilizan la noción de "red para comprender el ejercicio del poder, en el marco de un "Estado que se apoya en grupos de personas"

${ }^{18}$ La mayor parte de los estudios conducen a los siglos XIV y XV. R. BOULET, Comparaison des graphes, applications à l'étude d'un réseau de sociabilité paysan au Moyen Âge. Thèse de doctorat de mathématiques sous la direction de J.-L. Abbé, Université de Toulouse 2, 2008 (enfoque matemático para una reconstrucción de las redes campesinas). R. BOULET, F. HAUTEFEUILLE, B. JOUVE, P. KUNTZ, B. LE Goffic, F. Picarougne, N. Villa, «Sur l'analyse de réseaux de sociabilité de la société paysanne médiévale », en Méthodes Computationnelles pour Modèles et Apprentissages en Sciences Humaines et Sociales (MASHS), 10-11 mai 2007, Brest [disponible en http://conferences.telecombretagne.eu/data/mashs2007/Papier/Boulet Kuntz-et-al final.pdf] (artículo resultante de la colaboración entre medievalistas y matemáticos para reconstruir las redes de sociabilidad campesinas al final de la Edad Media, en una perspectiva de análisis estructural de redes; este tipo de enfoque, actualmente llevado a cabo por $F$. Hautefeuille, está en curso de realización en el cuadro de un proyecto ANR). A. POLDEN, «The social Networks of the Buckinghamshire Gentry in the Thirteenth Century », en Journal of Medieval History, 32/4, 2006, p. 371-394 (estudio realizado, gracias a los métodos de análisis de redes, sobre un grupo de una quincena de familias caballerescas y de los lazos que las unen). M. GRÜNBART, " "Tis Love that has warm'd us". Reconstructing Networks in $12^{\text {th }}$ Century Byzantium », en Revue belge de philologie et d'histoire, 83/2, 2005, p. 301-313 (esbozo de reconstrucción de una red de corresponsales bizantinos, pero poco desarrollado). D. G. SHAW, «Social Networks and the Foundations of Oligarchy in medieval Towns », en Urban History, 32/2, 2005, p. 200222 (estudio de la emergencia de las oligarquías urbanas, a partir del estudio de redes sociales de la ciudad de Wells). M. SORTOR, «The Measure of Success : Evidence for immigrant Networks in the southern Low Countries, Saint-Omer 1413-1455», en Journal of Family History, 30/2, 2005, p. 164190 (utilización de métodos de análisis sociológicos para reconstruir las redes de emigrantes -hombres y mujeres- instalados en Saint-Omer en la primera mitad del siglo XV). J. M. BENNETT, « The Tie that binds : peasant Marriages and Families in late medieval England », en C. NeEL (éd.), Medieval Families, Toronto, University of Toronto Press, 2004, p. 214-233 [reimpresión de un artículo de 1984] (utilización de métodos de análisis de redes para estudiar el rol de los matrimonios en las redes de parentesco campesinas en Inglaterra, en el siglo XIV). J. DUMOLYN, «Investeren in sociaal Kapitaal. Netwerken en sociale Transacties van Bourgondische Ambtenaren », en Tijdschrift voor sociale geschiedenis, 28/4, 2002, p. 417-438 (reflexión metodológica sobre el análisis de redes sociales y del capital social a partir del ejemplo de la corte de Borgoña, en los años 1385-1492). C. KLAPISCH-ZUBER, «"Kin, Friends, and Neighbors": the urban Territory of a merchant Family in $1400 »$, en P. FindLEN (éd.), The Italian Renaissance, Malden, Blackwell, 2002, p. 97-123 (reconstrucción de redes, principalmente de parenteco y de amistad de Lapo, un comerciante italiano de los años 1400, a partir del análisis de su libro de familia, pero sin el recurso directo de los métodos de análisis de redes). U. VonRuFs, Die Politische Führungsgruppe Zürichs zur Zeit von Hans Waldmann (1450-1489): Struktur, politische Networks und die sozialen Beziehungstypen Verwandtschaft, Freundschaft und Patron-Klient-Beziehung, Bern, Peter Lang, 2002. P. STABEL, «De gewenste Vreemdeling. Italiaanse kooplieden en stedelijke maatschappij in het laat-middeleeuws Brugge », en Jaarboek voor Middeleeuwse Geschiedenis, 4, 2001, p. 189-221 (comparación de redes sociales de diferentes comerciantes italianos en Brujas al final de la Edad Media). C. NOLTE, «Gendering princely Dynasties: some Notes on family Structure, social Networks, and Communication at the Courts of the Margraves of Brandenburg-Ansbach around 1500 , en Gender and History, 12/3, 2000, p. 704-721 (reconstrucción y análisis de la red familiar de un grupo aristocrático germánico al final de la Edad Media, a partir de su correspondencia y de sus evoluciones). M.-T. CARON, «Adellijke netwerken », en W. PreVEnIER (éd.), Prinsen en Poorters : Beelden van de laat-middeleeuwse samenleving in de Bourgondische Nederlanden, 1384-1530, Antwerpen, 1998, p. 258-267 (estructuras de las redes sociales aristocráticas burguiñonas al final de la Edad Media, analizadas en parte con fuentes iconográficas). F. VERHAEGHE, « Medieval and later social Networks: the Contribution of Archaeology », en H. Hundsbichler, G. JARITz, T. KüHTReiber (éd.), Die Vielfalt der Dinge : Neue Wege zur Analyse mittelalterlicher Sachkultur. Internationaler Kongreß Krems an der Donau 4. bis 7. Oktober 1994, Wien, Verlag der Österreichischen Akademie der Wissenschaften, 1998, p. 263-311 (redes sociales analizadas a través de la arqueología). J. F. PADGET, C. K. ANSELL, « Robust Action and the Rise of the Medici, 1400-1434 », en American Journal of Sociology, 98, 1993, p. 1259-1319 (Hipótesis, gracias a los métodos de análisis de redes, sobre las razones y las modalidades de la ascensión social 
$(\text { Personenverbandstaat })^{19}$. Más concretamente, el concepto viene a describir las prácticas sociales de la aristocracia merovingia y carolingia, cuyos miembros están unidos por relaciones de parentesco carnal o espiritual, de alianza, de amicitia y de fidelidad. Algunos trabajos han mostrado de esta forma que la participación en el poder se daba en función de redes, pero permitía también darles más consistencia $^{20}$. Por lo tanto, la existencia, la génesis o el funcionamiento de tales redes $-y$ especialmente el tipo de relaciones que las animan- son raramente objeto de demostraciones, pero se refieren, más bien, a una serie de postulados que asimilan todas las huellas de lazos sociales identificados en las fuentes como prueba de la existencia de una red constituida, factor de reconocimiento social y de poder: cualquier poderoso tiene necesariamente relaciones, es decir una "red" importante; una persona que escribe muchas cartas dispone forzosamente de una

de la familia de los Médicis por la valorización de las relaciones sociales complejas que mantenía con la nobleza florentina)

19 G. Melville, «L'institutionnalité médiévale dans sa pluridimensionnalité », en J.-C. SCHMITT, O. G. OeXLe (éd.), Les tendances actuelles de I'histoire du Moyen Âge en France et en Allemagne. Actes du colloque de Sèvres (1997) et Göttingen (1998) organisés par le Centre national de la Recherche scientifique et le Max-Planck-Institut für Geschichte, Paris, 2002, p. 243-264, ici p. 248-249. Cfr. sobre todo, G. Althoff, Verwandte, Freunde und Getreue. Zum politischen Stellenwert der Gruppenbindungen im frühen Mittelalter, Darmstadt, 1990.

${ }^{20}$ B. DUMÉZIL, « Gogo et ses amis : écriture, échanges et ambitions dans un réseau aristocratique de la fin du VI siècle », en Revue historique, 643/3, 2007, p. 553-593 (reconstrucción de la "red aristocrática" de Gogo, un noble merovingio, mediante el uso de técnicas prosopográficas, pero sin aplicar las formas de análisis sociológico). S. M. SINDBÆEK, « Networks and nodal Points : the Emergence of Towns in early Viking Age Scandinavia », en Antiquity, 81/311 (2007), p. 119-132 (redes urbanas y comerciales en Escandinavia, en los siglos VIII y IX). J. PALMER, « The « vigorous Rule » of Bishop Lull : between Bonifatian Mission and Carolingian Control », en Early Medieval Europe, 13/3, 2005, p. 249276 (explicación de la construcción de la leyenda de San Bonifacio según las relaciones políticas y de la inserción en las "redes monásticas" de su discípulo Lull de Mainz). J. STORY, « Charlemagne and the Anglo-Saxons », en J. STORY, Charlemagne. Empire and Society, Manchester, Manchester University Press, 2005, p. 195-210 (análisis de los lazos de amistad o de fidelidad y de las relaciones diplomáticas para comprender la influencia franca sobre Inglaterra, principalmente a partir de intercambios epistolares). J. HINES, « Society, Community and Identity », en T. ChARLES-EDWARDS (éd.), After Rome, Oxford, Oxford University Press, 2003, p. 61-101, p. 275-276 (redes en Irlanda e Inglaterra en la muy alta Edad Media). J. A. MCNAMARA, « Women and Power through the Family revisited », en M. C. ERLER, M. KowAleski (éd.), Gendering the Master Narrative: Women and Power in the Middle Ages, Cornell University Press, 2003, p. 17-30 (Análisis del poder ejercido por algunas mujeres en la alta Edad Media, gracias a sus lazos con las "redes" reales, empleado de forma metafórica). S. M. PEARCE, « Processes of Conversion in north-west Roman Gaul », en M. CARVER (éd.), The Cross Goes North, York, York Medieval Press, 2003, p. 61-78 (relaciones entre clérigos, principalente via cambios de relíquias, explicando la cristianización de la Galia, pero el empleo del término "red" es metafórico) H. ReImITZ, « Social Networks and Identities in frankish Historiography. New Aspects of the History of Gregory of Tours Historiæ », en R. Corradini, M. Diesenberger, H. Reimitz (éd.), The Construction of Communities in the Early Middle Ages. Texts, Resources and Artifacts, Leiden, 2002, p. 229-268 (análisis de las diferentes versiones conservadas de los Dix livres d'histoires de Grégoire de Tours, según los medios -más que las "redes"que están en el origen de los manuscritos). M. GARRISSON, « Les correspondants d'Alcuin », en B. JUDIC, Ph. Depreux (éd.), Alcuin, de York à Tours. Écriture, pouvoir et réseaux dans l'Europe du haut Moyen Âge. Annales de Bretagne et des pays de l'Ouest, 111, 2004, p. 319-331 (reconstrucción de la "red epistolar" de Alcuin, pero sin utilizar las formas de análisis sociológicas). R. LE JAN, « Continuity and Change in the Tenth-Century Nobility », en A. J. Duggan (éd.), Nobles and Nobility in Medieval Europe: Concepts, Origins, Transformations, Woodbridge, Boydell \& Brewer, 2000, p. 53-68, retomado en Femmes, pouvoir et société dans le haut Moyen Âge, Paris, 2001, p. 190-203 (evocación de la recomposición de "redes de poder" en el siglo X, pero sin utilizar las modos de análisis sociológicos ); cf también EAD., «Réseaux de parenté, memoria et fidélité autour de I'an 800 », Ibid., p. 108118 (mención de las "redes de parentesco" estructurando la sociedad, pero sin utilizar las formas de análisis sociológico). 
"red de interlocutores". Este punto de partida metodológico se explica por el hecho de que la utilización del término por los altos medievalistas no deriva de la adopción de tablas de análisis sociológicos (casi nunca evocadas en publicaciones de especialistas), sino -como en historia antigua- de una tradición de estudios prosopográficos cuyo objetivo principal reside en la constitución de bases de datos de personas que participan en un mismo grupo y donde se identifican con frecuencia lazos familiares o de amistad. La reflexión sobre las redes aparece aquí como secundaria, en el mejor de los casos, relegada al estatus de factor de explicación del poder de un individuo o de un parentesco, pero no como un objeto de estudio en si mismo. La ausencia de análisis reticulares sistemáticos en los estudios sobre la alta Edad Media no deriva por consiguiente solamente del carácter incompleto de las fuentes, sino de una doble tradición historiográfica. Esta última prioriza aproximaciones de corte antropológico frente a los planteamientos sociológicos. ${ }^{21}$ Está igualmente centrada, no tanto en el estudio de "redes" -que deben ser exploradas tanto desde el punto de vista de las personas que participan en ella, como de los vínculos que estos últimos mantienen entre ellas- sino en la reconstrucción de "medios sociales", "círculos", "grupos" o "entornos", es decir de grupos de personas reunidas por un interés común (la proximidad real, los lazos de parentesco, la participación en una corte o en un círculo de saber, etc.) y que se perciben a través de algunos de sus representantes.

Propongo aquí reflexionar sobre la adaptación de cuadros de análisis provenientes de lecturas sociológicas y de métodos de análisis informáticos de las redes a los problemas específicos de las sociedades de la alta Edad Media occidental, a partir del caso de un gran aristócrata del siglo $X$, Odón (nacido hacia 879 y muerto en 942), segundo abad de Cluny y reformador monástico aguerrido, al que he consagrado mi tesis doctoral ${ }^{22}$. Inscrito en una perspectiva biográfica, uno de los

\footnotetext{
${ }^{21}$ Con este uso masivo del término de "red" que es esencialmente metafórica, se pueden mencionar dos iniciativas originales relativas a la alta Edad Media, que utilizan claramente la sociología. Richard Gaskins ha aplicado así los conceptos del análisis reticular a la materia de las sagas islandesas, particularmente en sus relatos genealógicos, para sacar conclusiones de ellas sobre las evoluciones sociales y políticas ocurridas durante el período de la Commonwealth (entre 930 y 1262), que constituye el cuadro cronológico de sus relatos; cfr. R. GASKINS, "Network Dynamics in Saga and Society $\gg$, en Scandinavian Studies, 77/2, 2005, p. 201-216. El vocabulario y los métodos de la Networks' analysis han sido utilizados, por otra parte, por Søren Michael Sindbæk para jerarquizar algunos lazos de comercio vikingos, al mismo tiempo a partir de fuentes narrativas y catálogos de excavaciones arqueológicas, en una perspectiva de reconstrucción de redes comerciales; ; cfr. S. M. SINDBFK, «The small World of the Viking. Networks in early medieval Communications and Exchange », Norwegian Archaeological Review, 40/1, 2007, 59-74. Estos dos estudios se refieren no obstante ante todo a la Europa escandinava e intentan estudiar verdaderas redes sociales.

22 Me permito remitir a la publicación de este trabajo, I. RosÉ, Construire une société seigneuriale. Itinéraire et ecclésiologie de l'abbé Odon de Cluny (fin du IX $X^{e}$-milieu du $X^{e}$ siècle), Turnhout, Brepols, 2008.
} 
aspectos de mi trabajo consistía en reinsertar a este personaje en el seno de las redes aristocráticas del fin del siglo IX y de la primera mitad del siglo $X$. En concreto, se trataba de comprender cómo Odón consiguió desarrollar una forma de poder original, el multi-abadismo (es decir la dirección simultánea de una quincena de establecimientos monásticos tomados a su cargo tras reformas) a una muy gran escala geográfica, entre el Loira y la región de Roma, y analizar las fuentes, principalmente relacionales, de este dominio de un nuevo tipo. Había que delimitar a continuación a partir de este recorrido individual, las recomposiciones de la sociedad aristocrática en una época de transición entre la edad carolingia y el período feudal, marcada por una redistribución del poder en el seno de las redes nobiliarias. Más globalmente, se trataba finalmente de evaluar las continuidades y los cambios en el ejercicio del poder en un momento de eclipse de la autoridad real y de la toma de poder de las figuras principescas en el reino del Oeste. La adopción de cuadros de análisis egocéntricos, así como la representación gráfica de las redes personales, aparecieron como una aproximación metodológica pertinente para comprender las realidades sociales del siglo $\mathrm{X}$. $\mathrm{Y}$ además permiten renovar la aproximación biográfica, respondiendo especialmente a las críticas de Pierre Bourdieu en su contra ${ }^{23}$. Mencionando "la ilusión biográfica", este último había denunciado, en 1986, el postulado de la linealidad y de la sucesión de acontecimientos que implica este tipo de conducta en tanto que relato, en la medida en la que trata de darle una coherencia y atribuir un sentido "artificial" a la vida de un individuo. Subrayaba asimismo la falta de pertinencia metodológica que implica el estudio del tema como una entidad autónoma, mientras que los acontecimientos biográficos se definen tanto como "emplazamientos y desplazamientos" en un campo social en perpetua recomposición ${ }^{24}$. En otros términos, cada acontecimiento de la vida de un individuo sólo debería ser analizado en función de la inserción de éste en el seno de un cierto campo social. Ahora bien, esto es exactamente lo que permite la aproximación reticular, a condición de no considerar la vida de un individuo como un todo coherente, sino como un itinerario biográfico, es decir, como una sucesión de acontecimientos biográficos, siendo esos breves instantes "fijados" por la documentación los que abren, mediante la

\footnotetext{
23 P. BOURDIEU, «L'illusion biographique », en ID., Raisons pratiques. Sur la théorie de l'action, Paris, 1994, p. 81-89 [Primera publicación en Actes de la recherche en sciences sociales, 62-63, 1986].

${ }^{24}$ Para la cita, Ibid., p. 88.
} 
documentación, la posibilidad de un conocimiento puntual de la complejidad del campo social en el que se inserta un hombre ${ }^{25}$.

Mi reflexión se articulará en tres tiempos. Me entretendré primero en las teorías del análisis de redes, reflexionando sobre los problemas que plantean para la alta Edad Media. Propondré a continuación pistas metodológicas para reconstruir las redes sociales en la alta Edad Media. En último lugar, expondré el itinerario biográfico del abad de Cluny, adoptando una aproximación reticular.

\section{Redes sociales y especificidades de la Alta Edad Media}

El resurgimiento del enfoque biográfico, el interés por las manifestaciones de la singularidad lleva a la micro-historia, así como la afirmación de la necesidad de un "retorno del acontecimiento" explican -con un desajuste de algunos años- las iniciativas de tratamiento informático y de representación gráfica de las redes personales por algunos historiadores inspirados por la sociología, en los años 1990.26. Estos pasos revelan "análisis egocéntricos" porque parten de un individuo para determinar las relaciones que mantiene con otras personas.27. La iniciativa viene de algunos historiadores modernistas, especialistas de la "República de las Letras" que han creado un programa llamado Arcano, concebido en principio para editar correspondencias, conversaciones, memorias y diarios íntimos o de viaje, fuentes calificadas "ego documentos", es decir, "escritos personales que explican las trayectorias individuales"28. Este programa es también una base de datos, a la vez

25 Esta noción de "itinerario" ha sido adoptada en particular por especialistas de historia contemporánea: N. BAYON, Eugène Spuller (1835-1896). Itinéraire d'un républicain entre Gambetta et le ralliement, Villeneuve d'Ascq, 2006 ; F. LAFON, Guy Mollet. Itinéraire d'un socialiste controversé (19051975), Paris, 2006. Cfr. también en lo que respecta a los trabajos sociológicos, la noción de "recorrido de vida", de "trayectoria" o de "bifurcación biográfica", desarrollada por Claire Bidart, especialmente por sus estudios más reciente, C. BIDART, «Dynamiques des réseaux personnels et processus de socialisation: évolutions et influences des entourages lors des transitions vers la vie adulte », en Revue Française de Sociologie, 49/3, 2008, p. 559-583 ; EAD., « Crises, décisions et temporalités: autour des bifurcations biographiques », en Cahiers internationaux de sociologie, 120, 2006, p. 29-57 ; EAD., « Les temps de la vie et les cheminements vers l'âge adulte », en Lien social et Politiques, 54, 2005, p. 5163 ; EAD., D. LAVENU « Evolutions of personal Networks and life Events », en Social Networks 27/4, 2005, p. 359-376. Agradezco a C. Lemercier el haberme indicado estas referencias.

26 Sobre el renacer biográfico, F. DossE, Le pari biographique. Écrire une vie, Paris, 2005, p. 251-325. Sobre el "regreso del acontecimiento", P. NORA, « Le retour de l'événement », en J. LE GOFF, P. NORA (éd.), Faire de I'histoire. I. Nouveaux problèmes, Paris, 1978, p. 285-308 y, muy recientemente, F. DosSE, Renaissance de l'événement. Un défi pour l'historien : entre sphinx et phénix, Paris, PUF, 2010 (Le nœud gordien).

27 C. LEMERCIER, « Analyse de réseaux et histoire », loc. cit. n. iError! Marcador no definido., p. 9192.

28 Para las publicaciones del grupo de investigación ligado a Arcane, P.-Y. BEAUREPAIRE (éd.), La plume et la toile. Pouvoirs et réseaux de correspondance dans l'Europe des Lumières, Arras, 2002; ID., D. TAURISSON (éd.), Les Ego-documents à I'heure de l'électronique. Nouvelles approches des espaces et réseaux relationnels, Université Paul-Valéry-Montpellier III, 2003 ; P.-Y. BEAUREPAIRE, J. HÄSELER et A. McKenna (éd.), Les Réseaux de correspondance à l'âge classique (XVI $I^{e}-X V I I I^{e}$ siècle), Saint-Étienne, 
prosopográfico y relacional, donde algunas informaciones pueden ser informadas en campos distintos, a partir de diarios íntimos o de correspondencia mantenida por un individuo preciso.29. Permite asimismo captar la identidad de las personas encontradas, el lugar y la fecha de la interacción y el tipo de lazos mantenidos. A partir de esta captación, el programa construye automáticamente la red personal del individuo y conduce a una visualización de todas sus relaciones sociales en un tiempo y un lugar dados, por lo menos tal como pueden ser representadas gráficamente a partir de las fuentes tratadas. El programa representa también la naturaleza, la reciprocidad y la intensidad de estos lazos sociales por la intensidad y el sentido de las líneas de flecha (figura 1).

Manejar un análisis de este tipo, en términos de redes, supone en principio confrontar algunos postulados sociológicos con los problemas propios de los medievalistas. Yo propondría a continuación pistas metodológicas para reconstituir las redes para la alta Edad Media.

2006. Para una definición de los ego-documentos P.-Y. BEAUREPAIRE, D. TAURISSON, «Introduction », en Ibid., p. 9-20, p. 10 para la mención. Para una presentación del programa Arcane : http://arcanews.univ-montp3.fr/arcane/Arc/dcs ?ID=52433\%26Session=ITCGOHJXJJBFYNU002. Para una lista de los trabajos de edición y de reconstitución de las redes realizadas gracias a Arcane o en curso de realización, http://www.observatoire-critique.org/IMG/CercleArcane-2.pdf. Cf también en la continuidad de la micro-storia, las reflexiones de M. GRIBAUDI, «Percorsi individuali ed evoluzione storica : quattro percorsi operai attraverso la Francia dell'Ottocento », en Quaderni Storici, 106/1, 2001, p. 115-152. Agradezco a C.Lemercier por haberme indicado esta referencia.

${ }^{29}$ En la dimensión de base de datos prosopográfico y relacional de Arcane y sobre su funcionamiento, A. MCKenNA, A. LeRoux, «Les réseaux de correspondance de Pierre Bayle : réalité instable et représentation électronique », en P.-Y. BEAUREPAIRE, D. TAURISSON (éd.), Les Ego-documents, op. cit. $\mathrm{n}$. 28 , p. 399-420, disponible en la dirección siguiente: http://arcanews.univmontp3.fr/egodoc/Arc/dcs secmattxt?IDS $=1112112 \& I D=1112012 \% 260 c c=007 \quad y \quad$ sobre todo Z. MOUTOUKIAS

«Réseaux de négociants ou réseaux egocentrés : une approche méthodologique », en Ibid., p. 447468, disponible en: http://arcanews.univ-montp3.fr/egodoc/Arc/dc_d?ID=1074112\%260cc=00. 


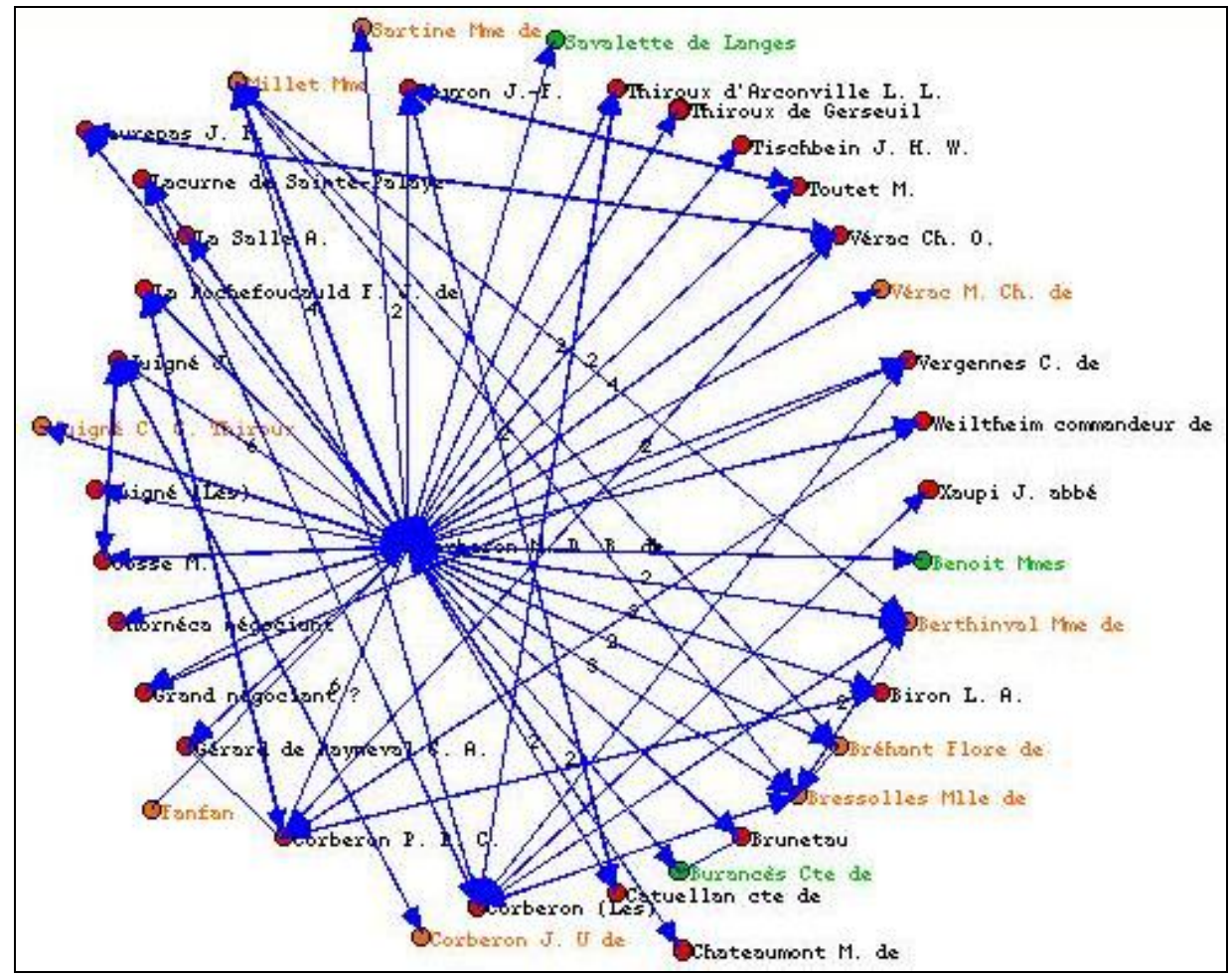

Figura 1. Ejemplo de construcción automática de red personal gracias a Arcane: los encuentros del caballero de Corberón en Paris en enero de $1775^{30}$

\subsection{Las redes en los estudios sociológicos}

El funcionamiento general de las redes ha sido aclarado por muchos estudios sociológicos que resumiré aquí para la claridad del estudio. ${ }^{31}$. Se entiende por "red" el conjunto formado por unidades sociales (individuos o grupos) y por los lazos que estas unidades cultivan los unos con los otros, directa o indirectamente: es el resultado de estos lazos sociales lo que se denomina "red". El núcleo del análisis reside así en los lazos entre las unidades sociales, de los cuales hay que intentar apreciar, o incluso de cuantificar la naturaleza, la calidad y la intensidad. Por definición, una red está en recomposición constante porque está construida a la vez por lo que llamaré en adelante "relaciones" que son frecuentemente duraderas, por ejemplo cuando resultan de parentesco o de una amistad, y por "interacciones",

\footnotetext{
30 Este grafo ha sido realizado a partir del Diario del caballero de Corberón y se presenta como un ejemplo de investigaciones que se ha podido hace gracias a Arcane en la dirección siguiente, en la que se puede hacer una utilización interactiva: http://arcanews.univmontp3.fr/egodoc/Arc/doc/cons/id771512/ids784912/.

31 Para un nuevo enfoque de las redes, E. LAZEGA, Réseaux sociaux et structures relationnelles, Paris, 1998 [réédition en 2007]; P. MERCKLÉ, La sociologie des réseaux sociaux, Paris, 2004 (Collection Repères, 398). Para un enfoque más complejo y más técnico, A. DEGENNE, M. ForsÉ, Les réseaux sociaux, op. cit. n. iError! Marcador no definido., p. 5-33.
} 
que son por definición encuentros puntuales y efímeros. Una red aparece entonces como la suma de lazos de todas clases, dinámicas y móviles, entre varias personas.

En los análisis estructurales, el fin es determinar en particular, a partir de cálculos, cuales son las personas "centrales" dentro de la red, las que se encuentran en posición de poder según diversos criterios. Se pueden tener tres tipos de "centralidad" que permiten determinar cuál es la influencia o el prestigio de alguien en un conjunto de lazos sociales. La centralidad de "grado" (degree) corresponde al número de vecinos inmediatos de una unidad social, es decir, el número de personas con las cuales se relaciona un individuo directamente: cuanto más lazos directos tiene un individuo, más "central" es. La centralidad de "proximidad" (closeness) es un cálculo basado en la "distancia geodésica", es decir, en el "camino" que tiene que recorrer siguiendo los lazos para unir dos unidades sociales: tras los cálculos de proximidad, un individuo aparece como "central" cuando esta distancia geodésica es débil (porque no se tiene necesidad de muchos intermediarios para alcanzarla). Finalmente, la centralidad de "intermediación" (betweeness) se apoya también sobre la noción de distancia geodésica y confiere un fuerte carácter "central" a una unidad social que se encuentra frecuentemente en el "camino", permitiendo unir los individuos de una red (ya que hay necesidad de pasar por ella para poder alcanzar otras unidades sociales).

La aproximación biográfica invita a inclinarse más precisamente por la noción de red personal ${ }^{32}$. Propongo ver ahí el conjunto formado por tres elementos: primero, un individuo en el centro del estudio ("ego"); después varios individuos que están en lazos directos con él (los "alter"); y por fin, y sobre todo, los lazos que estos individuos mantienen los unos con los otros, incluso las interacciones y relaciones que no dependen de la persona central. Tal definición de red personal se desmarca de las escalas ego-centradas en sentido estricto, como aquellas que se han realizado gracias a Arcano, porque el análisis se ha construido a partir del centro que es "ego", pero se da por objetivo una cierta exhaustividad en las reconstrucción de lazos sociales buscando sistemáticamente los que existen entre los "alter" y no solamente lo que se dice un "ego-documento"33. El modo propuesto aquí invita,

\footnotetext{
32 Ibid., p. 35-74 y 123-154.

${ }^{33}$ Agradezco aquí a Claire Lemercier que me hiciera el comentario sobre ello y me indicase referencias bibliográficas sobre estas cuestiones. Este tipo de proceso se parece a la "red completa enn bola de nieve" o snowball Sampling, cfr. P. DOREIAN, K. L. WOODARD, « Fixed List versus Snowball Selection of Social Networks », en Social Science Research, 21, 1992, p. 216-233. Más recientemente M. KASARJYAN, G. Buchenrieder, R. KorfF, « Social Capital in Armenia », en G. Fertig (éd.), Social Networks, Political Institutions, and Rural Societies, Turnhout, Brepols, a aparecer en 2010.
} 
pues, a agrandar la noción clásica de "red personal" para acercarse más a la perspectiva de la red completa.

En este tipo de análisis se puede prestar atención concretamente a tres elementos y ser objeto de cálculos. El primero es la "densidad" de la red, "la proporción de lazos existentes en relación con los lazos posibles" (fuerte si los alter están fuertemente relacionados entre ellos, independientemente de ego); el segundo es la "multiplicidad" (multiplixity), es decir teniendo en cuenta la diversidad de la naturaleza de los lazos entre las personas; el último es la "conectividad" que califica un grafo donde las personas están todas relacionadas entre sí, sin dejar islotes aislados $^{34}$. Como ha subrayado Claire Lemercier, el análisis egocéntricos pone en evidencia un "capital relacional" que puede ser objeto de análisis distintos: por una parte la comparación del capital relacional de varios individuos y, por otra parte -lo que me interesa aquí con Odón- la del mismo individuo en momentos diferentes de su vida ${ }^{35}$. Esta noción de capital relacional se une así a la de "capital social" tal como ha sido desarrollada por los sociólogos de redes. ${ }^{36}$. El capital social es un "recurso que puede ser acumulado y utilizado", "cuando la realización de un objetivo necesita una interacción entre individuos" ${ }^{37}$. Este capital social es a la vez heredado y construido, según las estrategias de crecimiento del poder (por ejemplo, en la alta Edad Media, la elección de un padrino socialmente más elevado es prueba de éxito social para un niño).

\subsection{Problemas de adaptación de las tablas de análisis sociológicos en la alta Edad Media}

La importación, en historia de la alta Edad Media, de estas reflexiones y técnicas de análisis sobre las redes plantea de golpe una serie de problemas en diferentes planos. El primero es de orden técnico y reside en la imprecisión de datos medievales en relación con los de épocas más tardías. Las fuentes de la Edad Media han sido raramente objeto de dataciones precisas, en particular para todos los documentos que son de género narrativo (para las que se dispone de intervalos cronológicos en el mejor de los casos), pero este problema se refiere también a los

\footnotetext{
${ }^{34}$ Ibid., p. 56-58 et C. LEMERCIER, « Analyse de réseaux et histoire », p. 91-92.

35 Ibid., p. 92.

${ }^{36}$ Sobre la noción de capital social en sociología de redes, S. PONTHIEUX, Le capital social, Paris, 2006, p. 23-31. Para trabajos futuros, sin embargo, habría que integrar los matices aportados a esta definición en particular por Pierre Bourdieu.

37 A. Degenne, M. Forsé, Les réseaux sociaux, op. cit. n. iError! Marcador no definido., p. 123 para las menciones y más globalmente, p. 123-154.
} 
actos de la práctica (diplomas, cartas o reseñas que son datadas frecuentemente únicamente por un reino, un episcopado o una abadía). Una tal imprecisión hace difícil la reconstrucción de las redes en una fecha dada e invita a reflexionar en términos de fases. Por otra parte, en las regiones más precoces, no hay un sistema antroponímico a/en/de dos elementos antes del siglo XII. Para la alta edad media, el historiador se ve necesariamente confrontado a nombres únicos para los cuales el único indicio de identificación reside, solamente para la más alta nobleza, en la mención de títulos (dux, marchio, comes, episcopus, abbas), remitiendo a los honores poseídos en una región, una ciudad o un monasterio. La tarea es tanto más ardua cuanto que existen numerosos homónimos (que reflejan las estrategias onomásticas propias del mundo nobiliario) y que la variabilidad de los títulos que califican a una misma persona resulta corriente a partir del fin del siglo IX38. Frecuentemente no se consigue identificar, pues, que alguien, gracias a su entorno inmediato, tal como éste último aparece en las fuentes de la práctica, una vez realizados cotejos e hipótesis39. Como para la datación de los documentos, el historiador medievalista debe, por tanto, contentarse con aproximaciones e hipótesis, poco compatibles con el rigor que exigen teóricamente los análisis reticulares. Más allá de estas dificultades técnicas, que hacen más compleja la reconstrucción de redes que para otros períodos, el especialista se encuentra finalmente con un problema de fondo: la cuestión del acceso al individuo, lo que sólo es posible a partir de principios del siglo XIII40. Ahora bien, los análisis egocéntricos se basan en el postulado de la trayectoria individual que, en la alta Edad Media solamente se comprende a través de la inserción de una persona en el seno de medios aristocráticos que descansan en gran parte sobre una parentela muy grande y que yo llamaría aquí "espacios relacionales" intermedios41. Conviene entonces tomar en cuenta los anacronismos y considerar la aproximación reticular,

\footnotetext{
38 Sobre la evolución de las prácticas onomásticas de la nobleza en la alta Edad Media, R. LE JAN, Famille et pouvoir dans le monde franc (VII ${ }^{e} X^{e}$ siècle). Essai d'anthropologie sociale, Paris, 1995, p. 179-223. Sobre las lógicas de variabilidad de los títulos a partir del siglo IX, O. GUYOTJEANNIN, « Rois et princes », en P. ConTAMine (dir.), Histoire de la France politique, t. 1, Le Moyen Âge. Le roi, l'Église, les grands, le peuple, Paris, 2002, p. 115-146, aquí p. 125 y 136-138.

39 En la historiografía alemana algunos trabajos prosopográficos, llevados a cabo gracias a programas informáticos, llevan en realidad a análisis de entornos, en particular a los de monasterios.Cfr. M. HillebrandT, «The cluniac Charters. Remarks on a Quantitative Approach for Prosopographical Studies », en Medieval Prosopography, 3, 1982, p. 3-25; EAD., "Social Groups as Recognition Patterns : a Means of Dating Medieval Charters », en M. GeRVERS (éd.), Dating Undated Medieval Charters, Woodbridge, 2000, p. 163-175. L. SCHÜTTE, Die alten Mönchslisten und die Traditionen von Corvey, Teil 2: Indices und andere Hilfsmittel, Paderborn, 1992.

40 D. IOGNA-PRAT, «La question de I'individu à l'épreuve du Moyen Âge », en D. IOGNA-PRAT, B. M. BEDOS-REZAK (éd.), L'individu au Moyen Âge. Individuation et individualisation avant la modernité, Paris, Aubier, 2005, p. 7-29.

${ }^{41}$ R. LE JAN, Famille et pouvoir dans le monde franc, op. cit. n. 38, p. 381-427.
} 
incluso cuando se centra en "ego" como un medio de conocer - a través de una persona precisa- las modalidades más globales de inserción en los grupos de poder.

La dificultad más importante para el alto medievalista es en cualquier caso de orden documental. De forma general las fuentes alto medievales no tienen el carácter homogéneo y relativamente exhaustivo de las series modernas o a fortiori contemporáneas. Los problemas ligados a su transmisión, voluntaria (la selección hecha por las mismas instituciones) e involuntaria (destrucciones debidas a acontecimientos históricos) han sido el objeto de varias reflexiones42. Me limitaré pues a poner en evidencia aquí las consecuencias de esta rareza documental sobre los análisis de redes para la alta Edad Media. Esta impide, para empezar, seguir a una persona de forma regular en las fuentes. Luego sesga la aproximación en la medida en que la documentación inexistente o perdida borra la huella de las interacciones sociales. Por último, el campo de análisis está necesariamente restringido al mundo aristocrático, prácticamente el único accesible en la documentación. Cuando se intenta reconstruir una red personal para la alta Edad Media no se intenta reconstruir el conjunto de los lazos sociales de un individuo, sino la amplitud de un sistema de interconocimiento aristocrático, un dato estructural de la participación en el poder que se juega en el seno del grupo nobiliario.

Al concluir esta presentación general, ¿cuáles son las fuentes que pueden ser explotadas para el análisis de las redes sociales en la alta Edad Media? Si nos colocamos en la perspectiva de los análisis egocéntricos, no se dispone de una verdadera equivalencia de los ego-documentos, en la medida en que el individuo sólo tiene sentido por su inserción en la colectividad (familiar o cristiana). La autobiografía cristiana podría formar parte de ellas pero el género iniciado por las Confession de Agustín no está verdaderamente representado antes de De Vita sua de Guibert de Nogent, escrito a principios del siglo XII43. Tal como subraya Pascale Bourgain, este largo eclipse no excluye el engarzamiento de relatos autobiográficos en otros tipos documentales (historias, crónicas o vidas de santos) pero estos

\footnotetext{
42 Sobre esta cuestión de la transmisión de documentos medievales, cf. el artículo de A. EsCH, « Überlieferungs-Chance und Überlieferungs-Zufall als methodisches Problem des Historikers », en Historische Zeitschrift, 240, 1985, p. 529-570, cuyas conclusiones se retoman en ID., «Chance et hasard de transmission. Le problème de la représentativité et de la déformation de la transmission historique », en J.-C. SCHmITt, O. G. OeXLE (éd.), Les tendances actuelles de I'histoire du Moyen Âge, op. cit. n. 19, p. 15-29; sobre todo J. MORSEL, «Les sources sont-elles le « pain de I'historien »? », en Hypothèses 2003. Travaux de l'école doctorale d'histoire de I'Université Paris I-Panthéon-Sorbonne, Paris, 2004, p. 273-286.

43 Cfr. Las diferentes contribuciones de L'autobiografia nel Medioevo. Atti del 34 Convegno storico internationale di Todi, Spolète, 1998.
} 
últimos no responden a la definición moderna del género: la puesta en escena introspectiva del autor no tiene sentido más que porque es reconocedora de su estado de pecador44. En otros términos, el peso del pensamiento cristiano en este tipo de texto excluye la mención de informaciones suficientemente explotables en sí mismas en el marco del análisis egocéntrico. Por el contrario, el género epistolar es, a primera vista, el que se acerca más a los ego-documentos, con algunos matices y especificidades. Extremadamente diverso, tanto en su forma de transmisión (cartas aisladas, epístolas con dedicatoria, recopilaciones llamadas epistolaria) como en su contenido (consejos espirituales, menciones/comentarios de acontecimientos, tratados doctrinales) tuvo un primer periodo de moda en los siglos VI-VII, después aumentó el interés por ellos en la época carolingia, antes de llegar a "una edad de oro" al final del siglo X y a lo largo de todo el siglo XI45. Las epistolæ de la alta Edad Media exponen pocas veces, a los ojos del lector, la sociabilidad de su autor contrariamente a las correspondencias modernas-, sino que suelen ser más una exposición moral, destinada a leerse ante un gran público, como en la antigüedad. En este caso, las posibilidades de reconstrucción de redes se reducen considerablemente ya que la única relación identificable es frecuentemente la del autor y del (o de los) destinatario(s) de la carta, suponiendo que se conozca el nombre de este (estos) último(s) que a menudo pasa a la posteridad solamente con su inicial. A pesar de su pobreza relativa, las cartas medievales constituyen el tipo de red utilizada más frecuentemente por los altos medievalistas que intentan reconstruir las redes, sin duda porque éstas permiten postular un lazo evidente y muy visible entre dos personas46. Sin embargo es difícil realizar análisis egocéntricos para la Edad Media, en el sentido estricto, a partir de tales fuentes

\footnotetext{
44 P. Bourgain, «Autobiographie», en C. Gauvard, A. De Libera, M. Zink (éd.), Dictionnaire du Moyen Âge, Paris, 2002, p. 112-113.

45 G. GIORDANENGO, « Épistolaire (genre)», en Ibid., p. 488-489, p. 489 para la cita.

46 Para la alta Edad Media, cfr. B. DumÉZIL, « Gogo et ses amis», loc. cit. n. 20, p. 570-572 ; J. STORY, «Charlemagne and the Anglo-Saxons », loc. cit. n. 20, p. 195-210; M. GARRISSON, « Les correspondants d'Alcuin », loc. cit. n. 20, p. 319-331. Para períodos un poco más tardíos, cfr. W. YSEBAERT, « Medieval Letter-Collections as a Mirror of Circles of Friendship ? The Example of Stephen of Tournai, 1128$1203 »$, en Revue belge de philologie et d'histoire, 83/2, 2005, p. 285-300 (el autor está, sin embargo, más en una perspectiva de análisis del vobabulario de l'amicitia en la literatura epistolar del siglo XII que en la de una reconstrucción de las redes de corresponsales); para un enfoque más global y metodológico ID., «Medieval Letters and Letter Collections as historical Sources: methodological Questions and Reflections and research Perspectives $\left(6^{\text {th }}-14^{\text {th }}\right.$ Centuries) $\gg$, en Studi medievali, 50, 2009 , p. 41-73. Para el mundo bizantino, ver las consideraciones metodológicas de $M$. Grünbart sobre la utilización de cartas en la reconstrucción de redes de interconexión M. GRÜNBART, " "Tis Love that has warm'd us" », op. cit. n. 18. Cfr. también para el fin de la Antigüedad, en el siglo IV, dos análisis recientes de la enorme correspondencia (más de 1500 cartas) del rector Libanius o Libanios, con formas de análisis sociológicos: I. SANDWELL, « Libanius' social Networks : Understanding the social Structure of the later Roman Empire », en Mediterranean Historical Review, 22/1, 2007, p. 133-147 ; S. BRADBURY, «Libanius' Letters as Evidence for Travel and epistolary Networks among Greek Elites in the fourth Century », en L. ELLIS, F. L. KIDNER, Travel, Communication and Geography in Late Antiquity, Aldershot, Ashgate, 2004, p. 73-80.
} 
porque el impacto del pensamiento cristiano y de los topoi literarios sobre la documentación hace casi imposible la reconstrucción de lo que los historiadores de épocas más tardías conocen como el punto de vista de ego.

La ausencia de verdaderos ego-documentos invita a volver hacia algunos tipos de fuentes, que se trata de cruzar, fundándose en los métodos puestos a prueba en el campo de los estudios prosopográficos, pero focalizándose en la reconstrucción de la biografía de las personas, sobre las relaciones sociales de estas últimas. Para la alta Edad Media, la reconstrucción de las redes depende ante todo de documentos diplomáticos que aportan indicaciones extremadamente preciosas en términos reticulares, en diversos lugares de su formulario. La dirección y la suscripción permiten, para empezar, identificar al autor del acto y su destinatario (principalmente gracias a los titulares y a veces a las referencias de su parentesco) que interaccionan por la existencia misma del documento. En los diplomas y las bulas, interviene frecuentemente también un petitor, que pide el privilegio en nombre del destinatario y que se coloca de intermediario entre los dos protagonistas principales del documento47. Si el preámbulo contiene a veces informaciones puntuales que permiten la reconstrucción de algunos lazos, el dispositivo es fundamental para especificar el tipo de interacción entre el autor y el destinatario del documento, en el momento preciso de su redacción. En último lugar el fin del acta es una mina de informaciones preciosas, gracias a la suscripción de uno o de los autor(es), seguido de la de los miembros de su entorno -padres, vasallos y amigos- es decir de su red personal, tal como se cristaliza en un momento dado, generalmente con ocasión de la ceremonia pública que acompañaba casi sistemáticamente los dones a las instituciones monásticas y a las que asistían el conjunto de los suscriptores. En definitiva, los documentos diplomáticos permiten distinguir dos categorías de lazos cuya portada difiere: por una parte los que son revelados por las fuentes (las menciones de lazos de parentesco, de vasallaje o de amistad); por otra parte los que son creados por el acontecimiento que da nacimiento a las fuentes, como huellas (las interacciones donante-beneficiario, entre los testigos del acta o con el escriba). Para la época que nos interesa, el problema es que muchas actas nos llegan gracias a copias efectuadas por eruditos de la época moderna que no están interesados a veces más que en el núcleo del acta, no reproduciendo más que la suscripción y el dispositivo,

\footnotetext{
47 En términos reticulares, el petitor (C) mantiene, en efecto, necesariamente, lazos con el autor(A) y el destinatario (B) del acto.
} 
y cortando mucho el preámbulo y las suscripciones48. En razón de las diversas modalidades de transmisión de los documentos, los corpus diplomáticos que se pueden reconstruir por el análisis reticular son pues, -casi necesariamente- no homogéneos, y por lo tanto susceptibles de sesgar los resultados. Se podría, por ejemplo deducir de manera errónea la existencia de redes más densas alrededor de algunos grandes aristócratas, comparándolos con otras que sólo están documentadas por fuentes truncadas a nivel de las suscripciones.

La documentación diplomática, fundamental para una aproximación a las redes de la alta Edad Media, puede cruzarse también con textos narrativos, principalmente los que revelan género histórico (anales, crónicas, Historia o Gesta). Su redacción se explica a veces por dimensión memorial que transforman la realidad histórica, a veces varios siglos después de los hechos relatados. Amy Remensnyder mostró así la dimensión a la vez no auténtica y legitimante de las menciones de protección de algunos monasterios por los soberanos carolingios, que no pueden explotarse, pues, en una perspectiva de reconstrucción de las redes sociales en época alta49. La dificultad se agudiza más todavía en el marco de la explotación de las fuentes hagiográficas en las que Michel de Certeay subrayó, en los años 1970, las dificultades de utilización en una perspectiva histórica50. Además de que la redacción de este tipo de fuentes se explica muy a menudo por la misma perspectiva memorial que la que sustentan muchos textos históricos, obedece igualmente a las leyes de su género, principalmente a un tópico fuerte que pasa la vida de una persona juzgada excepcional en una sucesión de pasos obligados, retomada de grandes modelos hagiográficos. Arsenio Frugoni y Jacques Le Goff mostraron bien el carácter parcial de los datos biográficos contenidos en los relatos históricos medievales y las vidas de santos y han alegado a favor de su estudio a través de un análisis de su medio de redacción51. Si esta aproximación crítica ha sido bien llevada, los datos de los textos hagiográficos pueden ser útiles, incluso indispensables, para la reconstrucción de las redes de poder en la alta Edad Media,

\footnotetext{
48 Se puede evocar el caso extremo del cartulario de Saint-Martin de Tours, la Pancarta nigra, copiada en el siglo XII, que contiene 150 documentos anteriores a 1131, pero que fue destruida en 1793; Émile Mabille intentó restituir las grandes líneas a partir de copias existentes: se trata pues, no de actas diplomáticas, sino de una especie de reconstrucción que da solamente el análisis de documentos, sin una sola suscripción, La Pancarte noire de Saint-Martin de Tours brûlée en 1793, restituée d'après les textes imprimés et manuscrits, É. MABILLE (éd.), Paris-Tours, 1866.

49 A. G. Remensnyder, Remembering Kings Past. Monastic Foundation Legends in Medieval Southern France, Ithaca-Londres, 1996. Cfr aussi P. CHASTANG, Lire, écrire, transcrire. Le travail des rédacteurs de cartulaires en Bas-Languedoc (XI $I^{e}$-XIII ${ }^{e}$ siècles), Paris, 2001, concretamente p. 137-139.

50 M. DE CERTEAU, L'écriture de I'histoire, Paris, 2002 [1975 para la edición de origen], p. 316-335.

51 A. Frugoni, Arnaud de Brescia, Paris, 1993 [Primera edición: Arnaldo da Brescia nelle fonti del secolo XII, Rome, 1954]. J. Le Goff, Saint Louis, Paris, 1996, p. 311-522.
} 
principalmente por identificar el medio de origen o el parentesco de una persona. Lo mismo sucede con los prefacios o cartas dedicatorias de algunas obras, principalmente teológicas, que permiten a menudo reconstruir lazos, a veces bien datados, entre un autor y quien encarga la obra.

Dada la rareza, el valor y la transmisión aleatoria de las fuentes, toda aproximación reticular a la alta Edad Media se apoya pues, necesariamente, en el cruce de documentos de naturaleza diversa. El medievalista está forzado pues a utilizar técnicas prosopográficas, ya que es casi imposible apoyarse en series documentales.

\section{Proposición de método de reconstrucción y de representación gráfica de las redes personales para la alta Edad Media: El caso de Odón de Cluny}

La red personal de Odón de Cluny se ha podido reconstruir gracias a un dossier documental muy rico para el siglo $X$, compuesto por tres tipos de fuentes: numerosos actas diplomáticas que emanan de diferentes instituciones; la producción literaria de Odón, que está ella inscrita en las redes de poder, gracias a la identificación de los destinatarios de sus obras; y finalmente textos narrativos, escritos entre el siglo $X$ y la época moderna, que mencionan a Odón, su biografía y sus actividades reformadoras y que han sido analizados previamente para criticar su dimensión memorial. Una de estas fuentes narrativas ocupa un lugar de primera importancia en el análisis: La Vita Odonis, un texto hagiográfico consagrado a Odón que fue redactado poco tiempo después de su muerte, sin duda hacia 943, por uno de sus discípulos, Jean de Salerne ${ }^{52}$.

\subsection{Preparación de los datos en Excel}

A partir de este corpus, ha sido necesario poner a punto una base de datos de los lazos de Odón con la aristocracia de su época. Cada certificado de relación o de interacción entre dos personas forma una entrada en una tabla realizada en formato Excel (figura 2). La base de datos funciona así como un repertorio de lazos entre dos personas concretas (Apellido $1 \gg y \ll$ Apellido $2 »)$. Estos datos se datan con precisión ("Fecha de comienzo" y "Fecha de fin", caracterizadas por su naturaleza ("Tipo de lazo") y se indica su fuente. La construcción de la base se desarrolla en dos fases, partiendo en principio de los documentos en los que Odón aparece. La

\footnotetext{
52 JeAn De SALERNe, Vita sancti Odonis prima et maior, en $P L$ 133, col. 43-86 [Désormais VO]. Sobre este texto, I. RosÉ, Construire une société seigneuriale, op. cit. n. 22, p. 27-31.
} 
recogida de datos ha sido ampliada a las fuentes en las que el abad de Cluny está ausente, pero donde son certificiadas personas que están en contacto directo con él, con el fin de identificar los círculos sociales en que se encuentran los intermediarios potenciales que le permiten tener acceso a nuevos espacios relacionales.

Antes de ir más lejos, quiero precisar algunos postulados metodológicos en relación con diferentes rúbricas. Se ha acordado primero una atención particular a la diferenciación de los tipos de lazos que pueden mantener dos personas, con el fin de subrayar la multiplicidad de la red de Odón. Algunas de entre ellas son "relaciones" que revelan parentesco, una noción muy englobante en la alta Edad Media y que esencialmente toma dos formas plurales ${ }^{53}$.

\begin{tabular}{|c|c|c|c|c|c|}
\hline Nom $1-$ & Nom 2 & Date Début $\nabla$ & Date fin - & Type de lien & Source \\
\hline Odon & Abbon (père d'Odon) & 879 & 920 & Parenté & VO I $5, \operatorname{col} 45 \mathrm{~B}-46 \mathrm{~A}$ \\
\hline Odon & Théotolon de Tours & 898 & 942 & Amitié & ADÉMAR DE CHABANNES, Chroni. \\
\hline Odon & Théotolon de Tours & 898 & 908 & Parenté spirituelle & Rosé, Construire, p. $78-79$ \\
\hline Odon & Bernon (abbé) & 908 & 927 & Parenté spirituelle & VO I 22 \\
\hline Odon & Geoffroi de Bourges & 910 & 911 & Souscription d'une charte & $\mathrm{N}^{\circ} 4, P A D O$, p. $34-35$ \\
\hline Odon & Thibert & 910 & 911 & Souscription d'une charte & $\mathrm{N}^{\circ} 4, P A D O$, p. $34-35$ \\
\hline Odon & Bernard & 910 & 911 & Souscription d'une charte & $\mathrm{N}^{\circ} 4, P A D O$, p. $34-35$ \\
\hline Odon & Adalard de Clermont (évêqu & 910 & 911 & Souscription d'une charte & $\mathrm{N}^{\circ} 4, P A D O$, p. $34-38$ \\
\hline Odon & Aimon & 910 & 942 & Amitié & ADÉMAR DE CHABANNES, Comm \\
\hline Odon & Turpion de Limoges & 910 & 942 & Amitié & ADÉMAR DE CHABANNES, Comm \\
\hline Odon & Guillaume le Pieux & 910 & 911 & Souscription d'une charte & $\mathrm{N}^{\circ} 4, P A D O$, p. $34-35$ \\
\hline Odon & Guillaume le Jeune & 910 & 911 & Souscription d'une charte & $\mathrm{N}^{\circ} 4, P A D O$, p. $34-35$ \\
\hline Odon & Bernard & 910 & 911 & Souscription d'une charte & $\mathrm{N}^{\circ} 4, P A D O$, p. $34-35$ \\
\hline Odon & Ingilberge & 910 & 911 & Souscription d'une charte & $\mathrm{N}^{\circ} 4, P A D O$, p. $34-35$ \\
\hline Odon & Bernon (abbé) & 910 & 911 & Souscription d'une charte & $\mathrm{N}^{\circ} 4, P A D O$, p. $34-35$ \\
\hline Odon & Turpion de Limoges & 917 & 918 & Parenté spirituelle & VO, 137 et Rosé, Construire, p. 136 \\
\hline Odon & Arnulf & 920 & 942 & Amitié & VO I 2 , col $45 \mathrm{~B}-46 \mathrm{~A}$ \\
\hline Odon & Adacius & 921 & 942 & Amitié & Vo $\| 12, \operatorname{col} .67 \mathrm{~A}$. \\
\hline Odon & Guv de Gianv & 926 & 927 & Souscrintion d'une charte & Testamentum domni Bernonis abbate. \\
\hline
\end{tabular}

Figura 2. Vista previa de la base de datos relacional de Odón de Cluny en formato Excel.

\footnotetext{
53 Sobre el caracter plural del parentesco en la alta Edad Media, R. LE JAN, Famille et pouvoir dans le monde franc, op. cit. n. 38, p. 161-177. Cfr sobretodo el conjunto de los trabajos de Anita GuerreauJalabert, concretamente su práctica síntesis, A. GueRREAU-JALABERT, «Parenté », en J. LE GofF, J.C. Schmitr, éd., Dictionnaire raisonné de l'Occident médiéval, Paris, Fayard, 1999, p. 861-876. Más específicamente sobre el parentesco en general EAD., «Sur les structures de parenté dans l'Europe médiévale », Annales ESC, 36/6, 1981, p. 1028-1049; EAD., « La désignation des relations et des groupes de parenté en latin médiéval », Archivum Latinitatis Medii Aevi, n46, 1988, p. 65-108. Sobre el parentesco espiritual: EAD., «Spiritus et caritas. Le baptême dans la société médiévale », en F. HÉRITIER (éd.), La parenté spirituelle, Paris, 1995 (Ordres sociaux), p. 133-203. Sobre la colocadión de los adolescentes: EAD., «Nutritus/oblatus : parenté et circulation d'enfants au Moyen Âge », en M. CORBIER, Adoption et Fosterage, Paris, De Boccard, 1999 (De l'archéologie à l'histoire), p. 263-290.
} 
Abarca primero el parentesco carnal, es decir la filiación por la sangre (consanguinitas), agrandada por la afinidad de se deriva de las alianzas matrimoniales ${ }^{54}$. A continuación corresponde al parentesco espiritual, en el que se han reagrupado cuatro relaciones distintas: la proximidad derivada de las prácticas de fosterage (aprendizaje guerrero de los jóvenes nobles junto a un aristócrata de más edad, el nutritor); la fraternitas establecida en el seno de las comunidades espirituales (monjes y canónigos) o entre ellas (la confraternidad); la paternitas entre un superior eclesiástico (obispo o abad) y sus fieles, entre un maestro y su discípulo, en el marco de una enseñanza, o entre un superior monástico y su auxiliar, el co-abad; finalmente l'amicitia, relación horizontal que está claramente afirmada en las fuentes. Otros lazos, correspondientes igualmente a relaciones, revelan la fidelidad que une un soberano a su vasallo. En la primera mitad del siglo $X$ esta última fue sujeta a duras negociaciones dentro del grupo aristocrático ${ }^{55}$. Una tercera categoría de lazos corresponde a la oposición de dos personas que toma la forma de una verdadera guerra o de un conflicto de propiedad (como ocurre frecuentemente alrededor de los monasterios). Estas relaciones conflictivas constituyen factores de explicación de las reconfiguraciones brutales de la red de Odón, a veces forzado a "cortar los puentes" con algunos medios -principalmente el de los papas o de los reyes-, implicados a la lógica del enfrentamiento aristocrático. De forma tal vez paradójica, estos lazos de oposición pueden explicar también, a más o menos largo plazo, un reforzamiento de las relaciones entre los protagonistas, ya que en esta época, el conflicto vale sobre todo porque su resolución permite una renegociación de los lazos entre las personas, así como una reafirmación del lugar respectivo de cada uno en la jerarquía social ${ }^{56}$. Un último conjunto de lazos reagrupa todas las acciones puntuales, lo que he calificado más arriba de "interacción", que dan lugar a la redacción de un documento, a menudo

\footnotetext{
54 Desde este punto de vista, el problema principal reside en el grado de parentesco que se tiene en cuenta y que, en la alta Edad Media, debería ser muy lejano, ya que los grupos familiares están organizados en Sippen que tienen una débil profundidad genealógica y descansan en la noción de parentesco que los extiende considerablemente en el plano horizontal.

55 Sobre la evolución de la fidelidad y juramentos, especialmente al soberano, a partir del fin del siglo IX, O. GuYOTJEANNIN, « Rois et princes », loc. cit. n. 38, p. 127-128 et 134-135.

56 El rol de los conflictos en la reafirmación de las jerarquías sociales ha sido el objeto de trabajos alemanes que han estudiado especialmente los ritos de "comunicación simbólica" para el soberano como medio para regular los conflictos en la Germanie des Ottoniens et des Saliens. Cfr entre otros, G. ALtHOFF, « Königsherrschaft und Konfliktbewältigung im 10. und 11. Jahrhundert », en Frühmittelalterliche Studien, 23, 1989, p. 265-290; G. ALTHOFF et Chr. WITTHÖFT, «Les services symboliques entre dignité et contrainte », en Annales HSS, 2003, p. 1293-1318. Esta problemática ha sido adoptada sobre todo por los especialistas de la época señorial, especialmente por los historiadores que han trabajado sobre la justicia en una perspectiva de antropología jurídica; cfr. sore este punto las publicaciones fundadoras de S. WHITE, « Pactum... legem vincit et amor judicium. The Settlement of Disputes by Compromise in $11^{\text {th }}$ Century France $»$, en American journal of legal history, 22, 1978, p.
} 
diplomático, en el que se pueden mencionar las formas más frecuentes: suscripción de una misma carta, donación, reforma monástica, concesión/recepción de un privilegio, alianza ${ }^{57}$. A pesar de su dimensión engañosa poco clara y plural, este tipo de lazo es fundamental, en la medida en que, siendo claramente mayoritario en la base de datos, permite delimitar más cerca, principalmente en el plano cronológico, las recomposiciones reticulares.

Esta diferenciación de los lazos está asociada con su datación, dada fundamentalmente por llegar a comprender cómo se recompone en el tiempo la red personal de Odón. La cuestión de su duración (con un "principio" y un fin") expone más ampliamente el problema de la perpetuidad de las relaciones sociales y ha ocasionado elecciones que podrán parecer, posiblemente arbitrarias. He considerado que las interacciones derivadas de acciones puntuales eran efímeras, atribuyéndoles una duración de un año, la unidad más pequeña en los análisis de redes. Las relaciones de fidelidad también se han datado, con duraciones extremadamente variables: se sitúan entre el momento en el que un vasallo acepta o es forzado a prestar homenaje a su soberano y la muerte, o más raramente, falso testimonio de uno de los protagonistas; se ha seguido el mismo razonamiento para los conflictos. Finalmente las relaciones de parentesco carnal se han considerado como las más permanentes, desde al nacimiento de una persona a su muerte o de su pariente; por lo que respecta al parentesco espiritual y del matrimonio, si el fin del lazo es idéntico al del parentesco carnal, el inicio se establece con una de las prácticas evocadas anteriormente (amicitia, fraternitas, fosterage, paternitas y unión conyugal). En total, la duración atribuida a estos lazos pone de evidencia el hecho de que no tienen todos el mismo alcance social. Es el parentesco el que constituye el dato más estructurante, pero no es forzosamente permanente. En efecto, está constituido a merced de las alianzas, pero puede desembocar también en conflictos que rompen, temporal o definitivamente, las interacciones eventuales entre las personas. Por otra parte, no está necesariamente materializado por

281-308 et P. GEARY, «Vivre en conflit dans une France sans État », en Annales ESC, 41, 1986, p. 1107-1133.

57 Son menos frecuentes otras acciones puntuales. 1) Presencia simultánea en una asamblea, por ejemplo en vistas a una elección real. 2) Suscripción de un aviso de juramento, es decir de una decisión judicial, tomada bastante frecuentemente en presencia de vasallos. 3) Presidencia de un juramento, es decir de una asamblea de justicia, a veces por varias personas. 4) Rol de petitor para solicitar un privilegio a una autoridad soberana (rey o papa) en favor de una tercera persona; este rol de petitor puede ser plural cuando hay intervención de varias personas. 5) Inversamente, en la medida en que el petitor es un intermediario, existen igualmente lazos entre este último y el beneficiario del privilegio demandado. 6) Consentimiento de algunos protagonistas con motivo de donaciones o de reformas, lo que deja suponer lazos de estos últimos con el(los) donante(s)/reformador(es), pero también con el(los) beneficiario(s). 7) Dedicatoria de una obra literaria a una persona particular. 8) 
interacciones concretas. Juega así el rol de una especie de matriz de la red, es decir, que ofrece un panel de relaciones e interacciones potenciales entre diferentes personas, pero que no están activadas forzosamente.

Finalmente, los lazos están orientados de "Nombre 1" a "Nombre 2". Algunas relaciones o interacciones son, en efecto disimétricas, instaurando de hecho una jerarquía entre los dos protagonistas (vasallaje) o diferenciando la persona que concede o envía (donación, reforma, privilegio, rol de petitor, consentimiento, dedicatoria, embajada) de la que recibe (beneficiario de un/una privilegio/donación/reforma, destinatario de una embajada o de una obra literaria, ejecutor testamentario). Para estos lazos orientados, el "nombre 1" se ha considerado como la persona jerárquicamente más elevada o el origen de la interacción puntual, mientras que el "nombre 2" designa al que es socialmente menos elevado o el destinatario de un acto concreto. Esta orientación de los lazos puede parecer problemática, en la medida en que en la alta Edad Media la sociedad funciona a grosso modo según el principio de donación-cambio: un juramento de fidelidad hecho por un vasallo a su soberano no tiene sentido porque entraña la entrega de una tierra al primero por el segundo; al mismo tiempo, otorgar un bien a una comunidad cenobial debe concretarse a cambio en plegarias monásticas a favor del alma de los donantes ${ }^{58}$. Me parece sin embargo que la orientación de los lazos puede ser rica en enseñanzas para algunas configuraciones reticulares, aunque sea conveniente considerar que todo lazo orientado engendra sistemáticamente, aunque no quede huella documental, una relación a cambio. Por lo tanto todos los lazos que quedan no están orientados, o más exactamente han sido duplicados en la base de datos, con una inversión de los protagonistas, para crear una relación simétrica ${ }^{59}$. Así he considerado como tales todos los lazos que

\footnotetext{
Embajada enviada por una persona a otra. 9) Ejecutor testamentario (fideijussor) que revela un lazo entre este último y la persona a la que representa. 10) Paz adoptada entre dos personas en conflicto.

58 La puesta en evidencia del funcionamiento de la sociedad medieval según el principio del don-cambio resulta de la utilización y de la adaptación por los medievalistas del modelo de M. Mauss. Para una primera síntesis historiográfica sobre la utilización de Mauss por los medievalistas, B. H. RosENWEIN, To be the Neighbor of Saint Peter. The social Meaning of Cluny's Property, 909-1049, Ithaca-New York, Cornell University Press, 1989, p. 125-129 y más recientemente, J.-P. DEVROEY, Économie rurale et société dans l'Europe franque ( $V I^{e}-I X^{e}$ siècles). Tome 1 : Fondements matériels, échanges et lien social, Paris, Belin, 2003 (Belin Sup. Histoire), p. 175-193. Cfr. sobre todo E. MAGNANI, « Les médiévistes et le don. Avant et après la théorie maussienne », en Revue du M.A.U.S.S., 31, 2008, en línea, p. 525-544.

59 Así, se ha computado un lazo de parentesco entre $A$ y $B$ en la base de datos de la forma siguiente: una entrada de $A$ (nombre 1 ) hacia $B$ (nombre 2), luego de B (nombre 1 ) hacia A (nombre 2 ), con los mismos datos de comienzo y de fin, el mismo tipo de lazo y la misma fuente. Se podría considerar sin embargo que en la época medieval hay una jerarquía en todas las relaciones de parentesco, fundada en la edad (entre padres e hijos, entre un abad y sus monjes, entre el mayor y los más jóvenes) y/o en el sexo (entre un hombre y su esposa, entre herederos chicos y chicas). Las únicas relaciones estrictamente igualitarias serían, desde este punto de vista los lazos entre monjes, entre amigos o en
} 
indican un gran parentesco, con excepción de la enseñanza y del co-abaciado que crean de hecho una relación jerárquica. Del mismo modo, se han definido como simétricas las interacciones resultantes de una alianza, de la conclusión de una paz, de un conflicto, de asistencia simultánea a una asamblea, de presidencia de una asamblea de justicia, de dos petitores juntos o de suscripción conjunta de un documento (carta o aviso de demanda).

\subsection{Codificación de los datos y explicación de los grafos en Netdraw}

Tras este trabajo de inventario, llega a una suma de interacciones entre personas, que se trata de codificar para explotarla bajo la forma de grafos y de someterla a cálculos simples gracias al programa Netdraw. La codificación de los datos se ha hecho previamente en formato Excel, comenzando por una hoja para las personas (los "nudos", en inglés nodes) y sus atributos (figura 3 ): en cada nodo, identificado por su nombre, se ha diferenciado por una parte la función social ejercida (monje, laico, rey, obispo, canónigo, papa) y por otra el grupo (o medio) aristocrático ampliado al que pertenece la persona (Robertiens, Guilhemides, Bosonides, Théophylactes, Rodolphiens, Richardides y otros $)^{60}$.

\begin{tabular}{|l|l|l|}
\hline nom & statut & groupe \\
\hline "Rodolphe I" & "Roi" & "Rodolphien" \\
\hline "Albéric" & "Laïc" & "Théophylacte" \\
\hline "Théophylacte" & "Laïc" & "Théophylacte" \\
\hline "Ardré de Tours" & "Laïc" & "Robertien" \\
\hline "Turpion de Limoges" & "évêque" & "Guilhemide" \\
\hline "Hugues d'Arles" & "Laïc" & "Bosonide" \\
\hline "Eudes" & "Roi" & "Robertien" \\
\hline
\end{tabular}

Figura 3. Codificación de los nodos.

Asignar tales atributos puede parecer problemático ya que cuajan la identidad de las personas y no toma en cuenta los cambios de estatuto o de paso a otro grupo aristocrático, con ocasión de un matrimonio, por ejemplo. Aún cuando sea posible

los grupos caballerescos. Me ha parecido preferible no entrar en tales precisiones para no complicar en exceso la representación gráfica de la red.

60 Las designaciones de estos parentescos -que pertenecen a la Reichsaristokratie - se han forjado por la historiogravía de la alta Edad Media, a partir del nombre de su representante más anciano y más prestigioso, que es recurrente a continuación en el patrimonio onomástico de la familia: Robert le Fort (conde [† 866]) para los Robertiens, Guillaume de Gellone (conde [† 812]) para los Guilhemides, Boson (conde, después rey de Provenza [† 887]) para los Bosonides, Théophylacte (duque, después "senador de los Romanos" [† hacia 925]) para los Théophylactes, Rodolphe I ${ }^{\text {er }}$ (rey de Bourgogne jurane [† 912]) para los Rodolphiens y Richard le Justicier (conde, después duque de Borgoña franca [† 921]) para los Richardides. En la época que nos ocupa, estas familias ejercen un poder importante (calificado de "poder principesco" por la historiografía) en las regiones en las que se han implantado. Polarizan, por otra parte, las fidelidades de la sociedad noble local que constituye su entorno y que yo califico aquí de "medio" o de "grupo", asociado al nombre de estos parentescos. 
en el plano técnico de integrar estas evoluciones, no se han tenido en cuenta aquí porque, en razón de homonimias frecuentes, hacen más compleja todavía la legibilidad y la interpretación de los grafos ${ }^{61}$. Desde el punto de vista del estatuto, he considerado así la situación final de cada individuo, incluso si han pasado casi todos por al menos dos estados diferentes -y más en el caso de las carreras eclesiásticas- mientras que he tomado en cuenta el grupo aristocrático inicial, es decir, el medio de origen. Estos dos tipos de atributos se han podido codificar en Netdraw para aparecer visualmente en los grafos. Los estatutos se han representado por formas: rombo para los monjes, círculo para los canónigos, cuadrado para los laicos, círculo en un cuadrado para los reyes, triángulo para los obispos y triángulo invertido para los papas. Los grupos familiares se han representado en colores: Robertiens en rojo, Guilhemides en verde, Bonsonides en amarillo, Théophylactes en naranja, Rodolphiens en azul claro, Richardides en malva, otros (es decir, desconocidos) en negro.

Los lazos (links en inglés) entre los nodos se han codificado en una segunda hoja, siempre en formato Excel, a partir de las cuatro categorías de relaciones e interacciones evocadas más arriba (figura 4$)^{62}$. Conviene subrayar que se ha añadido una categoría "parentesco+otro" para algunos casos raros en los que una relación familiar y una interacción se superponen en el mismo año. En definitiva, los lazos redundantes son muy raros cuanto se tiene en cuenta al mismo tiempo su duración y su tipo: el total de lazos por año (indicado en la columna "total intensidad" que resulta de la suma de los diferentes tipos de interacciones y relaciones por año) es así casi siempre de valor 1. Esta validación de los lazos, es decir el hecho de atribuir un valor numérico a cada lazo entre dos personas, es fundamental para la representación gráfica de la red, con el fin de delimitar la proximidad relacional entre nodos.

\footnotetext{
61 Para integrar la variación de los atributos bastaría con datarlos, tal como se ha hecho para los lazos.

62 La categoría « otro lazo » indica interacciones puntuales.
} 


\begin{tabular}{|c|c|c|c|c|c|c|c|c|c|}
\hline Nom 1 & Nom 2 & lien vassalité & lien parenté & lien autre & parenté+autre & opposition & total intensité & début du lien & Fin du lien \\
\hline "Rodolphe I" & "Adélaïde de Bourgogne" & 0 & 1 & 0 & 0 & 0 & 1 & 879 & 912 \\
\hline "Albéric" & "Jean XI" & 0 & 1 & 0 & 0 & 0 & 1 & 879 & 936 \\
\hline "Théophylacte" & "Albéric" & 0 & 1 & 0 & 0 & 0 & 1 & 879 & 925 \\
\hline "Ardré de Tours" & "Atton de Tours" & 0 & 1 & 0 & 0 & 0 & 1 & 879 & 898 \\
\hline "Turpion de Limoges" & "Aimon" & 0 & 1 & 0 & 0 & 0 & 1 & 879 & 942 \\
\hline "Hugues d'Arles" & "Boson (frère d'Hugues)" & 0 & 1 & 0 & 0 & 0 & 1 & 879 & 931 \\
\hline "Eudes" & "Robert" & 0 & 1 & 0 & 0 & 0 & 1 & 879 & 898 \\
\hline "Marozia" & "Jean XI" & 0 & 1 & 0 & 0 & 0 & 1 & 879 & 935 \\
\hline "Marozia" & "Albéric" & 0 & 1 & 0 & 0 & 0 & 1 & 879 & 935 \\
\hline "Théophylacte" & "Jean XI" & 0 & 1 & 0 & 0 & 0 & 1 & 879 & 925 \\
\hline "Théophylacte" & "Marozia" & 0 & 1 & 0 & 0 & 0 & 1 & 879 & 925 \\
\hline
\end{tabular}

Figura 4. Codificación de los lazos.

Como en los nodos, la orientación, la multiplicidad y la validación de los lazos aparecen visualmente en los grafos construidos gracias a Netdraw. Las interacciones y relaciones se representan en forma de flecha, de sentido único si los lazos están estrictamente orientados o de doble sentido si se trata de una relación recíproca. La naturaleza del lazo se indica por el color de los trazos: en verde las relaciones de parentesco (carnal o espiritual), en rojo las relaciones de fidelidad, en azul las guerras o conflicto, en negro los lazos puntuales resultantes de una interacción. En algunos casos se superponen trazos de diferentes colores, indicando la multiplicidad de los lazos que una persona mantiene con otra. Finalmente la validación de los lazos, en término de intensidad de las relaciones y de las interacciones entre dos nodos, se representa por el grosor del trazo ${ }^{63}$. Los datos pueden ahora ser utilizados en Netdraw, tras haber procedido a registrar diferentes atributos de lazos y de nodos evocados anteriormente. ${ }^{64}$

\subsection{Grafo general y primeros análisis de la red personal de Odón}

El grafo general se ha construido a partir de todas las relaciones e interacciones de Odón y las de sus alter, entre el 879 , año de su nacimiento, y 942 , momento de su muerte (figura 5$)^{65}$.

\footnotetext{
63 La medida de la intensidad de las relaciones e interacciones ha seguido los principios siguientes. 1) una relación de parentesco, de fidelidad o de oposición (o una reforma) incluso si ha sido indicada por varias fuentes distintas, constituye una sola entrada (lo que cuenta ahí es la relación). 2) Toda interacción puntual entre dos nodos, registrada por un documento diplomático constituye una entrada: si hay dos cartas diferentes que registran dos donaciones distintas de un aristócrata a un abad, en el mismo año, se cuenta dos « otros lazos ». 3) Por lo tanto, un mismo documento (especialmente diplomático) da lugar, frecuentemente a tantas entradas que registra interacciones y/o relaciones entre diferentes nodos mencionados en el documento (entre varios suscriptores por ejemplo).

64 La explotación con Netdraw puede hacerse sin utilizar el programa de cálculo Ucinet, copiando los datos preparados en Excel en un fichero texto, registrado en formato.vna.

65 Se han procesado 860 lazos en la base de datos.
} 
Tiene en cuenta la validación, la multiplicidad y la orientación de los lazos, con una colocación de los nodos fundada en el algoritmo spring embedding, que los sitúa en función de su posición en la red y no en su estatus o de su grupo aristocrático ${ }^{66}$.

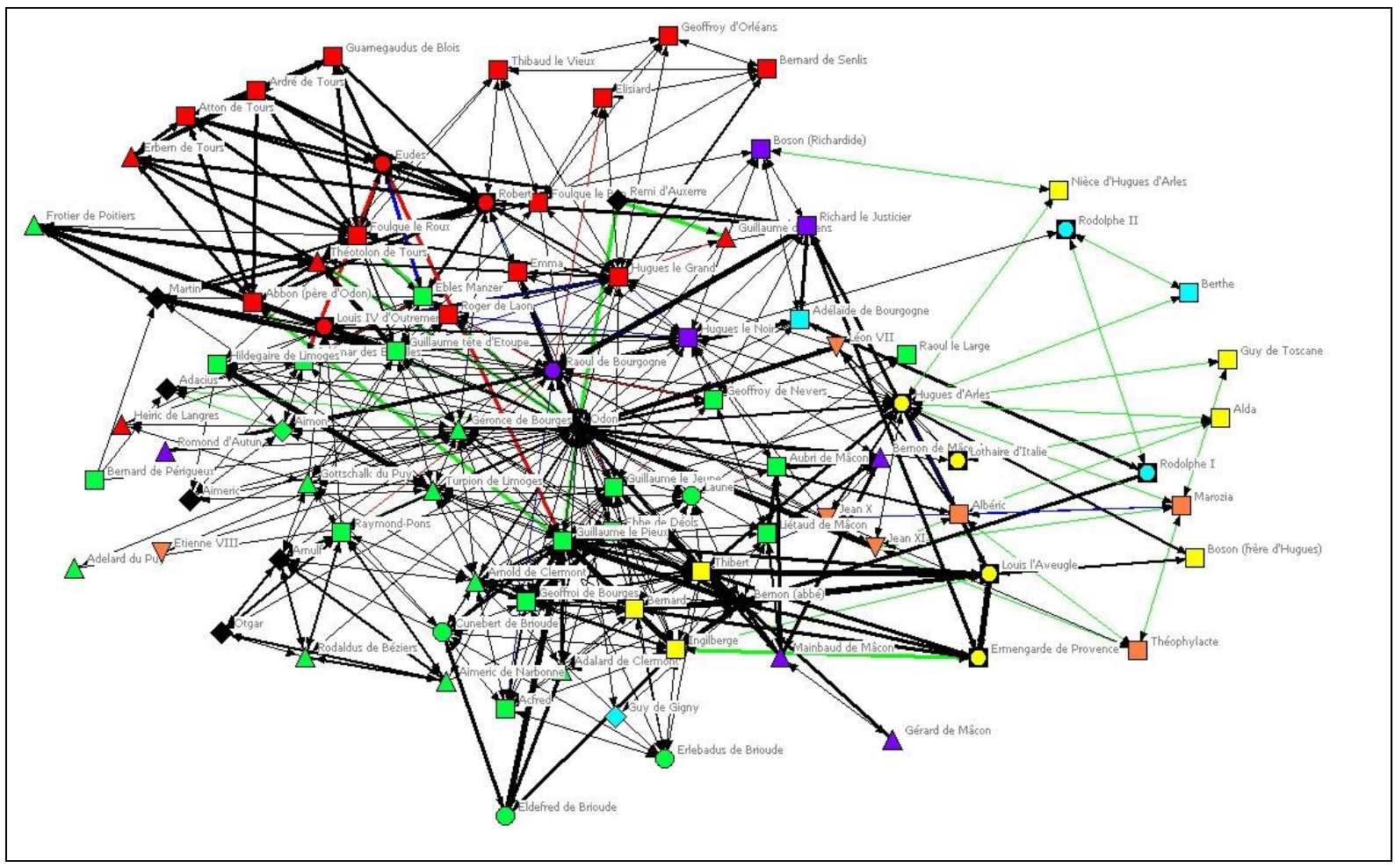

Figura 5. Grafo general de la red personal de Odón de Cluny (879-942).

Este primer grafo es difícilmente legible, pero se puede sin embargo subrayar que los conjuntos aristocráticos (distinguidos por colores) parecen fuertemente unidos entre ellos por lazos puntuales, sea la que sea la función de las personas interconectadas (distinguida por las formas). Esto significa que las redes se concretan en principio entre personas que pertenecen a un mismo entorno nobiliario, compuesto indiferentemente de laicos y de clérigos. Se pone de manifiesto también que la red de Odón es mucho menos densa en la derecha, que algunos de los lazos que se indican revelan esencialmente el parentesco y que los

66 Con el fin de facilitar (relativamente) la lectura, el grafo de la figura 5 no está completo, pero representa la red general de Odón, tras la supresión de los cinco nodos que solo tienen un lazo (funcion Pen Netdraw). La finalidad es, en efecto y ante todo, identificar círculos en los cuales no participan, por definición las personas aisladas. Estos últimos no son más que hombres de Iglesia y especialmente algunos co-abades de Odón en las abadías que dirige (Arigaud en Fleury, Baudouin en Saint-Paul-horsles-Murs, Théotard en saint-Élie de $\mathrm{Nepi}$ ), de las que se conoce el nombre solamente por una sola fuente narrativa que trata de la reforma, sin más detalle. De la misma forma, el abad Géraud de Solignac mantiene un solo lazo directo con Odón, porque contrató entre su abadía y la de Fleury, dirigida por el abad de Cluny, un lugar de confraternidad, conocido por un único documento diplomático. 
nodos pertenecen a los medios rodolphien, bosonide y théophylacte. Esta débil densidad se explica de tres formas. En el plan documental, en primer lugar, no se dispone de ninguna carta, o casi, para los Theophylactes mientras que los corpus son limitados para los primeros Rodolphiens. Estos nueve nodos periféricos representan por otra parte, para cuatro de entre ellos, a mujeres (« Nièce d'Hugues d'Arles », Berthe, Alda et Marozia). Esto no significa que el rol de las mujeres en las redes no sea importante (bien al contrario, son ellas las que permiten en particular extender los parentescos por los matrimonios), pero aparecen más raramente que los hombres en los la documentación relacionada con la práctica. Este dato estructural no impide a algunas mujeres jugar un papel importante en la red de Odón, principalmente cuando son reinas o condesas y que están estrechamente asociadas al poder y a las decisiones de su marido (la robertienne Emma, esposa de Raúl de Bourgogne, la bosónide Ingilbelrge, esposa del duque de Aquitania Guillaume) y cuando son viudas, particularmente en los casos de regencia (la bosonide Ermengarde, viuda de Boson y madre del futuro rey de Provenza Louis I'Aveugle, la rodolphienne Adélaïde, viuda de Richard le Justicier) ${ }^{67}$. En último lugar, estos nodos han estado activos principalmente en las periferias geográficas del itinerario biográfico de Odón, que pasó la mayor parte de su existencia en el reino de los Francos del Oeste: Italia ${ }^{68}$, que el abad de Cluny visita se queda puntualmente a partir de 927 y, sobretodo, el reino de Borgoña suiza en el que parece que estuvo una sola vez.

Los diferentes tipos de lazos dibujan estructuras reticulares diferentes. Así, las relaciones de parentesco (figura 6 ) forman siete círculos de nodos no unidos entre sí. Apartando los conjuntos formados por menos de cuatro personas, acabamos en dos grafos aislados. El primero (a la derecha) está compuesto esencialmente por laicos que pertenecen a parentescos distintos, pero que han contraído matrimonios para extender su grupo familiar de origen. El segundo grafo (a la izquierda), en cuyo centro se encuentra Odón de Cluny, es mucho más ecléctico. Sus miembros vienen, en efecto, de todos los medios aristocráticos (con excepción de los

\footnotetext{
67 Sobre la asociación de reinos en el poder LE JAN, «La reine Gerberge, entre Carolingiens et Ottoniens », en EAD., Femmes, pouvoir et société, op. cit. n. 13, p. 30-38.

Sobre el aumento de poder de las esposas de condes. EAD., « L'épouse du comte du IX ${ }^{\mathrm{e}}$ au XI ${ }^{\mathrm{e}}$ siècle : transformation d'un modèle et idéologie du pouvoir», en EAD., Femmes, pouvoir et société, op. cit. n. 13, p. 21-29. Sobre el rol de las viudas, E. SANTINELLI, Des femmes éplorées ? Les veuves dans la société aristocratique du haut Moyen Âge, Lille, 2003.

68 Es el caso muy evidente de los Théophylactes (Marozia, Théophylacte) que represpentan la aristocracia romana, pero también de algunos qui représentent l'aristocratie romaine, mais aussi pour certains Bosonides (Nièce d'Hugues d'Arles, Alda, Guy de Toscane), ya que este grupo familiar recuperó la corona del reino de Italia.
} 
Théophylactes), lo que indica que Odón tejió, en el curso de su existencia, lazos privilegiados, que le relacionan particular y recíprocamente con los representantes de las principales familias nobiliarias de la primera mitad del siglo X. Además, las personas que allí participan son mayoritariamente hombres de la Iglesia, monjes (rombos) u obispos (triángulo). Finalmente este círculo está unido ante todo por lazos de parentesco espiritual, particularmente entre Odón y otros monjes o clérigos, lo que explica su forma estrellada.

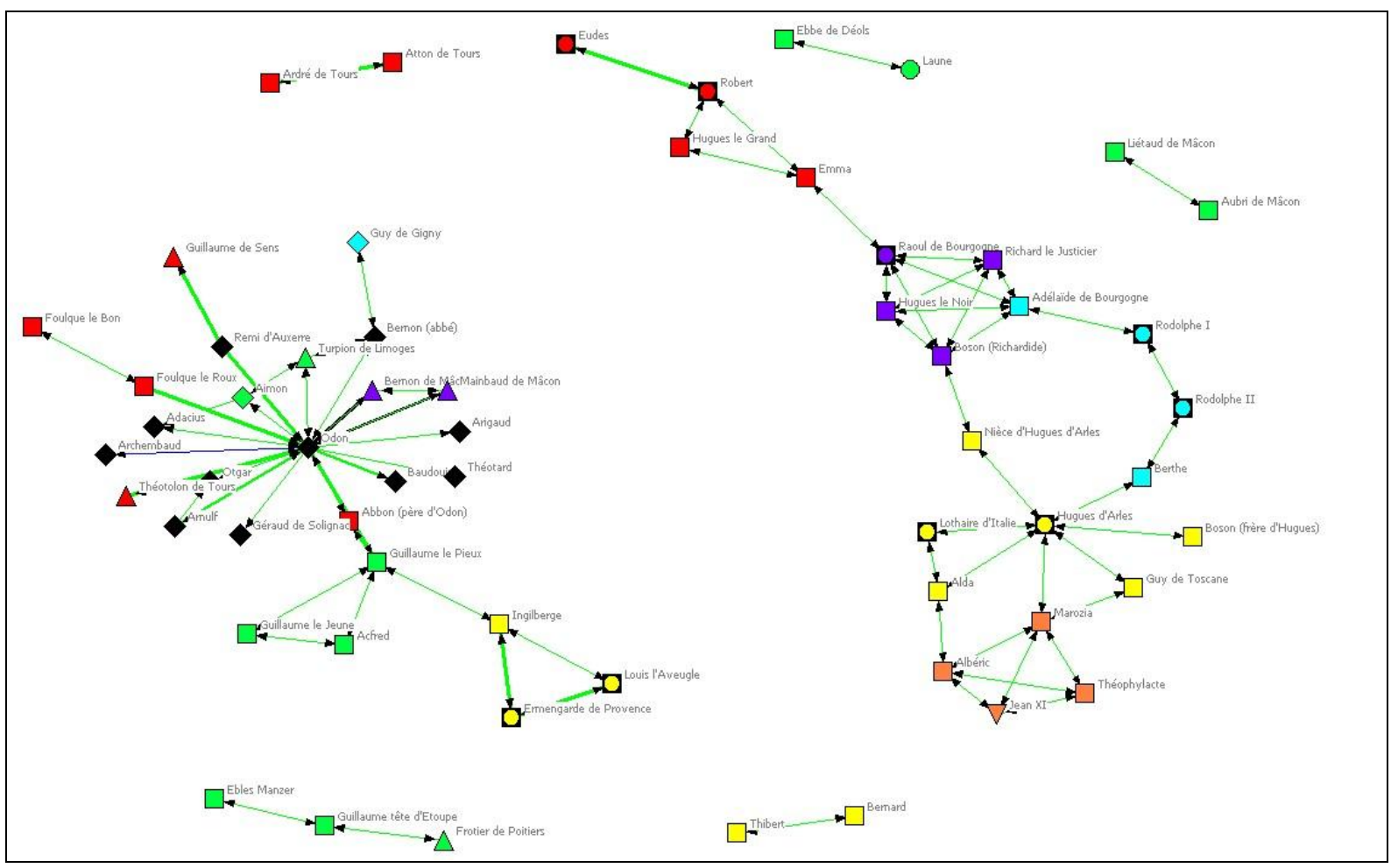

Figura 6. Los lazos familiares que estructuran la red "odoniana".

Si se tienen en cuenta ahora los lazos de parentesco y de fidelidad, acabamos en otro grafo (figura 7). Este último cuenta con más nodos (incluso aunque todos no estén presentes), es conexo porque se compone de un solo conjunto69. En otros términos, son lazos de vasallaje que permiten la articulación entre diferentes grupos de parientes y la agregación de algunos nodos suplementarios. Algunas personas juegan de esta manera el rol de "puntos de articulación"(Cutpoints), es decir que sin su existencia la red perdería su conectividad. Se trata más precisamente de Odón, Guillaume el Piadoso, su esposa Ingilberge, le abad Bernón,

69 Los nodos totalmente aislados, no representados en este grafo, son mayoritariamente hombre de Iglesia, clérigos o monjes, cuyo parentesco o inserción en una red de fidelidad son poco conocidos. Se unen pues, sin duda, al conjunto de la red de parentesco y de fidelidad, pero se ha perdido la huella de las relaciones de este tipo que mantenían. 
Hugues le Grand, Guillaume Tête d'Étoupe, Raoul de Bourgogne, Hugues de Arles y del conde Thibert. Con excepción de este último, vamos a ver que todos juegan un rol mayor en tanto que auxiliares de Odón de Cluny.

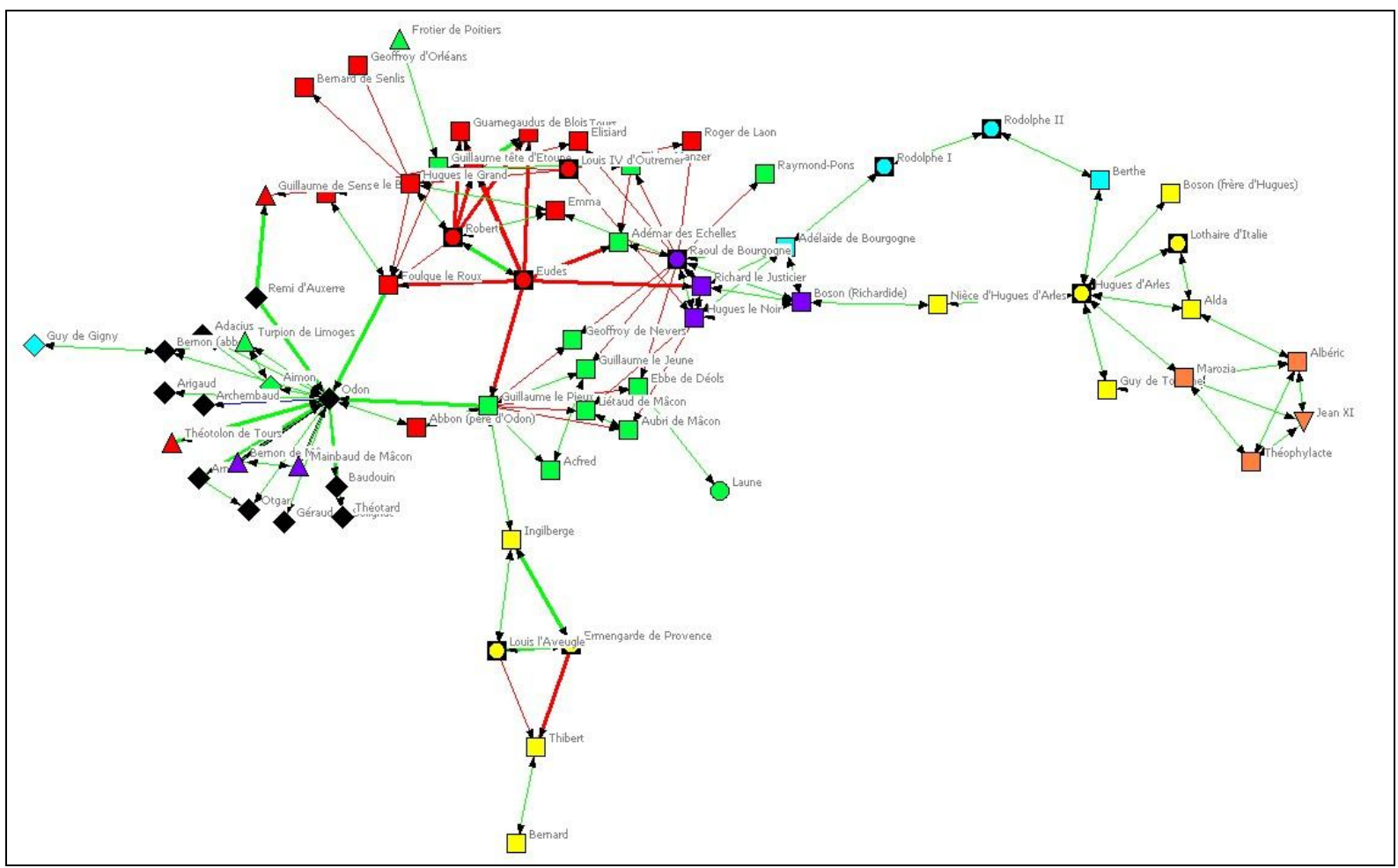

Figura 7. Los lazos de parentesco y de fidelidad que estructuran la red "odoniana".

\subsection{Ensayo de restitución de la recomposición permanente de la red de Odón de Cluny}

Incluso si permiten poner en evidencia algunos trazos estructurales del funcionamiento de la sociedad aristócrata del siglo $X$, estos gráficos globales son, no obstante, inexactos porque no tienen en cuenta la diacronía.

"Borran" el carácter móvil de las alianzas y sobre todo la construcción y la deconstrucción progresiva del lienzo de relaciones. Conviene, pues, analizar el itinerario biográfico de Odón en una perspectiva reticular, descomponiéndolo en el tiempo. La datación precisa de los lazos, tenida en cuenta en la codificación de los datos, permite delimitar más de cerca cómo evoluciona la red egocéntrica de Odón, año tras año, poniendo en evidencia la transformación de los grafos a lo largo del tiempo. 
Cada año es objeto de una "relación" (es decir, en lenguaje Netdraw, de una configuración reticular específica), y luego de un grafo particular, sin que el posicionamiento de los nodos sea modificado, lo que comprometería la legibilidad de la evolución dinámica de los lazos ${ }^{70}$. Precisemos que los diferentes nodos se han situado de forma relativamente arbitraria, pero reflejan a groso modo la implantación geográfica de las grandes familias aristocráticas, en el sentido inverso de las agujas del reloj: los Robertiens que controlan el Oeste del reino de Francia (colocados arriba a la izquierda), los Guilhemides situados en Aquitania (abajo a la izquierda), los Bosonides en Provenza (abajo, en posición central), los Théophylactes en la región de Roma (abajo, a la derecha), los Rodolphiens en el reino de Borgoña, en la Suiza actual (en el centro, a la derecha), finalmente, los Richardides, en el ducado de Borgoña, que corresponde a la región de Borgoña actual (arriba, a la derecha). En el plano geográfico, la red de Odón se extiende pues globalmente desde el Loira hasta la región romana. He intentado en vano encontrar una forma de representar los lazos en los que se llevan a cabo las interacciones, al menos las que tienen un carácter puntual. En este caso, el problema reside en la movilidad constante de los hombres que perjudicaría a la legibilidad de los grafos y a la toma de consideración de su evolución. Para investigaciones posteriores, convendrá reflexionar más claramente sobre esta cuestión y en la necesidad de representar gráficamente el desplazamiento geográfico como componente pleno de la interacción, en la medida en que un lazo entre vecinos no tiene el mismo sentido social que el que necesita, para su ejecución, un largo viaje ${ }^{71}$.

Al concluir este trabajo, disponemos de 63 grafos anuales, de 879 a 942 . Para cada grafo, los nodos que no estaban relacionados con otros se han suprimido de la representación, gracias a la función «Pen-», para no perjudicar su legibilidad. A continuación el objetivo ha sido poner estos grafos unos a continuación de otros y animarlos, para conseguir delimitar evoluciones reticulares. La solución más simple a sido pasar por el programa Powerpoint, dedicando una diapositiva a cada año de

\footnotetext{
70 Tengo que agradecer aquí a Claire Lemercier por haberme permitido poner a punto una técnica "artesanal" para llegar a obtener grafos anuales a partir de datos recogidos. Conviene utilizar, en Netdraw, los operadores « $\leq \gg y \ll \geq »$ respecto a cada fecha, después guardar los resultados con la función «Save as new Relation ». El proceso es laborioso, en la medida en que es necesario guardar, para cada milésima, tres "relaciones" que yo calificaría de "muletillas" en la medida en que son indispensables para lograr el resultado, aunque luego ya no sirven. La limitación perdura, de hecho, en términos de pesadez y de opacidad del fichero .vna,, pues todavía no es posible suprimir en Netdraw las "relaciones muletillas" para llegar a estos grafos anuales (la función « Delete column » en la pestaña "Link editor", en efecto, no funciona.

${ }^{71}$ Debo agradecer aquí a Alain Guerreau por haber subrayado esta idea.
} 
la vida de Odón ${ }^{72}$. El resultado es una especie de pequeño "film", animado gracias a la función "Transición" del programa que hace que se sucedan automáticamente las diapositivas, unas detrás de otras ${ }^{73}$. Se tiene así una visión de la reconfiguración, año tras año, de las redes aristocráticas en cuyo centro se encuentra Odón de Cluny.

\section{Análisis dinámico de la inserción de Odón de Cluny en las redes aristocráticas}

Más allá de su dimensión experimental, este "film" tiene un interés inmediato para los análisis de redes: permite poner en evidencia fases de la vida de Odón. Estas últimas corresponden a fuertes reconfiguraciones de sus prácticas relacionales que se explican esencialmente por tres factores. Los lazos del abad de Cluny con la aristocracia se modifican ante todo durante grandes rupturas que marcan etapas de su vida, principalmente en términos de cambios de estatus -por ejemplo, pasar de la situación de canónigo de catedral a la de monje en los años 908-910 se traduce para Odón en una neta reorquestación de sus prácticas relacionales, medios aristocráticos Robertiens hacia los de los Guilhemides. Este tipo de reconfiguración está además acentuado por el hecho de que estos cambios de estatus se acompañan frecuentemente por desplazamientos geográficos a una gran escala: cuando Odón abandona su profesión de canónigo para ser fraile, deja en esta ocasión la Touraine por la Borgoña. Un tercer factor de reconfiguración es externo a la biografía de Odón, ya que se trata del fallecimiento de uno o de varios miembros mayores de su red personal, desaparición que coincide con o desencadena a veces un cambio de su estatus. Es el caso de 924-927, en el momento de la muerte del predecesor de Odón, en Cluny, el abad Bernón, que le permite hacerse el superior único de la abadía. En revancha, en 936, la fuerte reconfiguración de las relaciones e interacciones sociales, parece debida esencialmente a los fallecimientos casi simultáneos de varios "pilares" de la red del abad de Cluny.

En total han sido identificadas cuatro fases. En primer lugar, el momento de la herencia y de la primera creación del capital social, del nacimiento de Odón, hacia 879, a su llegada a Borgoña como monje, hacia 908-910. A continuación la

\footnotetext{
72 Es posible visualizar la evolución directamente en Netdraw, pero el proceso es fastidioso, en particular porque no será posible suprimir las "relaciones-muletillas" que permiten crear las "relaciones" anuales. Para previsualizar en Netdraw, conviene pasar por «Properties », después « Lines », después «Multi-relation selection », y finalmente activar unas tras otras las fechas que se quieren visualizar.
} 
búsqueda de la construcción de lazos sociales, en un nuevo entorno cenobítico, de 909 a 926. En tercer lugar el acceso a las funciones de poder abacial, que queda marcado por la herencia familiar, entre 927 y 936 . Finalmente la extensión máxima del capital social inicial, de 936 a 942.

\subsection{El capital social y su primera puesta en ejecución (879-908)}

En la primera fase de su vida, la red personal de Odón está poco desarrollada, pero se constata que se relaciona bastante rápidamente con diversos grupos aristocráticos, representados por los diferentes colores (figura 8). Antes de entrar en el detalle de la génesis de esta red en el transcurso de este primer período, se pueden subrayar algunas características gracias a las funciones y cálculos que permite el programa Netdraw.

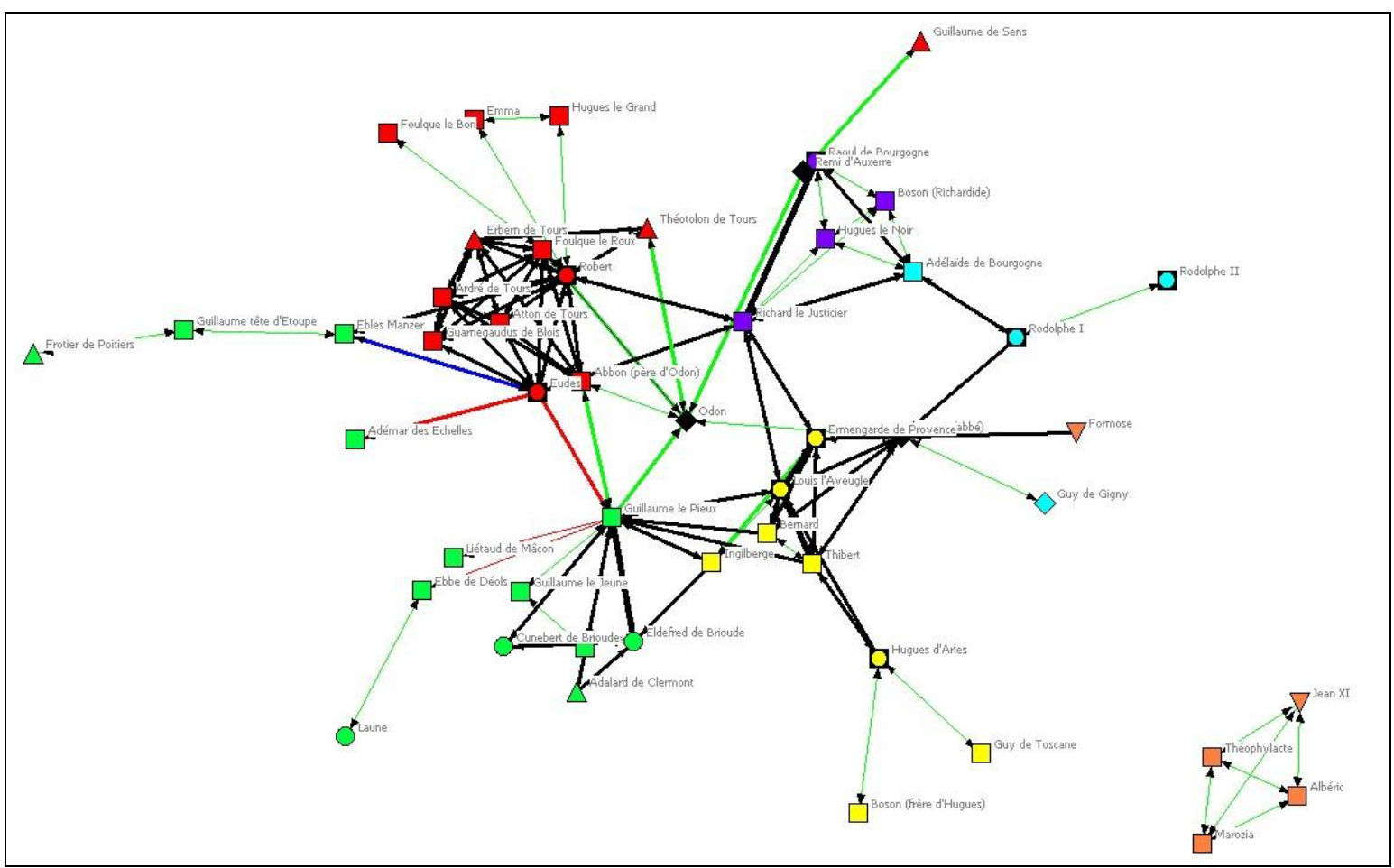

Figura 8. Red personal de Odón de Cluny de 879 a 908.

73 Este documento powerpoint está disponible en línea, en la dirección siguiente: http://medievistes. wikispaces.com/Isabelle+Ros\%C3\%A9. En caso de modificación de esta última, ver http://www.sites.univ-rennes2.fr/cerhio/spip.php?article221. 


\subsubsection{Características generales de la primera fase de la red "odoniana"}

Se constata de entrada, que con excepción de los Théophylactes, la red de Odón es conexa en esta primera fase, es decir que las personas que participan están todas relacionadas entre sí (figura 8). Esta conectividad resulta ante todo de lazos estructurando espacios relacionales, a los que se llama "cliques" (es decir grupos que presentan una conectividad fuerte entre sus miembros) y que recortan aquí a grosso modo la pertenencia a los medios aristocráticos. Netdraw ha permitido localizar tres personas que, en esta primera fase, permiten la conectividad de la red y juegan el rol de pasarela entre medios nobiliarios fuertemente relacionados entre ellos: el duque de Aquitania Guillaume le Pieux, el rey de los Francos Robert y finalmente Odón. Sin estos Cutpoints, los grupos aristocráticos estarían mucho más aislados los unos de los otros.

Netdraw permite por otra parte delimitar cuales son las personas "centrales" durante esta primera fase de génesis de la red "odoniana". Incluso si este tipo de proceso debe estar más bien reservado a los análisis estructurales de redes, los cálculos dan un orden de magnitud del poder relacional de algunas personas con las que el futuro abad de Cluny teje lazos, como una idea de la fisionomía general de las relaciones aristocráticas ${ }^{74}$. La persona más "central" en el curso de este período -en este primer estrato de la red "odoniana" agrandada- es muy claramente el duque de Aquitania Guillaume le Pieux quien, sea cual sea el cálculo, se encuentra siempre delante de las otras unidades sociales. Después, las posiciones de centralidad varían más, pero se pueden notar tres constantes. De forma muy general, primero se nota la fuerte centralidad de los grandes laicos, mucho más importante que la de los monjes y a fortiori de los clérigos, lo que significa que las interacciones y las relaciones sociales son orquestadas por ellos y alrededor de su persona. Se observa por otra parte que estos aristócratas que polarizan los lazos acumulan generalmente los tres factores de centralidad es decir que aparecen a la vez como las personas que tienen el mayor número de vecinos directos, como los que tienen la menor necesidad de intermediarios para alcanzar otras unidades sociales y como los que se ponen como intermediarios obligatorios para los otros

\footnotetext{
74 Los cálculos tratados por Netdraw en cada nodo han sido ordenados por orden decreciente (el cálculo de cada nodo se indica entre paréntesis); permiten pues delimitar una jerarquía de las personas centrales en esta primera fase. Para la «centralidad de grado» : 1) Guillaume le Pieux (14), 2) Robert $(12), 3)$ Eudes $(9)$, 4) Foulque le Roux $(9), 5)$ Bernón $(8), 6)$ Louis I'Aveugle $(8)$, 7$)$ Richard le Justicier (8). Para la « centralidad de proximidad »: 1) Guillaume le Pieux (344), 2) Eudes (349), 3) Abbon [padre de Odón] (354), 4) Louis I'Aveugle (354), 5) Richard le Justicier (356), 6) Robert (357), 7) Odon (358). Para la « centralidad de intermediario» : 1) Guillaume le Pieux $(409,612), 2)$ Richard le Justicier $(222,948), 3)$ Eudes $(214,233), 4)$ Robert $(175,975), 5)$ Odon $(172,998), 6)$ Bernón $(164,983)$.
} 
miembros de la red. En el curso de esta primera fase se observa por último una neta sobrerepresentación del grupo robertien entre los individuos centrales de la red de Odón.

Netdraw en último lugar permite analizar la estructuración de la red personal de Odón, poniendo en evidencia círculos de personas, más o menos próximos a él: el primero corresponde a los hombres con los que está directamente relacionado, el segundo a aquellos para los que necesita un intermediario, el tercero a aquellos para los que los intermediarios necesitan un intermediario, etc. ${ }^{75}$. Es el análisis del primer círculo, los vecinos directos, el que permite delimitar los fundamentos de la potencia relacional de Odón (figura 9). En el curso de esta fase, el futuro abad de Cluny no tiene más que seis vecinos directos, con los que mantiene prioritariamente lazos de parentesco, en sentido amplio: su padre, Abbon, los dos aristócratas a los que es confiado sucesivamente, Foulque le Roux después Guillaume le Pieux ; su maestro intelectual, Remí de Auxerre, Théotolon, canónigo al mismo tiempo que él en Tours; finalmente Bernón, su abad en Borgoña. Estas son las personas que permiten a continuación a Odón a acceder a otros aristócratas. Examinemos ahora cómo se forma este primer círculo relacional.

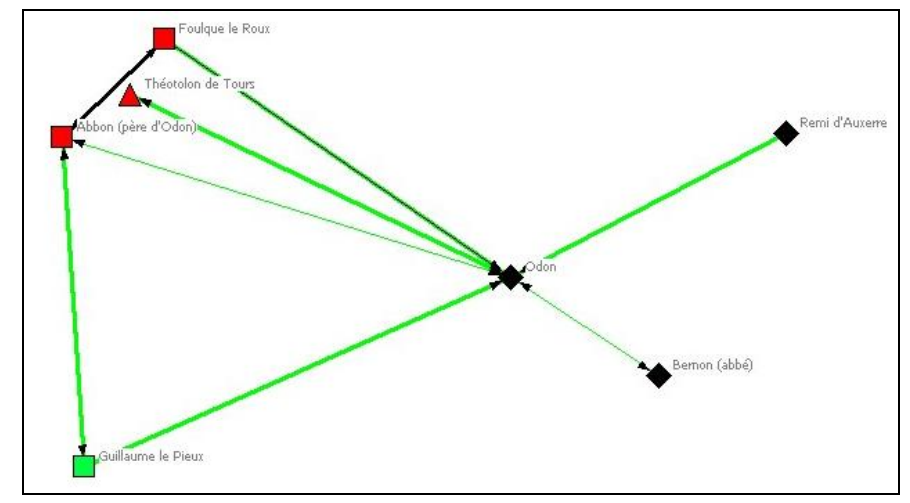

Figura 9. Primer círculo de la red personal "odoniana" en 879-908/910.

\footnotetext{
75 En teoría de grafos, los círculos corresponden a "distancias geodésicas" particulares. La distancia geodésica es "la más pequeña de las distancias del trayecto entre dos vértices", es decir, entre dos nodos; Cfr. A. DegenNe, M. Forsé, Les réseaux sociaux, p. 76. Más prosaicamente, se trata del número de lazos que separa, en un grafo, un nodo del otro, según el camino más corto. Aquí, para los vecinos de Odón, Netdraw considera que se trata de todas las personas que están a una distancia geodésica $\leq 1$ del futuro abad de Cluny (acceden a Odón con un sólo lazo, es decir, sin intermediario). En lo que respecta al círculo de persona para las que Odón tiene necesidad de un intermediario, la distancia geodésica es $\leq 2$, etc.
} 


\subsubsection{La herencia familiar (hacia 879-hacia 898)}

La primera fase en la construcción del capital social de Odón es una herencia familiar, ya que su padre, un jurista de Tours llamado Abbon, participa directamente en dos grupos aristocráticos.

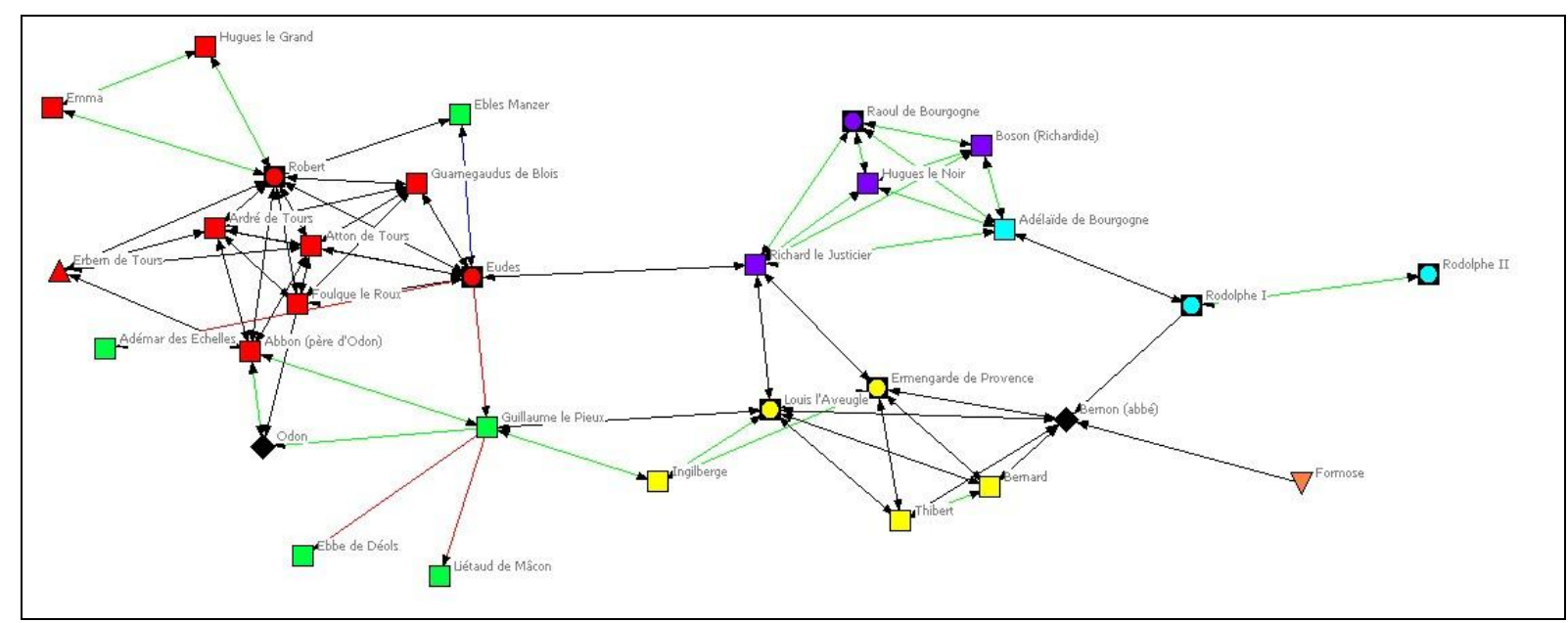

Figura 10. El capital social: Redes de Odón de 879 a 897.

El primero es robertien, ejerce su autoridad en Neustria et Abbon y participa directamente como lo muestra el grafo 10 . Este medio está fuertemente polarizado alrededor de dos personas cuya centralidad es fuerte: Eudes, rey de los francos (888-898), después su hermano, el duque Robert, futuro soberano (922-923). Está por otra parte más o menos situado en Touraine y reúne fieles de los Robertiens alrededor del centro simbólico de Neustria : Saint-Martin de Tours.

La inserción de Odón en este medio está marcada por el nombre mismo del futuro abad de Cluny, que forma parte del patrimonio onomástico de la familia robertienne ${ }^{76}$. Su anclaje se refuerza allí a continuación, al final de los años 880 , por lazos más directos y personales. Según la Vita Odonis, Odón es en efecto confiado, como nutritus, al futuro conde de d'Angers, Foulque le Roux, un fiel de los Robertiens, para recibir una primera educación laica ${ }^{77}$. Ahora bien, este tipo de

\footnotetext{
${ }^{76}$ R. LE JAN, « Dénomination, parenté et pouvoir dans la société du haut Moyen Âge $\left(\mathrm{VI}^{\mathrm{e}}-\mathrm{X}^{\mathrm{e}}\right.$ siècle) 》, en EAD., Femmes, pouvoir et société, op. cit. n. 13, p. 224-238, ici p. 228.

77 Sobre Foulque le Roux : K. F. WERNER, Enquêtes sur les premiers temps du principat français (IX $X^{e}-X^{e}$ siècles). Untersuchungen zur Frühzeit des französischen Fürstentum (9.-10. Jahrhundert) [traducido por B. SAINT-SORNY], Ostfildern, 2004, p. 37-67; ID., « Les premiers Robertiens et les premiers Anjou (IX siècle-début $X^{\mathrm{e}}$ siècle) », en O. Guillot, R. FAVREAu (éd.), Pays de Loire et Aquitaine de Robert le Fort aux premiers Capétiens. Actes du Colloque international tenu à Angers en septembre 1987, en Mémoires de la Société des Antiquaires de l'Ouest, 4, 1997, p. 9-67, ici p. 37-42 ; C. SetTIPANI, «Les comtes d'Anjou et leurs alliances aux $\mathrm{X}^{\mathrm{e}}$ et $\mathrm{XI}^{\mathrm{e}}$ siècles », en K. S. B. KEATS-RohAN (éd.), Family Trees and the Roots of Politics. The Prosopography of Britain and France from the Tenth to the Twelfth
} 
aprendizaje creaba lazos próximos de parentesco espiritual entre el nutritus y su nutritor $^{78}$. Foulques le Roux aparece en realidad como uno de los polos del espacio relacional robertien, situación que se perpetúa hasta los años 920, lo que hace de el una figura ascendente en la nobleza neustriana ${ }^{79}$. Este elemento explica que Abbon le hubiera confiado su hijo una garantía de gran carrera aristocrática. Inversamente, el hecho de que Foulque le Roux hubiera aceptado ocuparse de la educación de Odón, mientas que era sin duda solicitado por todos lados en razón de su posición social estratégica, permite precisar que la familia del futuro abad de Cluny pertenece probablemente a una nobleza intermedia: no era lo suficientemente elevada socialmente para permitir a Odón ser confiado directamente a los Robertiens, pero lo autorizó a pesar de todo a a integrarse en el séquito de uno de sus vasallos directos.

Odón es legalmente introducido en el grupo de los Guilhemides por su padre que era, según la Vita Odonis, un allegado del duque de Aquitania, Guillaume le Pieux ${ }^{80}$. Como con Foulque le Roux, Abbon confía su hijo como nutritus al duque de Aquitania hacia $896-898^{81}$. Existe pues igualmente un lazo directo, próximo a la parentela espiritual, entre Odón y Guillaume. Este paso por la corte Guilhemide es fundamental porque pone a Odón directamente en relación con uno de los príncipes territoriales más importantes de Francia occidental, como lo atestiguan los cálculos de centralidad mencionados anteriormente ${ }^{82}$.

Century, Woodbridge, 1997, p. 211-267. Sobre los lazos de Foulque con Odón: VO, I 11, col. 47 D. Cfr. también I. COCHELIN, "Quête de liberté et réécriture des origines: Odon et les portraits corrigés de Baume, Géraud et Guillaume », en M. LAUWERS (éd.), Guerriers et moines. Conversion et sainteté aristocratiques dans l'Occident médiéval (IX ${ }^{e}-X I I^{e}$ siècle), Antibes, 2002, p. 183-233, aquí p. 188-189.

78 Sobre los lazos de fosterage : R. LE JAN, «Apprentissages militaires, rites de passage et remises d'armes au haut Moyen Âge », en Éducation, apprentissages, initiation au Moyen Âge. Actes du premier colloque international de Montpellier, novembre 1991, Cahiers du CRISIMA, 1, 1993, p. 211-232, ici p. 222-223. Surtout, A. GUeRREAU-JALABERT, « Nutritus/oblatus : parenté et circulation d'enfants au Moyen Âge », op. cit., n. 53.

79 Los cálculos de centralidad en Foulque le Roux durante esta fase lo colocan, por otra parte, en bastante buena posición para la centralidad de grado (9) y de proximidad (366); Es, en cambio, menos central en el plano de intermediariedad.

${ }^{80}$ VO, I 5, col. 45 D-46 B.

${ }^{81}$ Ibid., I 3, col. 45 B et I 8, col. 47 A.

82 Sobre el poder de Guillaume le Pieux, primer grande que reivindica el título de dux, después de princeps, C. LAURANSON-Rosaz, L'Auvergne et ses marges (Velay, Gévaudan), du VII ${ }^{e}$ au XII ${ }^{e}$ siècle. La fin du monde antique ?, Le Puy-en-Velay, 1987, p. 66-84. Sobre Guillaume le Pieux y la consolidación de su poder, J.-P. BRUNTERC'H, «Naissance et affirmation des principautés au temps du roi Eudes. L'exemple de l'Aquitaine », en O. Guillot, R. FAVREAU (éd.), Pays de Loire et Aquitaine, op. cit. n. 77 , p. 69-116, p. 69-116. 
Los lazos sociales organizados alrededor de Guillaume son importantes porque permiten probablemente al joven Odón acceder a otro espacio relacional, el de los Bosonides de Provence. El duque de Aquitania ostenta en efecto un rol de intermediario mayor, o más bien de Cutpoint, principalmente a partir de los años 890 (o sea en el momento mismo en que Odón es su nutritus), cuando desposa a la hija de Boson, Ingelberge ${ }^{83}$. El grupo bosonide está polarizado en Ermengarde, viuda de Boson, y sobre todo por su hijo Luis l'Aveugle. En el curso de los años 890 los miembros de este grupo familiar tejen además lazos relativamente densos con un tal Bernón, abad del monaterio de Gigny en el Jura. Paralelamente, este último está en contacto con otros dos espacios relacionales: de una parte el del rey de Bourgogne Jurane, Rodolphe Io, aliados por lazos de parentesco con la familia de los Richardides; por otra parte los medios pontificales romanos, representados por el papa Formose.

\subsubsection{Materialización del capital social hacia una carrera eclesiástica (hacia 898-hacia 908)}

Este doble capital social inicial, robertien y guillemide, se concreta después en una carrera eclesiástica en dos tiempos. Entre alrededor de 898 y 908, Odón es primero canónigo en San Martín de Tours, donde los Robertiens son abades laicos ${ }^{84}$. Esta primera conversión está ligada a Foulque le Roux, cuya influencia directa está bien subrayada en la Vita Odonis ${ }^{85}$. Esto significa que una de las estrategias reticulares del padre de Odón, que había escogido a este nutritor para su hijo encuentra ahí una concreción. La entrada de Odón en la comunidad de canónigos martinienne refuerza además sus relaciones con el medio robertien. Pemite, en efecto, la creación de nuevos lazos de parentesco espiritual con sus correligionarios, principalmente con un tal Théotolon, que será después arzobispo de Tours ${ }^{86}$. La

\footnotetext{
83 Sobre la fecha de este matrimonio, B. H. ROSENWEIN, « La question de l'immunité clunisienne », en Bulletin de la Société des Fouilles Archéologiques de I'Yonne, 12, 1995, p. 1-12, ici p. 4 ; más recientemente, F. MAZEL, «La Provence entre deux horizons (843-1032). Réflexions sur un processus de régionalisation », en M. Gaillard, M. Margue, A. Dierkens, H. Pettiau (éd.), De la mer du Nord à la Méditerranée. Francia media, une région au cœur de l'Europe, Luxembourg, 2011 (Publications du CLUDEM, 25), p. 453-485, ici p. 466.

84 K. F. WERNER, « Les premiers Robertiens », loc. cit. n. 77, p. 26-30.

${ }^{85}$ VO, I 9, col. $47 \mathrm{C}$.

86 SobreThéotolon, G.-M. OURY, «L'archevêque Théotolon, restaurateur de Saint-Julien-de-Tours », en Revue Mabillon, 54, 1964, p. 118-123. H. NoIzET, La fabrique de la ville. Espaces et sociétés à Tours (IX $X^{e}$-XIII siècle), Paris, 2007, p. 121-122. No hay documentos de la práctica que menciona la presencia simultánea de Odón y de Théotolon en Saint-Martin de Tours, pero se deduce de fuentes diplomáticas que lo mencionan, de forma separada, en la comunidad martinianne en el transcurso de los mismos años. En cambio, varios textos narrativos (como la Vita Odonis) evocan el hecho de que los lazos de los dos hombres se remontan a su experiencia canónica. (en rapport avec St Martin de Tours: "religiosa de la abadia de St Martin de Tours".
} 
experiencia canónica de Odón está igualmente marcada por su formación intelectual al lado de Remi, anciano maestro de Saint-Germain d'Auxerre, que enseñaba entonces en París, ciudad controlada por los Robertiens, lo que deja suponer su influencia en el lugar de instrucción del futuro abad de Cluny. La enseñanza de Remi amplio probablemente las relaciones de Odón con otros alumnos, principalmente con Guillaume, que fue después arzobispo de Sens ${ }^{87}$.

A la edad de 30 años, hacia 908-909, la carrera eclesiástica de Odón toma un nuevo giro con su conversión como monje al lado de Bernón, el abad de Guigny mencionado anteriormente ${ }^{88}$. La elección de Bernón fue determinada sin duda por el medio guilhemide, via los Bosonides. Se trata de una nueva materialización del capital social heredado de su padre que desemboca esta vez en un nuevo espacio relacional en el que Odón era probablemente extraño.

Se pueden extraer tres enseñanzas de este primer periodo, fundamental en términos de génesis de la red personal "odoniana". Ante todo, desde un punto de vista documental, esta primera fase sería totalmente incomprensible sin la Vita Odonis. Esta fuente narrativa es, en efecto, indispensable para identificar el medio de origen del abad de Cluny, así como sus lazos con sus dos nutritores, tan determinantes en su vida posterior. Para volver al análisis de redes, se puede, por otra parte, subrayar que en el transcurso de esta primera fase de ahogo de la herencia familiar hasta 898, Odón se une más intensamente al grupo robertien que al de los Guilhemides, en el sentido en que mantiene más lazos con el primer medio, cuya densidad es más importante. Sin embargo, en términos de proximidad, está en interacción directa y privilegiada con el centro del grupo guilhemide, , Guillaume le Pieux, mientras que tiene necesidad de al menos un intermediario (su padre o Foulque) para acceder a uno de los polos del grupo robertien. En último lugar, si nos centramos en los diferentes círculos (según la distancia geogésica) que componen la red personal del futuro abad de Cluny, sólo se puede remarcar el poder relacional de las seis personas con las que Odón está en relación directa: gracias a ellas, Odón puede entrar en contacto -con sólo movilizar uno o dos intermediarios con los principales medios aristocráticos del fin del siglo IX y de la primera mitad del X. La llegada de Odón al lado de Bernón constituye desde

\footnotetext{
87 Sobre la formación por Remi, VO, I 19, col. 52 A. Sobre Remi y sus alumnos, C. JEUDY, « L'œuvre de Remi d'Auxerre », en D. IOGNA-PRAT, C. JEUDY, G. Lobrichon (éd.), L'École carolingienne d'Auxerre. De Murethach à Remi 830-908, Paris, 1991, p. 373-397.

88 VO, I 22, col. 53 B-C.
} 
entonces la primera ruptura importante en su itinerario biográfico, en el sentido en que ésta lo reorienta hacia espacios relacionales más meridionales.

\subsection{El anclaje de Odón en los espacios relacionales meridionales (908/910-} 926)

Desde su llegada a Borgoña, la red de Odón se desarrolla claramente, principalmente a partir de su dirección abacial del monasterio de Cluny, desde 923, fecha que cierra esta segunda fase de su vida. Esta última está marcada por un cambio meridional de la red de Odón en relación con los años precedentes y un estiaje de sus relaciones con los Robertiens.

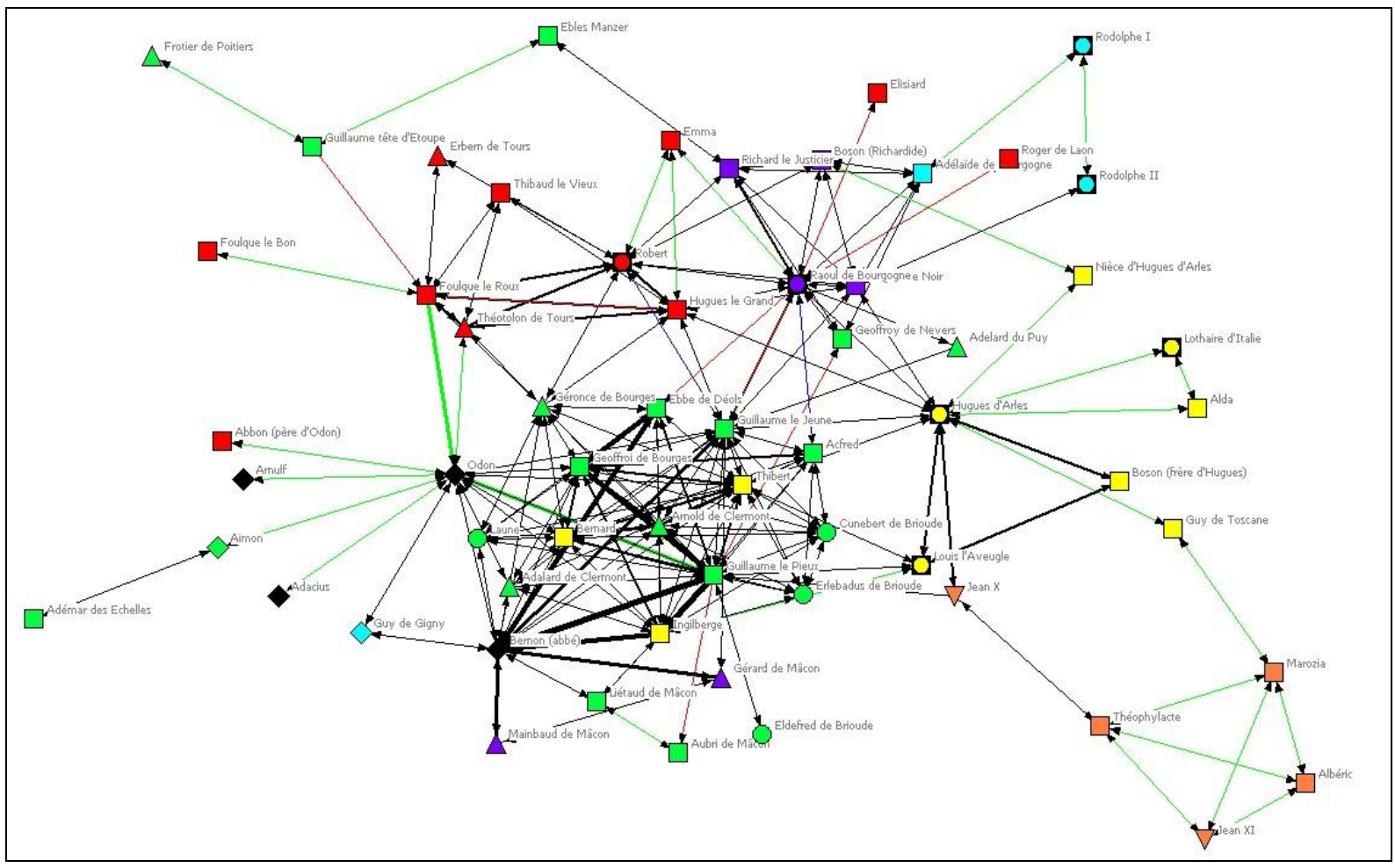

Figura 11. Red personal de Odón de Cluny de $908 / 910$ à 926.

\subsubsection{Características generales de la segunda fase de la red "odoniana"}

La primera impresión, sorprendente en relación al grafo de la primera fase, reside en la densificación, la mayor multiplicidad y la más fuerte conectividad de la red "odoniana" (figura 11). Los lazos entre las personas son, en efecto más numerosos (lo que resulta sin duda de un efecto de Fuente) y sobre todo mucho más diversificadas que anteriormente. Más exactamente, los lazos efímeros (en negro) ganan por la mano a las relaciones de parentesco o de fidelidad, lo que muestra 
que la red potencial (que resulta del parentesco), está, en lo sucesivo más concretada por interacciones puntuales que la activan. En último lugar, la red es conexa, es decir que a lo largo de esta fase los miembros del grupo théophylacte han tejido lazos que les permiten estar en relación con las otras familias aristocráticas. Igual que anteriormente, aparecen algunos nodos como Cutpoints sin los cuales estaría amenazada la conectividad de la red: Odón, el futuro conde de Angers Foulque le Roux, el duque de Aquitania Guillaume le Pieux, el duque de Borgoña, después rey de los Francs Raoul, el futuro rey de Italia Hugues d'Arles, además, en una menor medida, el conde de Poitiers Guillaume Tête d'Étoupe y el abad de Saint-Martial de Limoges, Aimon ${ }^{89}$. Si Guillaume de Aquitaine y Odón jugaban ya este rol en la fase precedente, los otros emergen, principalmente los grandes laicos, quienes posteriormente van a a ocupar funciones de soberano. Finalmente, se pueden localizar algunos espacios relacionales intermediarios que, como anteriormente, continúan recuperando -aunque de manera un poco menos clara- la pertenencia a los grupos nobiliarios.

Los cálculos de centralidad ponen en evidencia diferencias claras con la estructura de la red "odoniana" a lo largo de la fase precedente, incluso si se observa una constante: las personas centrales son siempre grandes laicos que acumulan globalmente -pero un poco menos que antes- los diversos tipos de centralidad ${ }^{90}$. Se constata en primer lugar, para las personas centrales, un claro aumento del número de vecinos directos (la centralidad de grado) y un descenso del índice de proximidad, signo a la vez de su rol de polarización más fuerte de las relaciones y de las interacciones sociales y, más globalmente, de un mayor número de lazos captados en el transcurso de esta fase. Se observa también el menor peso de Guillaume le Pieux dentro de la red, incluso si es la persona más central según los cálculos de centralidad de "grado" y de "proximidad"; en cambio, su fallecimiento brutal en 918, así como la intensificación de las relaciones e interacciones con otros nodos, explican que su rol de intermediario sea menos importante que en la fase precedente. La diferencia más sorprendente entre las dos fases reside sin embargo en el peso aplastante de representantes de grupos aristocráticos meridionales entre

\footnotetext{
89 Como anteriormente, el estatuto de Cutpoint ha sido calculado con Netdraw. Contrariamente a los otros que permiten ligar cliques, Guillaume Tête d'Étoupe y el abad Aimon son sólo Cutpoints para un nodo.

90 «Centralidad de grado» : 1) Guillaume le Pieux (21), 2) Guillaume le Jeune (19), 3) Thibert (17), 4) Bernón (16), 5) Raoul de Bourgogne (15), 6) Odon (15), 7) Ingilberge (15). « Centralidad de proximidad» : 1) Guillaume le Pieux (181), 2) Guillaume le Jeune (175), 3) Raoul de Bourgogne (187), 4) Thibert (188), 5) Hugues d'Arles (189), 6) Odon (189), 7) Hugues le Grand (191). « Centralidad de intermediario» : 1) Hugues d'Arles (376, 964), 2) Odon $(371,309), 3)$ Guillaume le Pieux $(326,626)$,
} 
los nodos centrales y la casi desaparición de los Robertiens. Con excepción de Foulque le Roux, todas las unidades sociales en posición de centralidad pertenecen, en efecto al medio guilhemide, bosonide, rodolphien o théophilacte. Señalemos finalmente que aparecen dos personas como centrales según los índices de intermediariedad: Hugues d'Arles y Odón, cuya elevación en el poder resulta de su capacidad de hacer el papel de "puente" entre los diferentes grupos aristocráticos.

El primer círculo de la red personal de Odón sufre también evoluciones a lo largo de esta fase (figura 12), incluso si -como anteriormente- el futuro abad de Cluny queda relativamente al margen del resto de las relaciones e interacciones sociales. Se constata en primer lugar un aumento del número de sus vecinos directos (15) y una estructura mucho más estrellada que anteriormente, principalmente con algunos abades (Aimon, Arnulf, y Adacius) y con el futuro obispo de Tours, Théotolon: se asiste así a una "monaquización" a una clericalización del primer círculo, compuesto por mitad de miembros de la Iglesia, lo que refleja con toda probabilidad en parte la evolución de la carrera personal del futuro abad de Cluny. Se observa también que Odón tiene acceso directamente a más grupos aristocráticos que anteriormente: además de Robertiens y Guilhemides, está en ese momento en relación con varias unidades sociales del grupo bosonide (Ingilberge, Thibert y Bernard) y con un miembro del medio (el sobrino de Bernón, Guy de Gigny), intermediarios importantes (algunos de los cuales tienen fuertes coeficientes de centralidad) que le permiten acceder al conjunto de la estructura reticular desde el segundo círculo. Finalmente, y sobre todo, hay una clara diferencia en los tipos de lazos que Odón mantiene en función de los grupos aristocráticos: sus relaciones con los Robertiens revelan solamente parentesco y se quedan entonces en la esfera de lo potencial, mientras que sus interacciones sociales efectivas se hacen esencialmente con los Bosonides y los Guilhemides, es decir con los espacios relacionales meridionales.

4) Guillaume le Jeune $(321,706), 5)$ Raoul de Bourgogne $(260,16), 6)$ Foulque le Roux $(203,514), 7)$ Jean X $(155,817)$. 


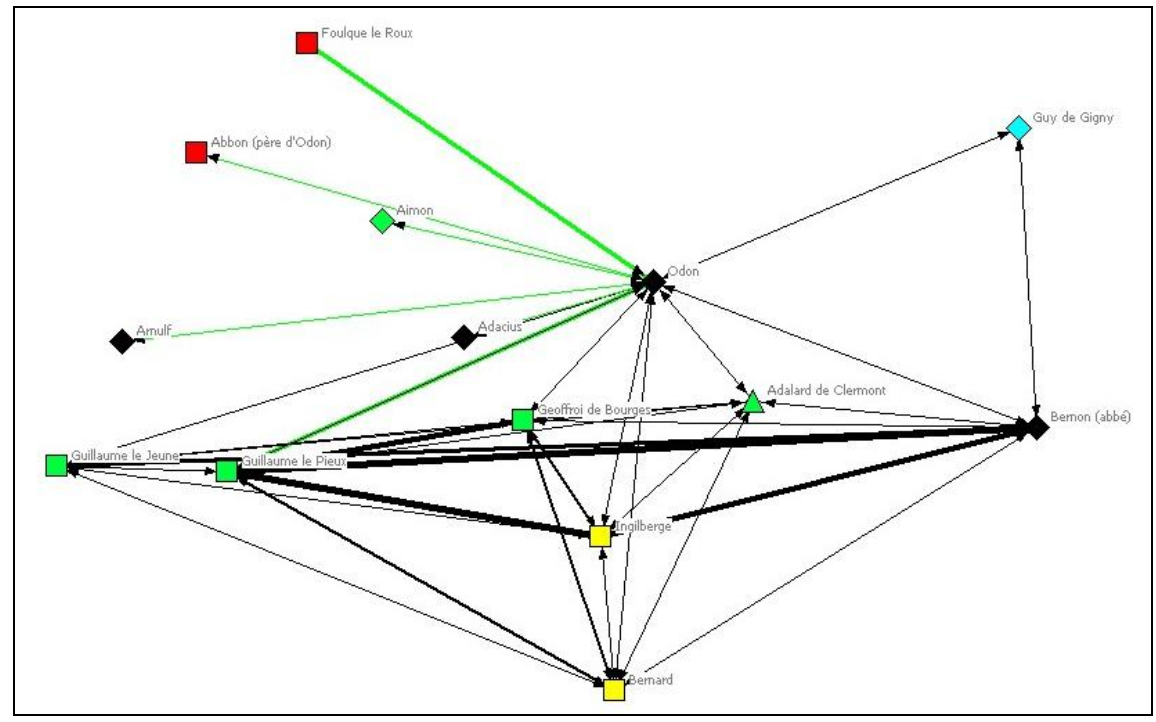

Figura 12. Primer círculo de la red personal "odoniana" en 908/910-926.

\subsubsection{Vuelco meridional de la red "odoniana"}

La llegada de Odón a Borgoña, como monje, alrededor de dos años antes de la fundación del monasterio de Cluny, refuerza su inserción en el medio guilhemide. Esta última se centra en Guillaume le Pieux hasta su muerte en 918, después se detiene con su sobrino Guillaume le Jeune, mientras que el hermano de éste, Alfred, permanece retirado. Durante esta nueva fase, el armazón del grupo guilhemide está constituida por relaciones de parentesco y sobre todo de fidelidad entre el duque de Aquitania y sus vasallos, repartidos entre las tres zonas de su principado: los fieles auvernianos, próximos al polo central, en la medida en que la Auvergne constituye la base histórica del poder de Guillaume; los fieles del Mâconnais y del Nivernais, condados que Guillaume adquirió más tarde; finalmente los fieles berrichons ${ }^{91}$. Hacia 912 el grupo guilhemide rompe sus lazos con el de los Bosonides $^{92}$. Ingilberge, la esposa de Guillaume le Pieux, ha estado "atrapada" por el medio de su esposo y no parece tener más lazos con su grupo de origen. Después de 905 y en ausencia de heredero legítimo adulto, el ejercicio del poder bosonide en Provenza tocó al conde de Vienne, Hugues de Arles (o de Provence), que gobierna

\footnotetext{
91 Los fieles auvergnats (en verde) son los grandes laicos Acfred, Geoffroy de Nevers y Adémar des Échelles ; los obispos Arnold de Clermont, Adalard de Clermont, Adelard du Puy ; el abad Aimon ; los canónigos Cunebert de Brioude, Erlebadus de Brioude y Eldefred de Brioude. Los fieles de Mâconnais (en azúl oscuro) son los grandes laicos Aubri de Mâcon y Liétaud de Mâcon ; los obispos Gérard de Mâcon y Mainbaud de Mâcon. Los fieles berrichons (en verde) son los laicos Geoffroi de Bourges y Ebbe de Déols, el arzobispo de Bourges Géronce y l'archidiácono Laune (hermano de Ebbe de Déols). (fieles del Berry)
} 
en lugar de Luis y que polariza desde entonces el grupo, que se vuelve a continuación hacia horizontes italianos.

La evolución del espacio relacional guilhemide tiende en último lugar a confirmar una hipótesis de Isabelle Cochelin sobre la sucesión de Bernón en Cluny ${ }^{93}$. La abadía se funda efectivamente en septiembre de 910 y este acontecimiento hace intervenir de cerca a Guillaume le Pieux, el fundador, Bernón, el primer abad y Odón, que redacta el acta tres hombres cuyas redes personales respectivas convergen en esta época. Ahora bien, es más que probable que se hubieran entendido, desde la fundación, para confiar Cluny a Odón después de la muerte de Bernón. Se observa la influencia del lazo de parentesco espiritual entre Odón y Guillaume, que desemboca en el ejercicio de una función de poder.

El grafo aclara el rol jugado por el abad Bernón en el anclaje de Odón en los espacios relacionales meridionales, guilhemide y bosonide (figura 13) ${ }^{94}$. Antes de ser monje en Cluny, el espacio relacional de Odón estaba intensamente vuelto hacia Neustria, con la cual no mantiene en adelante más que lazos frágiles Ahora bien, a partir de los años 910 Bernón refuerza claramente su inserción en el medio guilhemide, en particular en Berry, y abandona su anclaje burgiñón y provenzal original. Uno de los signos de refuerzo de lazos de Bernón con la aristocracia guilhemide se concreta por otra parte por sus relaciones con algunos miembros de la Iglesia de Aquitania, los hermanos Turpio y Aimon, respectivamente obispo de Limoges y abad de Saint-Martial con los cuales Bernón mantiene lazos de amistad mal datados ${ }^{95}$ Se puede suponer que esta amicitia deriva de la influencia de Guillaume Le Pieux, via los Bosonides. Señalemos que Bernón queda por otro lado casi totalmente desconocido en los espacios relacionales de los fieles de Guillaume en el ducado de Borgoña, principalmente en Mâconnais. Bernón juega así un rol de intermediario para Odón, porque parece legarle una parte de sus relaciones cuando le confía Cluny de forma anticipada hacia 926. La comparación de las redes de los dos primeros abades de Cluny en el curso de este mismo período atestigua en

\footnotetext{
92 Sobre la ruptura de lazos entre Guilhemides y Bosonides y por lo tanto del párrafo, F. MAZEL, « La Provence entre deux horizons », loc. cit. n. 83, p. 466-469.

93 I. CoCHeLIN, «Quête de liberté », loc. cit. n. 77, p. 200-201.

94 En la medida en que, para reconstruir la red de Odón, he considerado también sus alter, he integrado en la base de datos todas las relaciones conocidas de Bernón. Este paso permite, pues, a partir de los datos tomados, visualizar también la red personal del primer abad de Cluny, en diferentes fechas. Este mismo proceso permite igualmente visualizar la red de uno de los co-abades de Odón, Adacius, cfr. supra, p. 40.

95 Sobre Turpion, J. BECQUET, «Les évêques de Limoges aux $\mathrm{X}^{\mathrm{e}}, \mathrm{XI}^{\mathrm{e}}$ et $\mathrm{XII}^{\mathrm{e}}$ siècles », en Bulletin de la Société archéologique et historique du Limousin, 104, 1977, p. 63-90, ici p. 75-82.
} 
realidad que Odón está mucho mejor insertado que Bernón en la aristocracia, lo que demuestra una vez que dirige solo la abadía, a la muerte de su predecesor, en enero de 927.

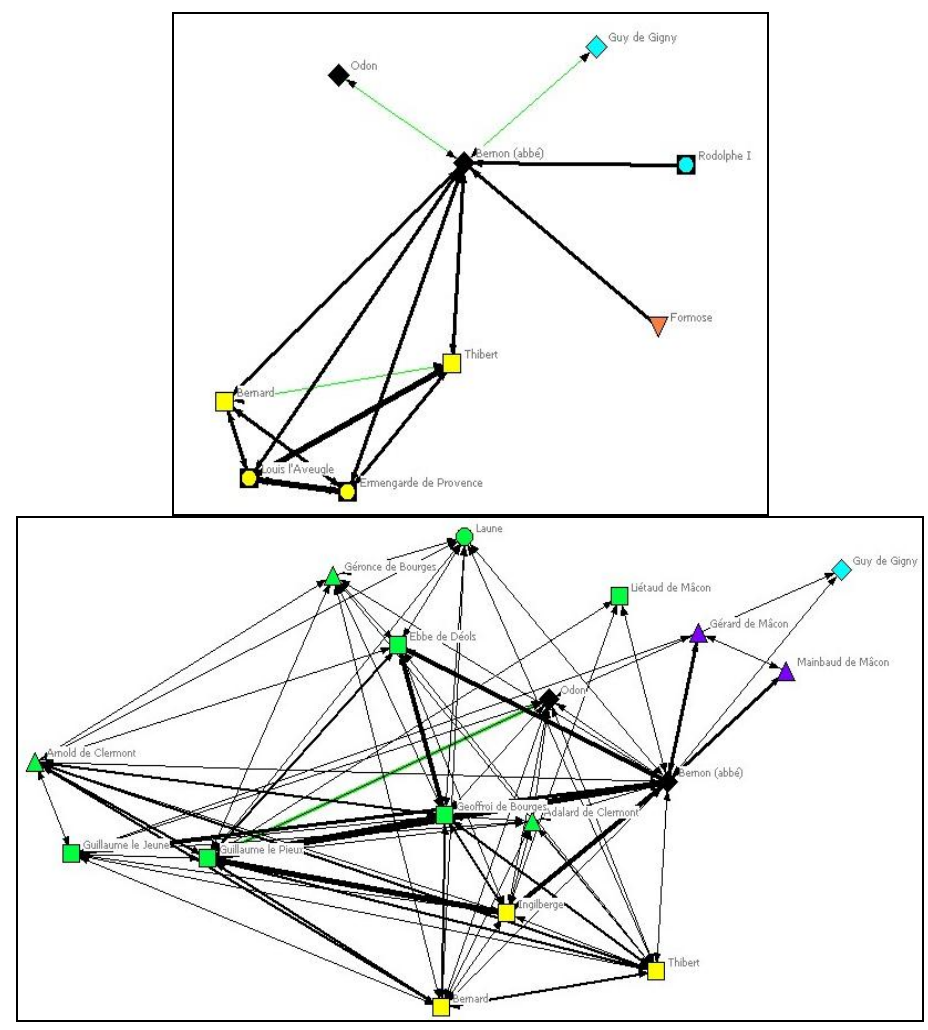

Figura 13. Primer círculo de la red personal de Bernón, sucesivamente en 879-908/910, más tarde en 908/910-926.

\subsection{La explotación del capital social en tanto que abad: privilegios, anclaje} burguiñón y primeras reformas en la estela guilhemide (927-936)

Esta tercera fase del itinerario biográfico de Odón se abre con su dirección abacial de Cluny y se acaba con la muerte de tres de sus principales auxiliares durante la primera parte de su vida. El ejercicio de funciones de poder modifica necesariamente el tipo de lazos que Odón mantiene con el mundo aristocrático, lo que transforma globalmente la estructura de su red personal, rearticulada alrededor de tres grupos nobiliarios y concretada por reformas. 


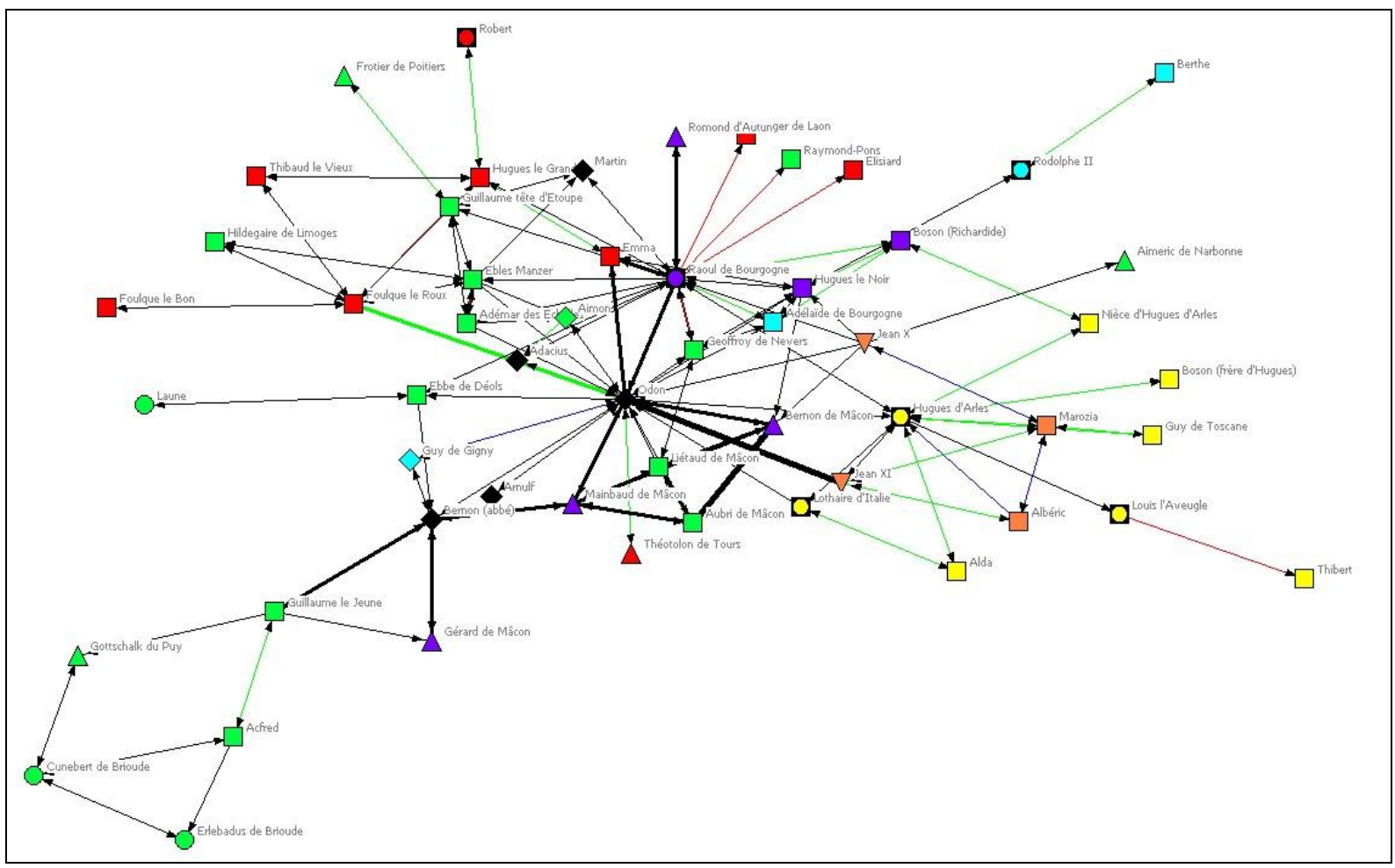

Figura 14. Red personal de Odón de Cluny de 927 a 936.

\subsubsection{Características generales de la tercera fase de la red "odoniana"}

Como en la fase precedente, el tercer estado de la red "odoniana" es conexo, pero es menos denso y está más organizado en estrellas alrededor de algunos nodos (Odón, Raoul de Bourgogne, que fue rey de los Francos, y Hughes de Arlés, luego soberano de Italia) que en cliques (figura 14). Las interacciones se tejen por otra parte más sistemáticamente que antes entre los miembros de diferentes medios aristocráticos, signo de una recomposición parcial de los espacios relacionales intermedios. A pesar de estas modificaciones, se nota un mantenimiento de los principales Cutpoints que permitían anteriormente la conectividad de la red personal del abad de Cluny: esencialmente Odón, Raúl de Borgoña, Hughes de Arles, Guillaume le Jeune (en tanto que sucesor de Guillaume le Pieux), Foulque le Roux, Hugues le Grand y Guillaume Tête d'Étoupe, que ha afirmado su estatuto de intermediario obligatorio ${ }^{96}$. Esto significa que a pesar de algunas diferencias estrucuturales, la red "odoniana" conserva la mayor parte de los atributos establecidos en el transcurso del período monástico.

\footnotetext{
${ }^{96}$ Louis I'Aveugle, Rodolphe II y Ebbe de Déols hacen el papel de Cutpoints secundarios.
} 
La gran novedad reside de hecho en el lugar central que ocupa Odón en las relaciones e interacciones sociales que emanan probablemente de su ascensión al estatus abacial. Si se examinan los cálculos de centralidad, el abad de Cluny aparece además, de lejos, como la persona más influyente, sea cual sea el criterio mantenido: él es el que tiene más vecinos directos, el intermediario más importante y la persona que puede entrar más fácilmente en contacto con cualquier miembro de la aristocracia ${ }^{97}$. Los otros nodos centrales conservan globalmente las características vistas anteriormente: se trata sobre todo de grandes laicos, que evolucionan ante todo en las esferas meridionales, que ejercían a veces ya una cierta influencia a lo largo de los años 908/910-926 y que la han consolidado frecuentemente accediendo a funciones prestigiosas, como Hugues d'Arles y Raoul de Bourgogne, que fueron respectivamente soberanos de Italia y del reino de los Francos del Oeste. Más que en el curso del período precedente, estas unidades sociales acumulan diferentes tipos de centralidad y se jerarquizan poco o mucho de la misma forma, sea cual sea el criterio mantenido.

El primer círculo de la red personal "odoniana" ha conocido nuevas evoluciones, ya que el abad de Cluny cuenta entre sus vecinos directos, todavía más numerosos que antes (23), al menos con dos miembros de cada medio aristocrático, lo que desmultiplica sus posibilidades de tener acceso a todos los miembros de los diferentes espacios relacionales (figura 15). Más aún, Odón se encuentra en lo sucesivo en relación privilegiada con los que están en posición de centralidad en la estructura reticular de conjunto, es decir con las personas que polarizan grupos aristocráticos (particularmente Raoul de Bourgogne, Hugues de Arles, Hugues le Noir y Ebles Manzer): su situación de centralidad es así desmultiplicada por lazos directos con estos nodos centrales. Como en el curso de la fase precedente, estos compañeros privilegiados pertenecen casi en su mitad al mundo eclesiástico en el que ejercen funciones de papa (Jean X y Jean XI), de obispos (Théotolon de Tours, Bernón y Maimbaud de Mâcon) y de monjes (Bernón, Adacius, Arnulf, Guy de Gigny y Aimon). Contrariamente a los grandes laicos, estos últimos no aparecen verdaderamente como intermediarios del abad de Cluny hacia otros grupos aristocráticos, sino más bien como intermediarios que permiten una conformación

\footnotetext{
97 Para la «centralidad de grado» : 1) Odon (23), 2) Raoul de Bourgogne (20), 3) Hugues d'Arles (11), 4) Hugues le Noir (9), 5) Ebles Manzer (8), 6) Foulque le Roux (7), 7) Bernón (6). Para la « centralidad de proximidad»: 1) Odón (150), 2) Raoul de Bourgogne (158), 3) Hugues d'Arles $(174), 4)$ Hugues le Noir (179), 5) Jean X (182), 6) Ebles Manzer (182), 7) Ebbe de Déols (183). Para la « centralidad de intermediario»: 1) Odon $(727,945), 2)$ Raoul de Bourgogne $(472,319), 3)$ Hugues d'Arles $(320,408)$, $4)$ Bernón $(290,500), 5)$ Guillaume le Jeune $(200,500)$, Foulque le Roux $(123,358)$, 7$)$ Hugues le Noir $(121,095)$.
} 
del poder abacial "odoniano", o sea, su anclaje local. Finalmente, desde el punto de vista de los lazos directos mantenidos por Odón con el mundo aristocrático, emergen dos elementos nuevos. Se constata al principio un fenómeno de intensificación de los lazos (representado por el espesor del trazo) entre el abad de Cluny y ciertos actores que no son forzosamente "centrales" en la estructura global de la red en el transcurso de este período. Se encuentra por supuesto el rey Raúl de Borgoña, pero también su esposa, la robertienne Emma, el papa Juan XI y finalmente los obispos de Mâcon Bernón, después Mainbaud. Se trata de personas con las que Odón mantiene lazos repetidos y que le permiten asentar su poder abacial recurriendo a diversos tipos de legitimidad -real, pontifical y episcopal- que juegan a diferentes escalas. Se remarca por otra parte que los lazos efectivos de Odón con el mundo aristocrático (en negro) son en adelante mucho más numerosos que los lazos potenciales resultantes del parentesco (en verde). Estos últimos se refieren sobre todo a los medios Robertiens, con los cuales el abad de Cluny parece no tener más interacciones concretas, como en el curso de la fase 908/910-926: ciertamente mantiene lazos con Emma, pero esta última ha sido "aspirada" a la órbita de su esposo, el rey Raúl, y no parece por otra parte mantener más lazos con su parentesco robertien. Las interacciones efectivas de Odón con el mundo aristocrático se refieren siempre a las esferas meridionales.

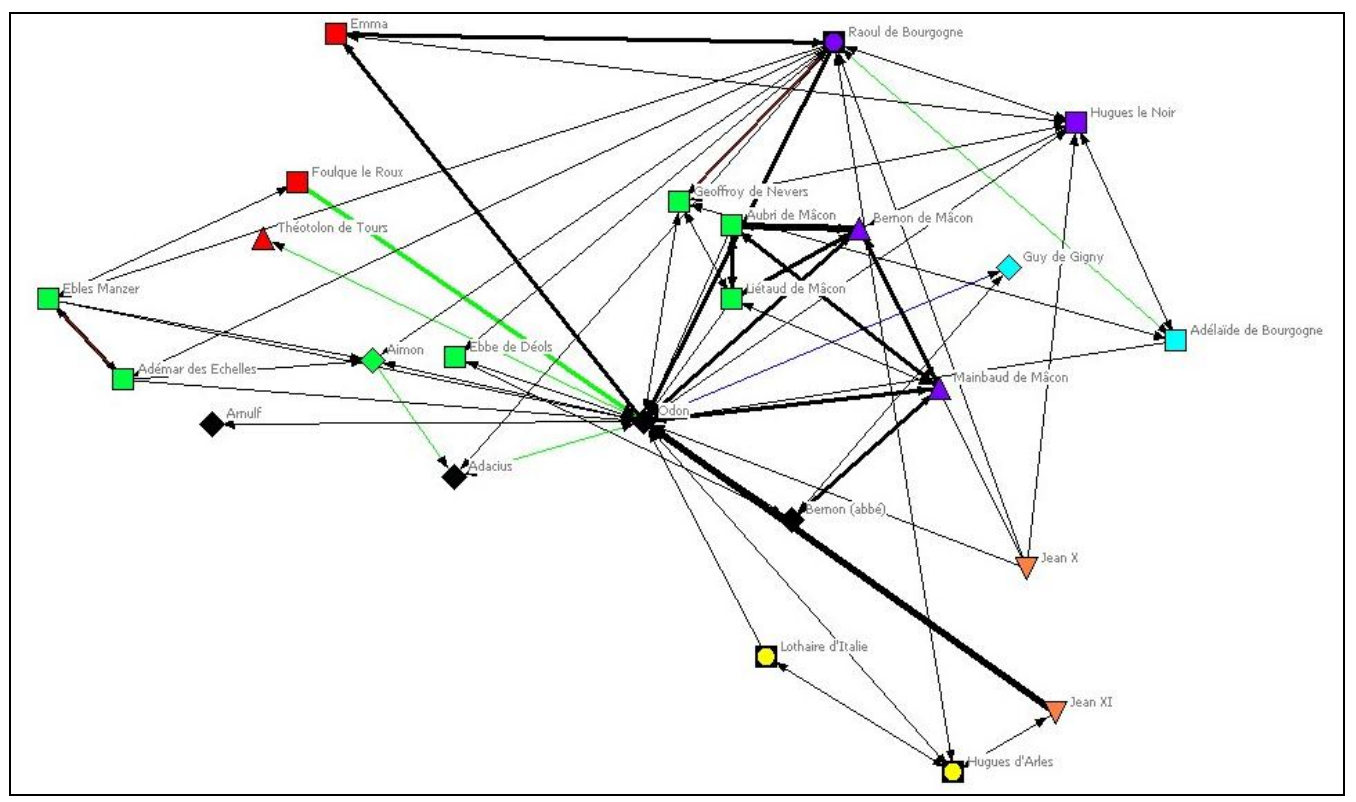

Figura 15. Primer círculo de la red personal de Odón en 927-935. 


\subsubsection{Relaciones e interacciones orquestadas sobre tres espacios relacionales}

Tras la muerte de Bernón, los lazos de Odón, en términos de intensidad y de frecuencia, se recomponen esencialmente sobre tres espacios relacionales intermediarios. El primero corresponde a medios pontificales romanos de los que obtiene privilegios para las abadías que él dirige, por primera vez por parte del papa Juan $X$, en $927^{98}$. El acceso de Odón a este espacio relacional pasa necesariamente por un intermediario cuya identidad es hipotética. Podría tratarse de Bernón, que había obtenido un privilegio de Formosa, pero esta vía es poco probable porque este papa fue objeto de una damnatio memoriae al final de los años $890^{99}$. Guillaume le Pieux pudo jugar igualmente este rol de intermediario ya que había obtenido de Juan X, en 914-918, una confirmación de posesiones de su monasterio de Moissat ${ }^{100}$. Finalmente se puede suponer una intervención del grupo bosonide, representado por Hugues de Arles, que es el aristócrata de Francia del Oeste, el mejor unido de los medios romanos en esta época. En efecto, en julio de 926, con el fin de hacerse elegir rey de Italia, Hughes estableció con Juan X una alianza diplomática que perdura hasta $928^{101}$.

Es, pues, más probable que gracias a su mediación Odón pudo entrar en contacto con el papa y, más ampliamente más tarde, con los medios pontificales romanos.

Este espacio relacional romano constituye una vía de acceso hacia los Théophylactes, la familia aristocrática que controla la región romana y también los cargos pontificios $^{102}$. Se pone de manifiesto que Hugues de Arles teje lazos de parentesco con una parte de esta familia, principalmente con Marozia, que ejerce su autoridad sobre la Villa desde 928 hasta 932. En revancha, en 932 es el hijo de Marozia, Alberico, quien toma el poder contra su madre, pero también contra Hugues. De 932 hasta 936, Odón cesa sus interacciones con los medios romanos, lo

\footnotetext{
98 Sobre esta bula, I. RosÉ, Construire une société seigneuriale, op. cit. n. 22, p. 167-182.

99 Sobre Formose, P. RICHÉ, «La Chrétienté occidentale ( $X^{\mathrm{e}}$-milieu du XI $\mathrm{I}^{\mathrm{e}}$ siècle) 》, en J.-M. MAYEUR, C. PIÉTRI, L. PIÉTRI, A. VAuCHez (éd.), Histoire du christianisme. t. IV : Évêques, moines et empereurs (610-1054), Paris, 1993, p. 767-866, ici p. 781-782.

100 N³5, Papsturkunden, I. 896-1046, éd. H. ZimmermanN, Vienne, 1984, p. 61-62.

101 Sobre esta alianza, LiUTPRAND DE CRÉMONE, Antapodosis, éd. G. H. PERTZ, Hanovre, 1839 (MGH, Scriptores, III), p. 273-339, ici Livre III, § 17, p. 306.

102 Sobre los Théophylactes, O. GERSTENBERG, Die politische Entwicklung des römischen Adels im 10. und 11. Jahrhundert, Dissertation, Berlin, 1933, p. 24-46 ; P. TOUBERT, Les structures du Latium médiéval. Le Latium méridional et la Sabine du IX siècle à la fin du XII ${ }^{e}$ siècle, Rome, 1973, tomo II, p. 963-997.
} 
que confirma, a posteriori, que su acceso a este grupo dependía mucho de Hugues de Arles.

Odón se vuelve igualmente hacia el medio rodolphien/richardide, centrado en Raúl de Borgoña, rey de los Francos del Oeste, de 923 hasta 936. Raúl es el hijo de Ricardo el Justiciero, conde de Borgoña y hermano de Bosón de Provenza ${ }^{103}$. Odón ha podido tener acceso a él por los Bosonides, via los Guilhemides, pero es más probable otra vía de acceso. En 921 Raúl desposa a Emma, hija del rey Robert I y hermana de Hugues el Grande, y se alía pues a la familia muy poderosa de los Robertiens, de los que Odón es cercano desde su nacimiento ${ }^{104}$. Como se ha señalado, en los años 927-936, Emma mantiene lazos directos y bastante intensos con Odón (muy visibles en el grosor del trazo en el grafo) ya que juega a menudo el rol de petitor de diplomas de su esposo dirigidos al abad. Subrayemos finalmente que Raúl arrastra una parte de su parentesco, que controla la Borgoña, en interacciones directas con Odón. Es en particular el caso de su madre, Adeláida y de su hermano Hugues le Noir.

Los medios rodolfien y guilhemide permiten conjuntamente a Odón agrandar su horizonte con un tercer espacio relacional: el de los grandes laicos y eclesiásticos del Mâconnais que comienzan a otorgar donaciones a Cluny. Una parte de ellos son antiguos fieles de Guillaume le Pieux y prodigan su favor a su antigüo nutritus. Otros son arrastrados por su fidelidad hacia los Richardides. Incluso si es difícil delimitar el origen de los lazos del abad de Cluny con los dos obispos de Mâcon, subrayamos finalmente que su intensidad contrasta fuertemente con la situación bajo el abaciado de Bernón ${ }^{105}$. Desde el inicio de su abaciado en Cluny, Odón ha aprovechado su capital social para reforzar su poder abacial, en particular por la obtención de privilegios y de donaciones.

103 Sobre los Richardides, M. CHAUME, Les origines du duché de Bourgogne, Dijon, 1925, tomo I, p. 360440; de forma sintética, O. GUILLOT, « Formes, fondements et limites de I'organisation politique en France au $X^{\mathrm{e}}$ siècle », en II Secolo di ferro : mito e realtà del secolo X. Atti della Settimane di Studio del Centro italiano di Studi sull'alto Medioevo, Spoleto, 19-25 aprile 1990, Spolète, 1991, vol. 1, p. 57-124, ici p. 74-80.

104 Sobre el matrimonio de Raoul y de Emma, R. LE JAN, « D'une cour à l'autre : les voyages des reines de Francie au X $X^{e}$ siècle », en EAD., Femmes, pouvoir et société, op. cit. n. 13, p. 39-52, ici p. 41.

105 Sobre el desarrollo de los lazos entre estos dos obispos y Cluny, U. WINZER, « Cluny und Mâcon im 10. Jahrhundert », en Frühmittelalterliche Studien, 23, 1989, p. 154-202, ici p. 154-168. Los grafos iError! No se encuentra el origen de la referencia., iError! No se encuentra el origen de la referencia. y iError! No se encuentra el origen de la referencia. son de hecho engañosos y es preferible fiarse del "film" de la vida de Odón, que muestra claramente que los lazos de los obispos de Mâcon con Cluny remontan a 926, o sea, un momento en el que Odón dirigía ya la abadía, lo que permite suponer su rol importante en el establecimiento de lazos entre la abadía y sus diócesis. 


\subsubsection{Redes y reformas monásticas}

Fuera de Cluny se permiten igualmente las primeras reformas monásticas de Odón por su participación en las redes aristocráticas. Sus iniciativas pueden ser repuestas en el juego de intermediarios Guilhemides y Ricardides. La dirección abacial de Déols, decidida por Bernón antes de su muerte, se explica también por el hecho de que el establecimiento ha sido fundado por Ebges de Déols, un fiel de Guillaume le Pieux. Por su parte, la reforma de Romainmôtier, por iniciativa de Adeláida de Borgoña, se deriva de la influencia del grupo ricardida. Finalmente la reforma de Tulle mezcla la mediación guilhemida por el sesgo de los medios limusines. (Adémar de Échelles y Ebles Manzer) a la de los Richardides, en la confirmación final del abaciado de Odón por el rey Raúl. ${ }^{106}$.

Estas reformas desembocan más tarde en la instauración de redes secundarias, cristalizadas alrededor de los co-abades de Odón que dirigen la abadía en su ausencia ${ }^{107}$. Si Arnulgo, el co-abad de Odón en Aurillac parece totalmente aislado durante esta fase, no es el caso de Adacius (figura 16), su abad en Tulle, que relaciona a Odón con la aristocracia guilhemide. Odón utiliza desde entonces su capital social para establecer una nueva forma de poder, el multi-abaciado, adquiriendo -gracias a su inserción en la aristocracia- abades a los que confirma los derechos, en el plano jurídico, obteniendo privilegios y donde asienta su autoridad, a escala local, gracias al establecimiento de redes intermediarias de sus co-abades. Su autoridad multi-abacial debe estar comprendida globalmente de forma reticular, tanto en su establecimiento como en su funcionamiento concreto.

\footnotetext{
106 Sobre estas reformas, I. RosÉ, Construire une société seigneuriale, op. cit. n. 22, p. 194-223. Sobre Tulle más particularmente, J.-P. BRUNTERC' $\mathrm{H}$, « La succession d'Acfred, Duc d'Aquitaine (927-936) », en Quæstiones medii ævi novæ, 6, 2001, p. 196-239.

107 Sobe el multi-abaciado, D. W. POECK, Cluniacensis Ecclesia. Der cluniacensische Klosterverband (10.12. Jahrhundert), Munich, 1998, p. 214-218. D. IogNA-PRAT, «Odon, Romainmôtier et l'Église clunisienne des origines », en ID., Etudes clunisiennes, Paris, 2002, p. 151-160, ici p. 154-155.
} 


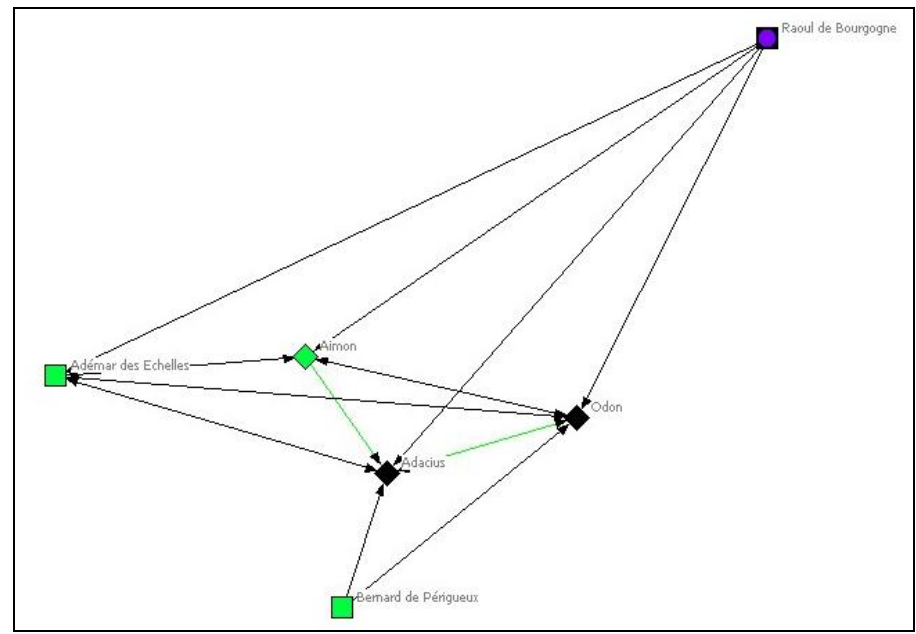

Figura 16. El primer círculo de la red personal del co-abad Adacius (927-935).

\subsection{La extensión máxima del capital social (936-942)}

936 constituye un nuevo giro en el itinerario biográfico de Odón pues la mayor parte de las personas que lo habían favorecido mueren ese año. Concretamente es el caso del rey Taúl y del papa Juan XI, después de Ebbes de Déols, que fallece un año más tarde. Estos acontecimientos acarrean una fuerte recomposición de la jerarquía aristocrática y, por tanto, de la inserción de Odón en las redes de poder.

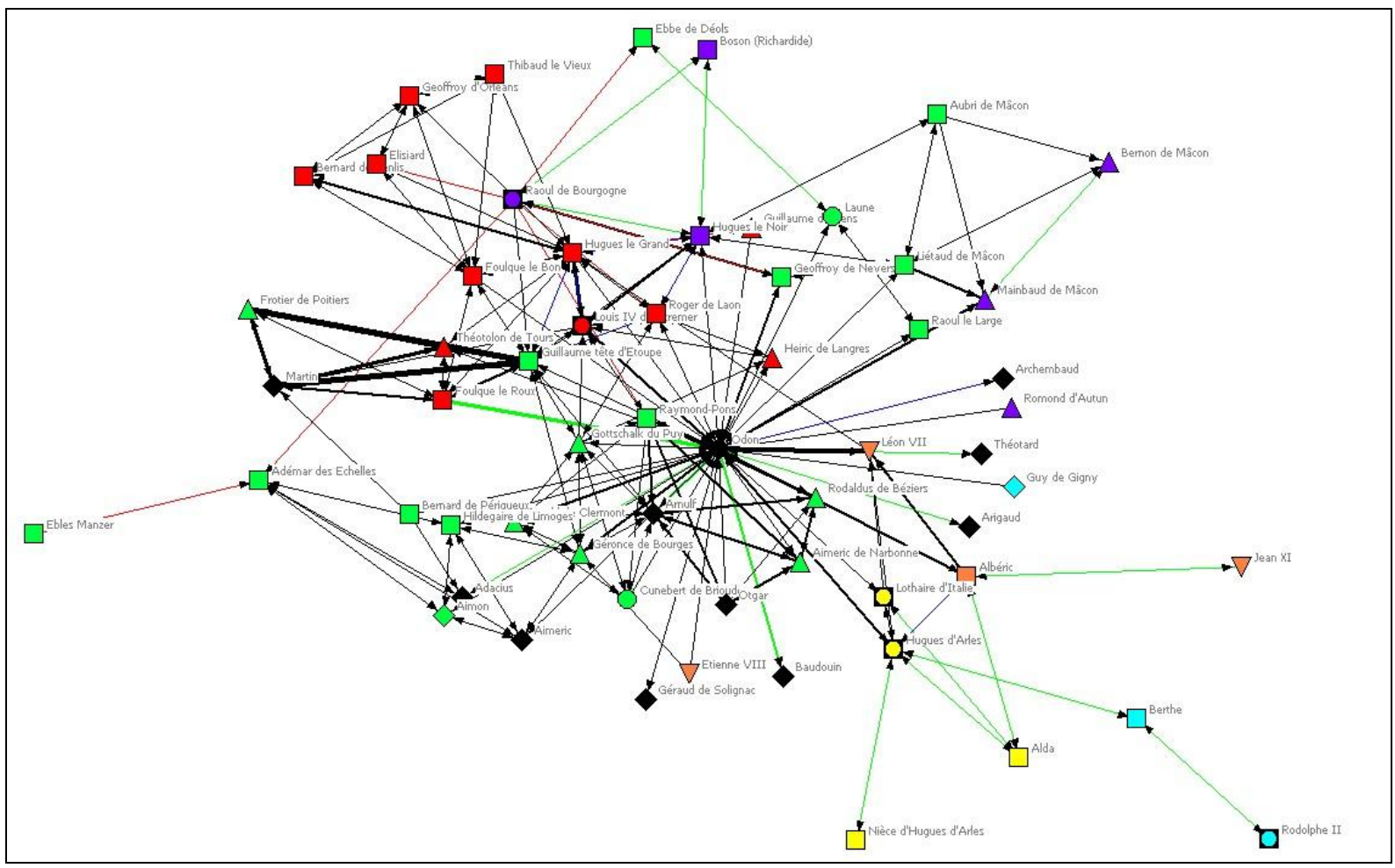

Figura 17. Red personal de Odón de Cluny (936-942). 


\subsubsection{Características generales de la cuarta fase de la red "odoniana"}

En esta última fase de su itinerario biográfico, la red personal de Odón (figura 17) permanece conexa y conserva parcialmente su dimensión estrellada, particularmente en sus interacciones con los actores eclesiásticos. Las novedades residen en la intensificación global de las relaciones sociales, la emergencia de nuevos actores, particularmente en Gaule, y la vuelta masiva al poder del polo robertien. En el transcurso de este período, Odón aparece como el Cutpoint principal, seguido de muy lejos por el princeps de Roma Albéric y el rey de Italia, Hugues de Arles $^{108}$. Se encuentra desde ahora de lleno en el corazón de la estructura reticular global y sus lazos con las personas que polarizan los diferentes espacios relacionales son cada vez más directos. En la última fase de su vida Odón está pues en una situación de gran proximidad con las personas influyentes de la aristocracia del reino del Oeste. Esta situación privilegiada le permite utilizar plenamente su capital social, para construir y legitimar su poder multi-abacial.

Los diferentes cálculos de centralidad confirman la posición de poder que ocupa Odón en el último período de su vida: aparece desde muy lejos y más todavía que antes, como la persona más central de la estructura reticular global ${ }^{109}$. En relación con la fase precedente ha doblado su número de vecinos directos (41) y tiene tres veces más que Hugues el Grande, la persona más central después de él; es un intermediario casi indispensable para los otros aristócratas, Por último pueden entrar fácil y rápidamente en contacto con todas las personas presentes en el grafo. Se advierte además una renovación casi completa de otros actores centrales, signo de una total recomposición de lazos sociales tras 936: sólo Raúl (que muere sin embargo rápidamente en 936) Hugues de Arles y Hugues le Noir jugaban ya este rol durante la fase precedente, pero parecen haber perdido su influencia en beneficio de otros actores. Estos últimos atestiguan un reequilibrio de relaciones e interacciones sociales hacia Neustria con la irrupción de aristócratas Robertiens (Hugues Le Grand, Roger de Laon), sin que los otros grupos familiares desaparezcan sin embargo por eso. Subrayemos finalmente la pérdida de

\footnotetext{
108 Los Cutpoints secundarios son el gran laico Adémar des Échelles y Berthe, esposa del rey de Bourgogne jurane Rodolphe II, después del rey de Italia Hugues de Arles.

109 Para la « centralidad de grado» : 1) Odon (41), 2) Hugues le Grand (14), 3) Guillaume Tête d'Étoupe $(14), 4)$ El obispo Gottschalk du Puy, 5) Raymond Pons, 6) L'abbé Arnulf, 7) Louis IV d'Outremer. Para la "centralidad de proximidad": 1) Odon (139), 2) Guillaume Tête d'Étoupe (172), 3) Hugues le Grand (175), 4) Hugues le Noir (176), 5) Roger de Laon (178), 6) Louis IV d'Outremer (180), 7) Raymond Pons (181). Para la «centralidad de intermediario»: 1) Odon (1254, 454), 2) Hugues d'Arles (187, $833), 3)$ Hugues le Grand $(135,988)$, 4) Hugues le Noir $(86,847), 5)$ Raoul de Bourgogne $(85,828), 6)$ Guillaume Tête d'Étoupe $(82,261)$, 7 ) Albéric $(75,333)$.
} 
centralidad de los titulares de la función real: todavía muy centrales en la fase precedente, han perdido su posición privilegiada en beneficio de algunos grandes laicos.

El primer círculo de la red personal "odoniana" (figura 18) se sitúa en la continuidad de la fase precedente, salvo que está considerablemente amplificada y cuenta ahora con 43 vecinos directos -23 de los cuales son miembros de la Iglesia- que pertenecen a todos los medios aristocráticos y que aparecen frecuentemente como los polos de espacios relacionales intermediarios. Como anteriormente, el abad de Cluny mantiene con sus vecinos directos interacciones ante todo puntuales (trazos negros), que son más señalados con algunos actores: el obispo de Mâcon Mainbaud, el papa León VII, el arzobispo Géronce de Bourges, los reyes Hugues de Arles (Italia) y Louis IV d'Outremer (reino de los Francos del Oeste y finalmente los grandes laicos Albéric, princeps de Roma, y Raymond Pons, conde de Toulouse. Se encuentra así la lógica del período precedente, pero desmultiplicada al lado de actores más numerosos: haciendo referencia a aquellas formas de legitimidad, Odón confirma su poder abacial a dos diferentes escalas. Con esta perspectiva, se puede subrayar el desarrollo de redes intermediarias construidas alrededor de sus co-abades Aimeric, Arnulf, Adacius et Otgar, todos situados en la antigua área de influencia guilhemida. Estas últimas juegan un rol de relevo de la autoridad de Odón y están insertadas también en una tela de relaciones y de interacciones sociales, menos densa que la del abad de Cluny. El desarrollo de estas redes intermediarias está ligado posiblemente al rol específico que juega Odón en esta zona geográfica. Es él, en efecto, quien aparece como el intermediario principal entre los diferentes herederos de los Guilhemides, en adelante compartimentados entre Aquitania, Berry, Poitou y Mâconnais. 


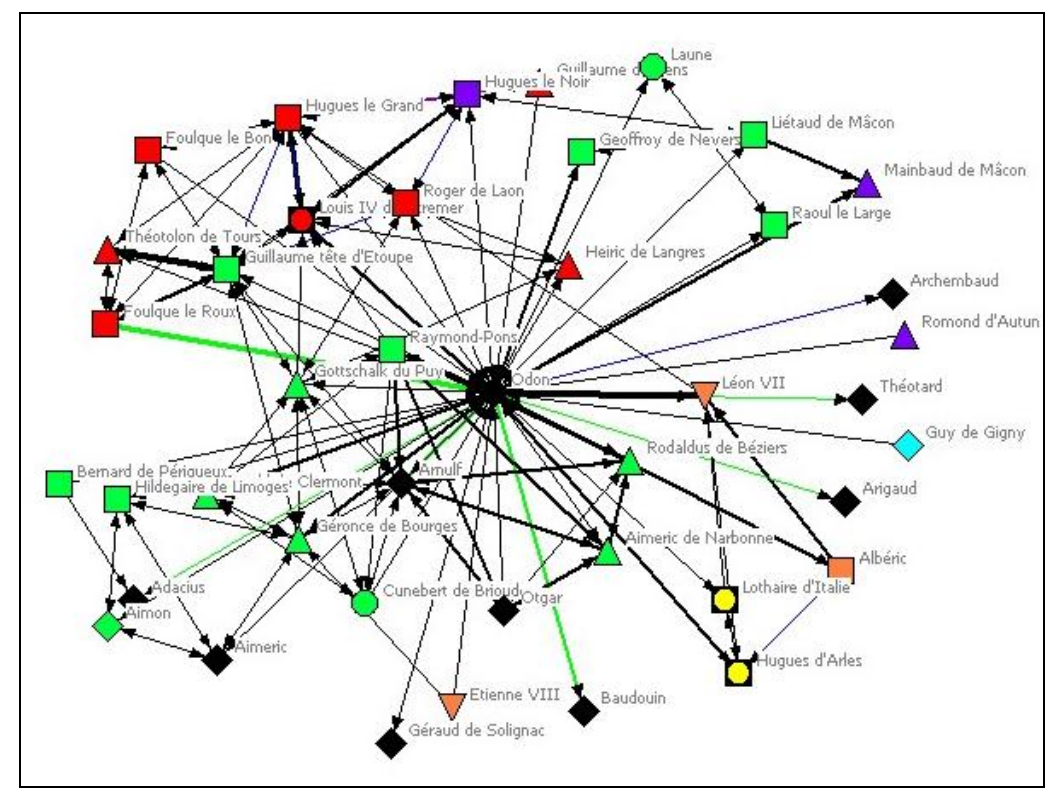

Figura 18. Primer círculo de la red personal de Odón en 936-942.

\subsubsection{Una reconfiguración de la red personal de Odón entre cuatro medios aristocráticos}

Tras el fallecimiento de sus principales benefactores en 936, Odón se adapta a la reconfiguración global de las relaciones de poder en Francia occidental, evolucionando de su posición central. Participa así en cuatro medios que se hacen visibles con motivo de reformas monásticas.

El grupo romano se ha centrado en Albéric ${ }^{110}$. Los lazos que Odón mantiene con éste último manan de una alianza matrimonial entre su hija Alda y Hugues de Arles, con quien el abad de Cluny tiene relación directa desde hace varios años. Por otro lado, Albéric mantiene lazos sin intermediario con Odón, confiándole varios monasterios a reformar, mientras que el papa León VII, próximo al princep de Roma le otorga siete bulas, lo que explica la intensidad de sus lazos mutuos.

El segundo medio corresponde a la base burguiñona de Cluny y se centra en el hermano de Raúl, Hugues le Noir, que se hace duque de Borgoña. Sólo el conde de Nevers y el obispo de Mâcon parecen no formar parte de él pero continúan estando en contacto directo con Odón. Este medio richardide constituye probablemente la vía de acceso principal a la persona del rey carolingio Luis IV d'Outremer quien

110 Sobre Albéric, G. ARNALDI, « Alberico di Roma », en Dizionariò biografico degli Italiani, Rome, 1960, vol. I, p. 647-656. 
establece fidelidades en el ducado de Borgoña a partir de $937^{111}$. Más tarde, Odón está en contacto directo con este soberano, del que obtiene privilegios.

El tercer grupo, el de los Guilhemides, se ha disgregado entre varios herederos tras el fallecimiento de Acfred, muerto sin hijos en $927^{112}$. Después de 936 se vuelve a centrar en personas que ejercen su poder a una escala más reducida: los condes de Poitiers Ebles Manzer, después Guillaume Tête d'Étoupe, verdadero heredero de Guillaume en términos de centralidad de grado y de proximidad; el conde de Toulouse, Raymond-Pons, y finalmente de grandes aristócratas auvernianos, en particular los obispos de Limoges, del Puy y de Clermont. Sólamente el arzobispo de Bourges, Gérence, queda en el centro de este medio aristocrático. Todas estas personas promueven reformas de Odón en Aquitania, principalmente en Saint-Pons de Thomières, en Chanteuges o en Sarlat ${ }^{113}$. Esta nueva configuración del grupo aquitano atestigua interacciones más dispersas que antes, índice de una fragmentación global del poder. Por otra parte, la aristocracia eclesiástica y monástica juega ahí un rol más polarizante y estructurante que en otros sitios, señal de la parte tomada por los obispos en el gobierno de la gente en el Midí, que se concreta también por el rol más visible de los co-abades de Odón.

El último grupo, el de los Robertiens, se vuelve a centrar desde 936 en el duque de los Francos, Hugues el Grande, y se renueva profundamente. Se destaca aquí, en efecto, la aparición de nuevos hombres, promovidos condes por Hugues le Grand, que sólo eran sus fieles en decenios precedentes ${ }^{114}$. Este medio conoce, por otra parte, una extensión geográfica de las fidelidades, que se vuelven a centrar en la cuenca parisina y en el norte de Borgoña, al tiempo que se hacen más densas. Odón está, por otra parte, vinculado a las dos personas que juegan un rol de polarización de las relaciones aristocráticas: Hugues le Grand, a cuya petición reforma las abadías de Fleury y de Saint-Pierre-le-Vif de Sens, y Théolón, al que conoce cuando era canónigo en Saint.Martin y que le pide reformar la abadía de

\footnotetext{
111 Sobre Louis IV y estos años 936-942, K. F. WERnER, Les origines (avant I'an Mil), Paris, 1984, p. 463-464; L. THEIS, L'héritage des Charles, Paris, 1990, p. 167-171; P. LAUER, Le règne de Louis IV d'Outremer, Paris, 1900, p. 11-35 ; O. GUILLOT, «Formes, fondements et limites », loc. cit. n. 103, p. 88-97. M. ChaUme, Les origines, op. cit. n. 103, p. 423-435.

112 J.-P. BRUNTERC'H, « La succession d'Acfred », loc. cit. n. 106, p. 196-239.

113 Sobre estas reformas, I. RosÉ, Construire une société seigneuriale, op. cit. n. 22, p. 288-304.

114 Sobre esta estrategia de Hugues le Grand, Y. SASSIER, «Thibaud le Tricheur et Hugues le Grand », en O. Guillot et R. FaVreau, éd., Pays de Loire et Aquitaine, op. cit. n. 77, p. 146-157 ; H. Noizet, La fabrique de la ville, op. cit. n. 86, p. 69-71; EAD., «L'ascension du lignage robertien : du Val de Loire à la Francie », en Annuaire-Bulletin de la société de I'histoire de France (année 2004), 2006, p. 19-35, ici p. 26-35.
} 
Saint-Julien de Tours ${ }^{115}$. Al final de su vida Odón reactiva así fuertemente los espacios relacionales de su juventud, lo que explica en parte su muerte en Tours, en 942.

\section{Conclusión}

En definitiva ¿qué aportan la reconstrucción y la representación gráfica de las redes de poder al conocimiento de las práctica sociales de la aristocracia de la alta Edad Media, en una época de conmoción de la sociedad? Muestran en primer lugar cómo el poder social de un hombre, Odón, se construye a largo plazo, a escala de una vida, apoyándose en personas que están en posición de centralidad, una estructura reticular más amplia. El análisis ha clarificado en particular el rol que juega el padre de Odón en la carrera de su hijo confiándolo a dos nutritores influyentes. El poder de este capital social inicial se desmultiplica con alianzas matrimoniales o diplomáticas entre los miembros de diferentes medios aristocráticos, favoreciendo el acceso a otras personas, gracias a estar los espacios relacionales intermediarios ensartados los unos en los otros. Al final, la disgregación de su formación aristocrática entre Robertiens y Guilhemides permite a Odón tener un acceso directo a todas las personas centrales dentro de diferentes medios aristocráticos y encontrarse él mismo en posición de centralidad. Más todavía, el poder multiabacial de Odón está inscrito en estas lógicas y se apoya en estrategias que juegan en la estructura reticular de la sociedad a diferentes escalas: Odón pasa por sus relaciones para que le confíen la dirección de monasterios y después confirma su autoridad abacial con una demanda sistemática de privilegios, pontificales y reales, obtenidos gracias al juego de redes aristocráticas. Su dirección multi-abacial se apoya en último lugar en co-abades que son intermediarios de su autoridad en las redes locales en las que participan.

Este estudio testifica por otra parte el proceso de reconfiguración de las redes aristocráticas, pasando de una estructura carolingia a una estructura señorial. La construcción reticular de la sociedad, todavía relativamente centrada en los reyes en los años 880 , se recompone y se repolariza así progresivamente alrededor de los príncipes, en espacios relacionales intermediarios, perdiendo los soberanos poco a poco su posición exclusiva de centralidad. Este trastorno tiene, evidentemente, consecuencias en las estrategias sociales de los miembros de la nobleza. Si los resortes del poder de un individuo continúan descansando en su inserción en los

\footnotetext{
115 La reforma de Saint-Pierre-le-Vif de Sens es sin duda también apoyada por el arzobispo Guillaume,
} al que Odón pudo conocer durante su formación en Paris al lado de Remi d’Auxerre. Cfr. infra, p. 30. 
medios aristocráticos, se asiste a dos cambios mayores en relación con la época carolingia. En primer lugar, la sola proximidad real no es prueba de gran carrera: hay que participar en adelante en el entorno de los príncipes, que mediatizan claramente las fidelidades y que son, más ampliamente, los primeros actores de la creación y de la recreación de lazos sociales ${ }^{116}$. El caso de Odón ilustra por otra parte el desarrollo de estrategias de multipertenencia a varios medios aristocráticos principescos, en el caso de algunos miembros de la Iglesia. En una sociedad en la que los poderes se recomponen a una escala geográfica más restringida, tal actitud desemboca en una posibilidad mayor de poder, caracterizada por la búsqueda de una proximidad directa con varias personas que se encuentran cada una en el centro de espacios relacionales intermediarios, pero también de la renovación puntual de interacciones con ellas. Si ellas permiten desarrollar una forma de poder supra regional (el multi-abaciado) sin estar demasiado íntimamente ligado a un medio particular, tales estrategias sorprenden por las fuertes tensiones que supone su puesta en marcha: en el contexto de luchas aristocráticas hay siempre el riesgo de ser tenido como desleal en un medio concreto; hay que ser capaz a continuación de mantener al mismo tiempo todas las relaciones para poder activarlas en caso de necesidad. Es esta última coacción la que explica uno de los rasgos más originales de las prácticas reticulares en esta época: la construcción y la activación de las redes resultan de los desplazamientos de diferentes personas que allí participan. Así la movilidad de los hombres viene a alimentar sus relaciones sociales, cristalizándose en algunos momentos bajo la forma de interacciones, alrededor de personas, como el entorno de un grande o alrededor de lugares, por ejemplo en fundaciones o restauraciones monásticas. Estos desplazamientos regulares son la característica más evidente de las relaciones sociales en el transcurso de un período en el que las instituciones no están todavía ancladas en lazos fijos.

En último lugar, el análisis reticular demuestra la dimensión eminentemente aristocrática y familiar de las redes de poder de la alta Edad Media, que no descansan sobre las funciones ejercidas por los hombres. Esto se ve bien con las reformas abaciales, que no se hacen jamás sólo entre los monjes, sino en una colaboración entre monjes, obispos y laicos. Los grafos muestran así claramente la participación en las reformas -y más ampliamente en todas las formas de lazos -de una misma aristocracia, tanto laica como eclesiástica: son grupos de clérigos y de laicos, unidos por relaciones de parentesco o de fidelidad, que promueven las

\footnotetext{
116 Sobre el proceso de mediatización de la fidelidad por los príncipes, O. GuYOTJEANNIN, « Rois et princes », loc. cit. n. 38 , p. $124-125$.
} 
restauraciones monásticas, en una convergencia de interés que trasciende los ordines. La participación de un mismo grupo social en las reformas hace así particularmente visibles las estrategias desarrolladas para asegurar la dominación global del grupo aristocrático en la sociedad. El interés de los grandes laicos por guardar un derecho de control sobre la forma de poder que es la Iglesia reúne así las expectativas de la institución eclesial hacia de la aristocracia laica, proveedora de bienes materiales y "reserva" necesaria de futuros clérigos y monjes.

El análisis de redes tiene así un gran valor heurístico ya que permite estudiar las fuentes de una forma nueva, descubrir los hechos sociales desconocidos o testificar, mediante cálculos, cambios que se "sentían" sin poderlos demostrar verdaderamente. En consecuencia, el interés del proceso me parece que reside ante todo en la utilización de métodos cuantitativos al servicio de un análisis cualitativo.

Más allá de estas conclusiones sobre la estructuración, los modos de funcionamiento y las evoluciones de la aristocracia del siglo $X$, ¿cuáles son los límites y las aportaciones de un proceso en una perspectiva diacrónica, incluso transdisciplinaria? Conviene subrayar ante todo que las fuentes de la alta Edad Media no permiten delimitar algunos elementos, bien perceptibles en otros periodos mejor documentados. Así, no hay ninguna huella de reformas que hubieran fracasado, ni de tensiones de Odón con sus co-abades, por la sencilla razón de que la mayor parte de las restauraciones y de los actos del abad de Cluny sólo son conocidas por textos hagiográficos o de dimensión memorial que no evocan evidentemente los fracasos de las personas que ponen en escena. De la misma forma, es imposible delimitar la dimensión, intencional o no, de las estrategias sociales: se puede pensar que la elección de un nutritor concreto era precisamente objeto de especulaciones sobre el largo plazo pero no se conocen prácticas de fosterage, o de donación que no se hayan concretado por una carrera brillante, en particular en el seno de la Iglesia porque su huella se conserva solamente en las Vidas de santos. El hecho de que solo el éxito social sea perceptible en la documentación podría pues dar la impresión de una aproximación mecánica de la red como único actor de explicación del poder de Odón. Desde mi perspectiva, la cuestión no es solamente ver lo que una red personal permite explicar (las reformas monásticas, la obtención de privilegios....), sino, después de haberla reconstruido, delimitar el funcionamiento, la estructuración y, sobre todo, reconstruir su dinámica de construcción a largo plazo. 
Más ampliamente, el enfoque experimentado en este artículo podría abrir pistas para otros períodos históricos. Así, la ampliación de la noción de "red personal", integrando las relaciones de los alter da acceso, no sólo a las simples relaciones de un hombre, sino a una amplia parte del mundo aristocrático, de una duración bastante larga. Esta elección metodológica permite sobrepasar el análisis clásico de redes egocentradas para inclinarse sobre el de los círculos sociales, que he calificado -falta de medios en lo inmediato- de "espacios relacionales intermediarios" que estructuran el conjunto del universo nobiliario y que evolucionan también, independiente o conjuntamente los unos de los otros según los contextos. Otra novedad susceptible de desarrollar para otros períodos es la integración de la dimensión diacrónica y evolutiva de la red personal, hecha de rotura de relaciones, de redefiniciones de los lazos que forman, ellos mismos, nuevas interacciones. Esta preocupación permite reconstruir de más cerca las trayectorias individuales, de analizar cómo se elabora -en función de los períodosel trayecto de vida, cuáles son las elecciones que cuentan, en términos de estrategias sociales, en función de la estructura reticular más global de la sociedad.

Nos podemos preguntar, para terminar, sobre las formas de prolongar este tipo de análisis para la época medieval. Una vía a explorar sería la de reconstruir la dimensión espacial de las relaciones sociales, fundamental en las configuraciones reticulares de la alta Edad Media. A esta primera interrogación sigue otra: llegar a tomar en cuenta también la verticalidad de las relaciones sociales, es decir el hecho de que toda persona que ejerce un poder se defina en esta época ante todo mediante un vínculo privilegiado con las realidades inmateriales tales como Dios y los santos. Así, los aristócratas laicos ejercen sus funciones legítimamente porque han hecho de ciertos santuarios con reliquias el centro simbólico de su poder; las comunidades monásticas y sus abades son los representantes en la tierra de los santos a cuyo nombre se ha consagrado su iglesia; los obispos se erigen en defensores de los apóstoles y mártires de los primeros siglos que han fundado su catedral. Estos santos están anclados en lugares fijos y son ellos los que dan legitimidad a la mayor parte de las práctica sociales, como el hecho de desplazarse hacia ellos para cambiar de función (ser monje, clérigo, rey), establecer una alianza o firmar una carta. A la red social "real", que se juega en el plano horizontal en el seno de la aristocracia responde, pues, en espejo, una red ideal que hace intervenir a Dios, los santos y los antepasados que vienen a legitimar, en la tierra, las relaciones entre los hombres. 


\section{Bibliografía}

Althoff, Gerd (1989). «Königsherrschaft und Konfliktbewältigung im 10. und 11. Jahrhundert » en Frühmittelalterliche Studien, 23, pp. 265-290.

Althoff, Gerd (1990). Verwandte, Freunde und Getreue. Zum politischen Stellenwert der Gruppenbindungen im frühen Mittelalter. Darmstadt: Wissenschaftliche Buchgesellschaft.

Althoff, Gerd y Witthöft, Chr. (2003). «Les services symboliques entre dignité et contrainte » en Annales HSS, pp. 1293-1318.

Arnaldi, Girolamo (1960). «Alberico di Roma» en Dizionario biografico degli Italiani. Rome: Treccani, vol. I, pp. 647-656.

Artifoni, Enrico (2006). «Segreti e amicizie nell'educazione civile dell'età dei comuni ». Micrologus, 14, pp. 259-274.

Ayton, Andrew (2005). «The Battle of Crécy : Context and Significance » en Ayton, Andrew y Preston, P. éd. The Battle of Crécy, 1346. Woodbridge: Boydell \& Brewer, pp. 1-34.

Balletto, Laura (1995). «Ethnic Groups, cross-social and cross-cultural Contacts on Fifteenth-Century Cyprus ». Mediterranean Historical Review, 10/1-2, pp. 35-48.

Barnes, J. A. (1954). « Class and Commities in a norwegian Island Parish ». Human Relations, VII/1, p. 39-58.

Bayon, Nathalie (2006). Eugène Spuller (1835-1896). Itinéraire d'un républicain entre Gambetta et le ralliement. Villeneuve d'Ascq: Presses Universitaires du Septentrion.

Beaurepaire Pierre-Yves. éd. (2002). La plume et la toile. Pouvoirs et réseaux de correspondance dans l'Europe des Lumières. Arras: Artois Presses Université, Histoire.

Beaurepaire, Pierre-Yves y Taurisson, D. éd. (2003). Les Ego-documents à I'heure de l'électronique. Nouvelles approches des espaces et réseaux relationnels. Montpellier: Publications de Montpellier III.

Beaurepaire, Pierre-Yves y Taurisson, D. (2003a). «Introduction » en Beaurepaire Pierre-Yves y Taurisson, D. éds. (2003). Les Ego-documents à I'heure de 
l'électronique. Nouvelles approches des espaces et réseaux relationnels. Montpellier: Publications de Montpellier III, pp. 9-20.

Beaurepaire, Pierre-Yves, Häseler, J. y McKenna, A. éds. (2006). Les Réseaux de correspondance à l'âge classique (XVI ${ }^{e}-X V I I I^{e}$ siècle). Saint-Étienne: Publ. de I'Université de Saint-Etienne.

Becquet, Jean (1977). "Les évêques de Limoges aux $\mathrm{X}^{\mathrm{e}}, \mathrm{XI}^{\mathrm{e}}$ et $\mathrm{XII}^{\mathrm{e}}$ siècles ». Bulletin de la Société archéologique et historique du Limousin, 104, pp. 63-90.

Bennett, Judith M. (2004). « The Tie that binds: peasant Marriages and Families in late medieval England » en Neel, Carol. éd. Medieval Families. Toronto: University of Toronto Press.

Bidart, Claire (2005). «Les temps de la vie et les cheminements vers l'âge adulte ». Lien social et Politiques, 54, pp. 51-63.

Bidart, Claire (2006). « Crises, décisions et temporalités: autour des bifurcations biographiques ». Cahiers internationaux de sociologie, 120, pp. 29-57.

Bidart, Claire (2008). «Dynamiques des réseaux personnels et processus de socialisation: évolutions et influences des entourages lors des transitions vers la vie adulte ». Revue Française de Sociologie, 49/3, pp. 559-583.

Bidart, Claire y Lavenu, D. (2005). «Evolutions of personal Networks and life Events ». Social Networks 27/4, pp. 359-376.

Bijsterveld, Arnoud-Jan A. (2004). « Overqualified for their Jobs? Rural Deans in the Diocese of Liège (Fifteenth and Sixteenth Centuries) » en Goudriaan, Koen, van Moolenbroek, J. y Tervoort, A. éds. Education and Learning in the Netherlands, 1400-1600. Leiden: Brill, pp. 87-111.

Boone, Marc (1998a). «Het falen van de netwerken » en Prevenier, Walter. éd. Prinsen en Poorters: Beelden van de laat-middeleeuwse samenleving in de Bourgondische Nederlanden, 1384-1530. Antwerpen: Mercatorfonds, pp. 344-354.

Boone, Marc (1998b). «Netwerken in de steden», en Prevenier, Walter. éd. Prinsen en Poorters: Beelden van de laat-middeleeuwse samenleving in de Bourgondische Nederlanden, 1384-1530. Antwerpen: Mercatorfonds, pp. 232-257. 
Boulet, Romain (2008). Comparaison des graphes, applications à l'étude d'un réseau de sociabilité paysan au Moyen Âge. Thèse de doctorat de mathématiques sous la direction de J.-L. Abbé. Toulouse: Université de Toulouse 2.

Boulet, Romain, Hautefeuille, F., Jouve, B., Kuntz, P., Le Goffic, B., Picarougne, F. y Villa, N. (2007). «Sur I'analyse de réseaux de sociabilité de la société paysanne médiévale ». Méthodes Computationnelles pour Modèles et Apprentissages en Sciences Humaines et Sociales (MASHS), Brest, 10-11 mai.

Bourdieu, Pierre (1994). «L'illusion biographique » en ID., Raisons pratiques. Sur la théorie de l'action. Paris: Seuil, pp. 81-89 [Primera publicación en Actes de la recherche en sciences sociales, 62-63, 1986].

Bourgain, Pascale (2002). «Autobiographie » dans Gauvard, Claude, De Libera, A. y Zink M. éds. Dictionnaire du Moyen Âge, Paris: P.U.F., pp. 112-113.

Bourin, Monique y Chareille P. éds. (1988-95), Genèse médiévale de I'anthroponymie moderne, t. I, II, III, Tours: Publications de I'Université de Tours, 1988, 1992 y 1995.

Bouter, Nicole. éd. (1991). Naissance et fonctionnement des réseaux monastiques et canoniaux (Actes du premier colloque international du CERCOM, Saint-Étienne, 16-18 novembre 1985). Saint-Étienne: Publ. De I'Univ. De Saint-Etienne.

Bradbury, Scott (2004). «Libanius' Letters as Evidence for Travel and epistolary Networks among Greek Elites in the fourth Century » en Ellis, Linda y Kidner, F. L. Travel, Communication and Geography in Late Antiquity. Aldershot: Ashgate, pp. 73-80.

Brechon, Franck (1998). «Le réseau urbain en Cévennes et Vivarais » en Coulet, Noël y Guyotjeannin O. éds. La Ville au Moyen Age. I : Ville et espace. Paris: Éditions du CTHS, pp. 265-277.

Brechon, Franck (2000). Réseau routier et organisation de l'espace en Vivarais et sur ses marges au Moyen Âge. Thèse de doctorat d'histoire sous la direction de M.T. Lorcin. Lyon: Université Lumière-Lyon II.

Bruand, Olivier (2002). Voyageurs et marchandises aux temps carolingiens. Les réseaux de communication entre Loire et Meuse aux VIII et $I X^{e}$ siècles. Bruxelles: De Boeck. 
Brunterc'h, Jean-Pierre (2001). «La succession d'Acfred, Duc d'Aquitaine (927936) ». Quæstiones medii ævi novæ, 6, pp. 196-239.

Brunterc'h, J.-P. (1997 ). «Naissance et affirmation des principautés au temps du roi Eudes. L'exemple de I'Aquitaine » en Guillot, Olivier y Favreau, R. éds. Pays de Loire et Aquitaine de Robert le Fort aux premiers Capétiens, actes du colloque scientifique international (Angers, septembre 1987). Poitiers: Société des antiquaires de l'Ouest.

Buchholzer-Rémy, Laurence (2006). Une ville en ses réseaux: Nuremberg à la fin du Moyen Âge Paris: Belin.

Burton, Janet (2006). « Fundator noster: Roger de Mowbray as Founder and Patron of Monasteries » en Burton, Janet y Jamroziak, E. éds. Religious and Laity in Western Europe 1000-1400. Brepols: Turnhout, pp. 23-39.

Burgtorf, Jochen y Nicholson H. éds. (2006). International Mobility in the Military Orders (Twelfth to Fifteenth Centuries): Travelling on Christ's Business. Cardiff: University of Wales Press.

Cardon, Bert y De Keyzer, B. (2000). «Dirk Bouts in de universiteitsstad: intellectuele netwerken » en Veelenturf, Kees. éd. Geen povere schoonheid: Laatmiddeleeuwse kunst in verband met de Moderne Devotie. Nijmegen: Valkhof Pers.

Caron, Marie-Thérèse (1998). «Adellijke netwerken », en Prevenier, Walter. éd. Prinsen en Poorters: Beelden van de laat-middeleeuwse samenleving in de Bourgondische Nederlanden, 1384-1530. Antwerpen: Mercatorfonds.

Cartron, Isabelle (2010). Les pérégrinations de Saint-Philibert. Genèse d'un réseau monastique dans la société carolingienne. Rennes: Presses Universitaires de Rennes.

Castaño González, Javier (1997). « Social Networks in a Castilian Jewish Aljama and the Court Jews in the Fifteenth Century: a preliminary Survey (Madrid 14401475) ». En la España medieval, 20, pp. 379-392.

Chastang, Pierre (2001). Lire, écrire, transcrire. Le travail des rédacteurs de cartulaires en Bas-Languedoc (XI ${ }^{e}-X I I I^{e}$ siècles). Paris: CTHS.

Chattaway, Carol M. (1999). «Looking a medieval Gift Horse in the Mouth: the Role of the Giving of Gift Objects in the Definition and Maintenance of the Power 
Networks of Philip the Bold ». Bijdragen en mededelingen betreffende de geschiedenis der Nederlanden, 114/1, pp. 1-14.

Chaume, Maurice (1925). Les origines du duché de Bourgogne. Dijon: E.Rebourseau.

Cochelin, Isabelle (2002). «Quête de liberté et réécriture des origines: Odon et les portraits corrigés de Baume, Géraud et Guillaume » en Lauwers, Michel éd. Guerriers et moines. Conversion et sainteté aristocratiques dans I'Occident médiéval (IX $X^{e}-X I I^{e}$ siècle). Antibes: Éditions APDCA, pp. 183-233.

Comber, Michelle (2001). «Trade and Communication Networks in early historic Ireland ». Journal of Irish Archaeology, 10, pp. 73-92.

Dahl, Gunnar (1998). Trade, Trust, and Networks : commercial Culture in late medieval Italy. Lund (Sweden): Nordic Academic Press.

Damen, Mario (2003). « Het Hof van Holland in de late Middeleeuwen ». Holland, $35 / 1$, pp. 1-8.

De Certeau, Michel (2002). L'écriture de l'histoire. Paris: Gallimard [1975 pour l'édition d'origine].

Deflou-Leca, Noëlle (2010). Saint-Germain d'Auxerre et ses dépendances (Ve-VIIIe siècle). Saint-Étienne: Presses Universitaires de Saint-Étienne.

Degenne, Alain y Forsé, M. (2004). Les réseaux sociaux. Paris: Armand Colin [2 ${ }^{\text {ème }}$ édition].

Delacroix, Christian, Dosse, F., Garcia, P. (2005). Les courants historiques en France, XIXe-XXe siècle. Paris: Armand Colin.

Devroey, Jean-Pierre (2003). Économie rurale et société dans I'Europe franque (VIeIXe siècles). Tome 1: Fondements matériels, échanges et lien social. Paris: Belin.

Dimmock, Spencer (2005). «Urban and commercial Networks in the Later Middle Ages: Chepstow, Severnside and the Ports of southern Wales». Archaeologia Cambrensis, 152, pp. 53-68.

Doreian, Patrick y Woodard, K. L. (1992). « Fixed List versus Snowball Selection of Social Networks ». Social Science Research, 21, pp. 216-233. 
Dosse, François (2005). Le pari biographique. Écrire une vie. Paris: Éd. La Découverte.

Dosse, François (2010). Renaissance de l'événement. Un défi pour l'historien: entre sphinx et phénix. Paris: P.U.F.

Dumézil, Bruno (2007). «Gogo et ses amis : écriture, échanges et ambitions dans un réseau aristocratique de la fin du VIe siècle ». Revue historique, 643/3, pp. 553593.

Dumolyn, Jan (2002). «Investeren in sociaal Kapitaal. Netwerken en sociale Transacties van Bourgondische Ambtenaren ». Tijdschrift voor sociale geschiedenis, 28/4, pp. 417-438.

Dumolyn, Jan (2006), «Les réseaux politiques locaux en Flandre sous la domination bourguignonne: les exemples de Gand et de Lille ». Revue du Nord, 88, pp. 309-329.

Dumolyn, Jan (2007). "Jan van den Driessche / Jehan de la Driesche, un fonctionnaire flamand au service de Louis XI ». Revue historique, 309/1, pp. 71-90.

Esch, Arnold (1985a). «Überlieferungs-Chance und Überlieferungs-Zufall als methodisches Problem des Historikers ». Historische Zeitschrift, 240, pp. 529-570.

Esch, Arnold (1985b). «Chance et hasard de transmission. Le problème de la représentativité et de la déformation de la transmission historique » en Schmitt, Jean-Claude y Oexle, O. G. éds. (2002), Les tendances actuelles de I'histoire du Moyen Âge en France et en Allemagne. Paris: Publications de la Sorbonne.

Fabris, Cécile (2005). Étudier et vivre à Paris au Moyen Âge: le collège de Laon. Paris: Droz.

Fossier, Robert (2006). Sources de I'histoire économique et sociale du Moyen Âge occidental. Questions, sources et documents commentés. Turnhout: Brepols.

Fray, Jean-Luc (2006) Villes et bourgs de Lorraine: réseaux urbains et centralité au Moyen Âge. Clermont-Ferrand: Université Blaise Pascal.

Frugoni, Arsenio (1993). Arnaud de Brescia, Paris: Belles Lettres [Première édition: Arnaldo da Brescia nelle fonti del secolo XII, Rome: Istituto storico italiano per il Medio Evo 1954]. 
Garrisson, Mary (2004). «Les correspondants d'Alcuin » en Judic, Bruno et Depreux Ph. éds. Alcuin, de York à Tours. Écriture, pouvoir et réseaux dans l'Europe du haut Moyen Âge. Annales de Bretagne et des pays de l'Ouest, 111, pp. 319-331.

Gaskins, Richard (2005). « Network Dynamics in Saga and Society ». Scandinavian Studies, 77/2, pp. 201-216.

Geary, Patrick J. (1986). «Vivre en conflit dans une France sans État ». Annales ESC, 41, pp. 1107-1133.

Gerstenberg, Otto (1933 ). Die politische Entwicklung des römischen Adels im 10. und 11. Jahrhundert (Dissertation). Berlin : Friedrich-Wilhelms-Universität.

Giordanengo, Gérard (2002). «Épistolaire (genre)», en Gauvard, Claude, De Libera, A. y Zink M. éds. Dictionnaire du Moyen Âge. Paris: P.U.F., pp. 488-489.

Goldin, Simlu (1996). " "Companies of Disciples" and "Companies of Colleagues": Communication in Jewish intellectual Circles» en Menache Sophia éd. Communication in the Jewish Diaspora: The Pre-Modern World. Leiden: Brill.

Gribaudi, Maurizio (2001). «Percorsi individuali ed evoluzione storica: quattro percorsi operai attraverso la Francia dell'Ottocento ». Quaderni Storici, 106/1, pp. 115-152.

Grummitt, David (2003). «Public Service, private Interest and Patronage in the fifteenth-century Exchequer » en Clark, Linda. éd. The Fifteenth Century, III. Woodbridge: Boydell \& Brewer, pp. 149-162.

Grünbart, Michael (2005). «"Tis Love that has warm'd us". Reconstructing Networks in 12th Century Byzantium ». Revue belge de philologie et d'histoire, 83/2, pp. 301313.

Guerreau-Jalabert, Anita (1999). «Parenté » en Le Goff, Jacques y Schmitt, J.C. éds. Dictionnaire raisonné de l'Occident médiéval. Paris: Fayard, pp. 861-876.

Guerreau-Jalabert, Anita (1981). «Sur les structures de parenté dans I'Europe médiévale ». Annales ESC, 36/6, pp. 1028-1049 ;

Guerreau-Jalabert, Anita (1988). «La désignation des relations et des groupes de parenté en latin médiéval ». Archivum Latinitatis Medii Aevi, 46, pp. 65-108. 
Guerreau-Jalabert, Anita (1995). «Spiritus et caritas. Le baptême dans la société médiévale », en Copet-Rougier, Elisabeth y Héritier, F. éds. La parenté spirituelle. Paris: Editions des Archives contemporaines, pp. 133-203.

Guerreau-Jalabert, Anita (1999). «Nutritus/oblatus : parenté et circulation d'enfants au Moyen Âge » en Corbier, Mireille. Adoption et Fosterage. Paris: De Boccard, pp. 263-290.

Guillot, Olivier (1991). «Formes, fondements et limites de I'organisation politique en France au Xe siècle », en II Secolo di ferro: mito e realtà del secolo X. Atti della Settimane di Studio del Centro italiano di Studi sull'alto Medioevo, Spoleto, 19-25 aprile 1990, Spolète: CISAM, vol. 1, p. 57-124.

Guyotjeannin, Olivier (2002). «Rois et princes», en Contamine, Philippe. dir. Histoire de la France politique, t. 1, Le Moyen Âge. Le roi, l'Église, les grands, le peuple. Paris: Seuil, pp. 115-146.

Guyotjeannin Olivier, Pycke J. y Tock, B.-M. (2006). Diplomatique médiévale. Turnhout: Brepols.

Haines, Margaret (2000). «Artisan family Strategies: Proposals for Research on the Families of Florentine Artists » en Ciappelli, Giovanni y Rubin, P. L. éds. Art, Memory, and Family in Renaissance Florence. Cambridge: Cambridge University Press.

Haseldine, Julian P. (2001). «Thomas Becket: martyr, saint and friend ? » en Gameson, Richard y Leyser H. éds. Belief and Culture in the Middle Ages: Studies presented to Henry Mayr-Harting. Oxford: Oxford University Press, pp. 305-317.

Hill, Barbara (1996). «Alexios I Komnenos and the imperial Women » en Mullett, Margaret y Smythe D. éds. Alexios I Komnenos: Papers on the Second Belfast Byzantine International Colloquium, 14-16 April 1989. Belfast: Belfast Texts and Translations, pp. 37-54.

Hillebrandt, Maria (1982). «The cluniac Charters. Remarks on a Quantitative Approach for Prosopographical Studies ». Medieval Prosopography, 3, pp. 3-25.

Hillebrandt, Maria (2000). «Social Groups as Recognition Patterns: a Means of Dating Medieval Charters» en Gervers, Michael éd. Dating Undated Medieval Charters. Woodbridge: Suffolk, pp. 163-175. 
Hines, John (2003). «Society, Community and Identity » en Charles-Edwards, Thomas. éd. After Rome. Oxford: Oxford University Press.

Iogna-Prat, Dominique (2005). «La question de l'individu à l'épreuve du Moyen Âge » en Iogna-Prat, Dominique y Bedos-Rezak, B. M. éds. L'individu au Moyen Âge. Individuation et individualisation avant la modernité. Paris: Aubier, pp. 7-29.

Iogna-Prat, Dominique (2002). «Odon, Romainmôtier et l'Église clunisienne des origines » en Id., Études clunisiennes. Paris: Picard, pp. 151-160.

Jamroziak, Emilia (2005). « Networks of Markets and Networks of Patronage in thirteenth-Century England » en Prestwich, Michael, Britnell, R. y Frame R. éds. Thirteenth Century England, X. Woodbridge: Boydell \& Brewer, pp. 41-49.

Jean de Salerne, Vita sancti Odonis prima et maior, dans PL 133, col. 43-86.

Jeudy, Colette (1991). «L'œuvre de Remi d'Auxerre », en Iogna-Prat, Dominique, Jeudy, C. y Lobrichon, G. éds. L'École carolingienne d'Auxerre. De Murethach à Remi 830-908. Paris: Beauchesne, p. 373-397.

Jurkowski, Maureen (2005). «Lollard Book Producers in London in 1414 » en Barr, Helen y Hutchison, A. M. éds. Text and Controversy from Wyclif to Bale. Turnhout: Brepols.

Kahl, Hans-Dietrich (2003). «Feldkirchen und Dietrichstein zwischen den Mächtigen des zwölften Jahrhunderts. Ein Beitrag zu den Anfängen bambergischer Besitzungen in Kärnten ». Carinthia, 193, pp. 225-251.

Kasarjyan, Jana Fritzsch, Buchenrieder, G. y Korff, R. (à paraître) « Social Capital in Armenia » en Fertig, Georg. éd. Social Networks, Political Institutions, and Rural Societies. Turnhout: Brepols.

Klapisch-Zuber, Christiane (2002). «"Kin, Friends, and Neighbors": the urban Territory of a merchant Family in $1400 »$ en Findlen Paula éd. The Italian Renaissance. Malden: Blackwell.

Kusman, David (1999). «Entre noblesse, ville et clergé. Les financiers lombards dans les anciens Pays-Bas aux $\mathrm{XIV}^{\mathrm{e}}-\mathrm{XV}^{\mathrm{e}}$ siècles: un état de la question ». Publications du Centre européen d'études bourguignonnes (XIV $-X V I^{e}$ s.), 39, pp. 113-132. 
L'autobiografia nel Medioevo. (1998) Atti del 34 Convegno storico internationale di Todi, Spolète: Centro italiano di studi sull'alto Medioevo.

Lafon, François (2006). Guy Mollet. Itinéraire d'un socialiste controversé (19051975). Paris: Fayard.

Lauer, Philippe (1900). Le règne de Louis IV d'Outremer. Paris: Bouillon.

Laughton, Jane, Jones, E. y Dyer, C. C. (2001). «The urban Hierarchy in the later Middle Ages: a study of the East Midlands ». Urban History, 28/3, pp. 331-357.

Lauranson-Rosaz, Christian (1987). L'Auvergne et ses marges (Velay, Gévaudan), du VIIe au XIIe siècle. La fin du monde antique? Le Puy-en-Velay: Les Cahiers de la Haute-Loire.

Lazega, Emmanuel (1998). Réseaux sociaux et structures relationnelles. Paris: P.U.F. [réédition en 2007].

Le Goff, Jacques (1996). Saint Louis. Paris: Gallimard, p. 311-522.

Lemercier, Claire (2003). Un si discret pouvoir. Aux origines de la chambre de commerce de Paris, 1803-1853, Paris: Editions La Découverte.

Lemercier, Claire (2005a). «Analyse de réseaux et histoire ». Revue d'Histoire moderne et contemporaine, 52/2, p. 88-112.

Lemercier Claire (2005b). «Analyse de réseaux et histoire: une bibliographie. Support d'une intervention pour la préparation de l'agrégation de sciences sociales - mars $2006 »$, en ligne sur http://www.quanti.ihmc.ens.fr/document.php?id=106.

Lemercier, Claire (2005c). « Les carrières des membres des institutions consulaires parisiennes au XIXe siècle ». Histoire et mesure, 20/1-2, pp. 59-95 ;

Lemercier, Claire (2006). «Liens privés et régulation de l'économie: la famille et I'institution (Paris, XIXe siècle) ». Revue d'histoire du XIXe siècle, 33, pp. 23-53.

Lemercier, Claire, Zalc, C. (2008). Méthodes quantitatives pour I'historien. Paris: La Découverte.

Le Jan, Regine (1993). «Apprentissages militaires, rites de passage et remises d'armes au haut Moyen Âge » en Éducation, apprentissages, initiation au Moyen 
Âge. Actes du premier colloque international de Montpellier, novembre 1991. Cahiers du CRISIMA, 1, p. 211-232.

Le Jan, Regine (1995). Famille et pouvoir dans le monde franc (VIIe-Xe siècle). Essai d'anthropologie sociale. Paris: Publications de la Sorbonne.

Le Jan, Regine (2000). «Continuity and Change in the Tenth-Century Nobility » en Duggan, Anne J. éd. Nobles and Nobility in Medieval Europe: Concepts, Origins, Transformations. Woodbridge: Boydell \& Brewer, pp. 53-68.

Le Jan, Regine (2001). Femmes, pouvoir et société dans le haut Moyen Âge. Paris: Picard.

Le Jan, Regine (2001a). «D'une cour à l'autre : les voyages des reines de Francie au Xe siècle » en Le Jan (2001), pp. 39-52.

Le Jan, Regine (2001b). «Réseaux de parenté, memoria et fidélité autour de I'an $800 \gg$ en Le Jan (2001), pp. 108-118.

Le Jan, Regine (2001c). «La reine Gerberge, entre Carolingiens et Ottoniens » en Le Jan (2001), pp. 30-38

Le Jan, Regine (2001d). «L'épouse du comte du IXe au XIe siècle: transformation d'un modèle et idéologie du pouvoir » en Le Jan (2001), pp. 21-29.

Le Jan, Regine (2001e). «Dénomination, parenté et pouvoir dans la société du haut Moyen Âge (VIe-Xe siècle) », en Le Jan (2001), pp. 224-238.

Liutprand de Crémone (1839). Antapodosis, éd. Pertz, Georg Heinrich, Hanovre (MGH, Scriptores, III), pp. 273-339.

Mabille, Emile. éd. (1866). La Pancarte noire de Saint-Martin de Tours brûlée en 1793, restituée d'après les textes imprimés et manuscrits. Paris-Tours: Hénaux.

Magnani, Eliana (2008). «Les médiévistes et le don. Avant et après la théorie maussienne », en Revue du M.A.U.S.S., 31, pp. 525-544 (en ligne).

Martines, Lauro (1994). «Love and Hate in Renaissance Patronage: Italy ». The Italianist, 14, pp. 5-31.

Mazel, Florian (2011). «La Provence entre deux horizons (843-1032). Réflexions sur un processus de régionalisation » en Gaillard, Michèle, M. Margue, A. Dierkens, 
H. Pettiau. éds. De la mer du Nord à la Méditerranée. Francia media, une région au cœur de l'Europe, Luxembourg: Publications du CLUDEM, pp. 453-485.

McCray, Patrick W. (1999). «Creating Networks of Skill: Technology Transfer and the Glass Industry of Venice ». Journal of European Economic History, 28/2, pp. 301-333.

McKenna, Antony y Leroux, A. (2003). «Les réseaux de correspondance de Pierre Bayle: réalité instable et représentation électronique » en Beaurepaire, Pierre-Yves y Taurisson, D. éds. Les Ego-documents à I'heure de l'électronique. Nouvelles approches des espaces et réseaux relationnels. Montpellier: Publications de Montpellier III, pp. 399-420.

McNamara, Jo Ann (2003). «Women and Power through the Family revisited » en Erler, Mary C. y Kowaleski M. éds. Gendering the Master Narrative: Women and Power in the Middle Ages. Ithaca (NY): Cornell University Press, pp. 17-30.

Mercklé, Pierre (2004). La sociologie des réseaux sociaux. Paris: La Découverte,

Melville, Gert (2002). «L'institutionnalité médiévale dans sa pluridimensionnalité » en Schmitt, Jean-Claude y Oexle, O. G. éds. Les tendances actuelles de I'histoire du Moyen Âge en France et en Allemagne. Actes du colloque de Sèvres (1997) et Göttingen (1998) organisés par le Centre national de la Recherche scientifique et le Max-Planck-Institut für Geschichte. Paris: Publications de la Sorbonne, pp. 243-264.

Mooers, Stephanie L. (1986). « Networks of Power in Anglo-Norman England». Medieval Prosopography, 7/2, pp. 25-54.

Morsel, Joseph (2004). «Les sources sont-elles le «pain de l'historien»? ». Hypothèses 2003. Travaux de l'école doctorale d'histoire de I'Université Paris IPanthéon-Sorbonne, Paris: Publications de la Sorbonne, pp. 273-286.

Moutoukias, Zacahrias (2003). «Réseaux de négociants ou réseaux egocentrés: une approche méthodologique » en Beaurepaire, Pierre-Yves y Taurisson, D. éds. Les Ego-documents à I'heure de l'électronique. Nouvelles approches des espaces et réseaux relationnels. Montpellier: Publications de Montpellier III, pp. 447-468.

Mullett, Margaret (1997). Theophylact of Ochrid: Reading the Letters of a Byzantine Archbishop. Aldershot: Ashgate Variorum. 
Murray, James M. (2000). « Of nodes and Networks: Bruges and the Infrastructure of Trade in Fourteenth-Century Europe » en Stabel, Peter, Blondé, B. y Greve A. éds. International Trade in the Low Countries (14th-16th Centuries): Merchants, Organisation, Infrastructure. Proceedings of the International Conference, GhentAntwerp, 12th-13th January 1997. Leuven: Garant, pp. 1-14.

Noizet, Hélène (2006). «L'ascension du lignage robertien: du Val de Loire à la Francie ». Annuaire-Bulletin de la société de I'histoire de France (année 2004), pp. 19-35.

Noizet, Hélène (2007). La fabrique de la ville. Espaces et sociétés à Tours (IXe-XIIIe siècle). Paris: Publications de la Sorbonne.

Nolte, Cordula (2000). «Gendering princely Dynasties: some Notes on family Structure, social Networks, and Communication at the Courts of the Margraves of Brandenburg-Ansbach around $1500 \gg$. Gender and History, 12/3, pp. 704-721.

Nora, Pierre (1978). «Le retour de l'événement » en Le Goff, Jacques y Nora P. éds. Faire de I'histoire. I. Nouveaux problèmes. Paris: Gallimard, pp. 285-308.

O'Keeffe, Tadhg (2006). «Wheels of Words, Networks of Knowledge: Romanesque Scholarship and Cormac's Chapel » en Bracken, Damian y O' Riain-Raedel D. éds. Ireland and Europe in the Twelfth Century. Dublin: Four Courts Press.

O'Sullivan, Robin Anne (2006). « The School of Love: Marguerite Porete's Mirror of Simple Souls ». Journal of Medieval History, 32/2, pp. 143-162.

Oury, Guy (1964). «L'archevêque Théotolon, restaurateur de Saint-Julien-deTours ». Revue Mabillon, 54, pp. 118-123.

Padgett, John F. y Ansell, Christopher K. (1993). « Robust Action and the Rise of the Medici, 1400-1434 ». American Journal of Sociology, 98, pp. 1259-1319.

Palmer, James (2005). «The «vigorous Rule» of Bishop Lull: between Bonifatian Mission and Carolingian Control ». Early Medieval Europe, 13/3, pp. 249-276.

Pascua, Esther (2001). "South of the Pyrenees: Kings, Magnates and political Bargaining in Twelfth-Century Spain ». Journal of Medieval History, 27/2, pp. 101120.

Pearce, Susan M. (2003). « Processes of Conversion in north-west Roman Gaul » en Carver Martin. éd. The Cross Goes North. York: York Medieval Press. 
Poeck, Dietrich W. (1998). Cluniacensis Ecclesia. Der cluniacensische Klosterverband (10.-12. Jahrhundert). Munich: Fink.

Polden, Anne (2006). «The social Networks of the Buckinghamshire Gentry in the Thirteenth Century ». Journal of Medieval History, 32/4, pp. 371-394.

Ponthieux, Sophie (2006). Le capital social, Paris: La Découverte.

Prevenier, Walter y Boone, M. (1993). « De steden van de Zuidelijke Nederlanden in de late middeleeuwen: stedelijke identiteit en corporatieve solidariteiten ».Tijdschrift van het Gemeentekrediet, 183, pp. 25-45.

Prevenier, Walter (1998). «De netwerken in actie» en Prevenier, Walter. éd. Prinsen en Poorters: Beelden van de laat-middeleeuwse samenleving in de Bourgondische Nederlanden, 1384-1530. Antwerpen: Mercatorfonds, pp. 294-319.

Rapp, Claudia (1997). «Ritual Brotherhood in Byzantium». Traditio, 52, pp. 285326.

Reimitz, Helmut (2002). «Social Networks and Identities in frankish Historiography. New Aspects of the History of Gregory of Tours Historiæ » en Corradini, Richard, Diesenberger, M. y Reimitz H. éds. The Construction of Communities in the Early Middle Ages. Texts, Resources and Artifacts. Leiden: Brill, pp. 229-268.

Remensnyder, Amy.G. (1996). Remembering Kings Past. Monastic Foundation Legends in Medieval Southern France. Ithaca-Londres: Cornell University Press.

Reveney, Denis (2005). «Middle English Writings for Women: Ancrene Wisse » en Johnson, David y Treharne, E. éds. Readings in Medieval Texts. Oxford: Oxford University Press, pp. 198-212.

Riché, Pierre (1993). «La Chrétienté occidentale (Xe-milieu du XIe siècle) » en Mayeur, Jean-Marie, Piétri, C., Piétri, L. y Vauchez, A. éds. Histoire du christianisme. t. IV: Évêques, moines et empereurs (610-1054). Paris: Desclée, pp. 767-866.

Richmond, Colin (1997). «Ruling Classes and Agents of the State: formal and informal Networks of Power ». Historical Sociology, 10/1, pp. 1-26.

Rollo-Koster, Joelle (2000). «Amongst Brothers: Italians' Networks in Papal Avignon (1360s-80s) ». Medieval Prosopography, 21, pp. 153-189. 
Rosé, Isabelle (2008). Construire une société seigneuriale. Itinéraire et ecclésiologie de I'abbé Odon de Cluny (fin du IXe-milieu du Xe siècle). Turnhout, Brepols.

Rosenwein, Barbara H. (1989). To be the Neighbor of Saint Peter. The social Meaning of Cluny's Property, 909-1049. Ithaca-New York: Cornell University Press.

Rosenwein, Barbara H. (1995). «La question de I'immunité clunisienne ». Bulletin de la Société des Fouilles Archéologiques de I'Yonne, 12, pp. 1-12.

Sandwell, Isabella (2007). «Libanius' social Networks: Understanding the social Structure of the later Roman Empire ». Mediterranean Historical Review, 22/1, pp. 133-147.

Santinelli, Emmanuelle (2003). Des femmes éplorées? Les veuves dans la société aristocratique du haut Moyen Âge. Villeneuve d'Ascq: Presses Universitaires du Septentrion.

Sassier, Yves (1997). « Thibaud le Tricheur et Hugues le Grand » en Guillot, Olivier et Favreau, R. éds. Pays de Loire et Aquitaine de Robert le Fort aux premiers Capétiens. Actes du Colloque international tenu à Angers en septembre 1987. Poitiers: Société des Antiquaires de I'Ouest.

Sawyer, Birgit (2003). «The Civil Wars revisited ». Historisk tidsskrift (Oslo), 82/1, pp. 43-73.

Shaw, David Gary (2005). «Social Networks and the Foundations of Oligarchy in medieval Towns ». Urban History, 32/2, pp. 200-222 .

Scheepsma, Wybren (2004). «Mystical Networks in the Middle Ages? On the first Women Writers in Dutch and their literary Contacts » en Van Dijk, Suzan, Broomans, P. Van der Meulen, J. Van Oostrum P. éds. I Have Heard about You. Hilversum: Uitgeverij Verloren, pp. 43-60.

Schütte, Leopold (1992). Die alten Mönchslisten und die Traditionen von Corvey, Teil 2: Indices und andere Hilfsmittel. Paderborn: Bonifatius.

Scott, Karen (1994). «Urban Spaces, Women's Networks, and the lay Apostolate in the Siena of Catherine Benincasa » en Matter, Ann y Coakley J. éds. Creative Women in Medieval and Early Modern Italy: A Religious and Artistic Renaissance. Philadelphia: University of Pennsylvania Press. 
Servant, Hélène (1998). Artistes et gens de Lettres à Valenciennes à la fin du Moyen Âge (vers 1440-1507). Paris: Klincsieck.

Settipani, Christian (1997). «Les comtes d'Anjou et leurs alliances aux Xe et XIe siècles » en Keats-Rohan, Katherine. S. B. éd. Family Trees and the Roots of Politics. The Prosopography of Britain and France from the Tenth to the Twelfth Century, Woodbridge: Boydell \& Brewer.

Sindbæk, Søren Michael (2007a).« The small World of the Viking. Networks in early medieval Communications and Exchange ». Norwegian Archaeological Review, 40/1, pp. 59-74.

Sindbæk, Søren Michael (2007b). «Networks and nodal Points: the Emergence of Towns in early Viking Age Scandinavia ». Antiquity, 81/311 pp. 119-132.

Sortor, Marci (2005). «The Measure of Success: Evidence for immigrant Networks in the southern Low Countries, Saint-Omer 1413-1455 ». Journal of Family History, 30/2, pp. 164-190.

Stabel, Peter (2001a). «De gewenste Vreemdeling. Italiaanse kooplieden en stedelijke maatschappij in het laat-middeleeuws Brugge». Jaarboek voor Middeleeuwse Geschiedenis, 4, pp. 189-221.

Stabel Peter (2001b). «Markets and Retail in the Cities of the late medieval Low Countries. Economic Networks and socio-cultural Display » en Cavaciocchi, Simona. éd. Fiere e mercati nella integrazione delle economie europee, secc. XIII-XVIII. Florence: Le Monnier, pp. 797-817 .

Story, Joanna (2005). « Charlemagne and the Anglo-Saxons » en Story, Joanna. Charlemagne. Empire and Society. Manchester: Manchester University Press.

Szabó, Thomas (1996). « Der Übergang von der Antike zum Mittelalter am Beispiel des Straßennetzes » en Lindgren, Ute. éd. Europäische Technik im Mittelalter, 800 bis 1400: Tradition und Innovation. Berlin: Gebr. Mann, pp. 25-43.

Theis, Laurent (1990). L'héritage des Charles. Paris: Seuil.

Toubert, Pierre (1973). Les structures du Latium médiéval. Le Latium méridional et la Sabine du IXe siècle à la fin du XIIe siècle. Rome: Bibliothèque des écoles françaises d' Athènes et de Rome. 
Verhaeghe, Frans (1998). «Medieval and later social Networks: the Contribution of Archaeology » en Hundsbichler, Helmuth, Jaritz, G. y Kühtreiber, T. éds. Die Vielfalt der Dinge: Neue Wege zur Analyse mittelalterlicher Sachkultur. Internationaler Kongreß Krems an der Donau 4. bis 7. Oktober 1994. Wien: Verlag der Österreichischen Akademie der Wissenschaften.

Vonrufs, Ulrich (2002). Die Politische Führungsgruppe Zürichs zur Zeit von Hans Waldmann (1450-1489): Struktur, politische Networks und die sozialen Beziehungstypen Verwandtschaft, Freundschaft und Patron-Klient-Beziehung. Bern: Peter Lang.

Werner, Karl Ferdinand (1984). Histoire de France vol. I: Les origines (avant I'an Mil), Paris: Fayard.

Werner, Karl Ferdinand (1997). «Les premiers Robertiens et les premiers Anjou (IXe siècle-début Xe siècle) » en Guillot, Olivier y Favreau, R. éds. Pays de Loire et Aquitaine de Robert le Fort aux premiers Capétiens, actes du colloque scientifique international (Angers, septembre 1987). Poitiers: Société des antiquaires de I'Ouest, pp. 9-67.

Werner, Karl Ferdinand (2004). Enquêtes sur les premiers temps du principat français (IXe- $X^{e}$ siècles)/ Untersuchungen zur Frühzeit des französischen Fürstentum (9.-10. Jahrhundert) [traduit par B. Saint-Sorny]. Ostfildern: Thorbecke.

White, Stephen D. (1978).«Pactum... legem vincit et amor judicium. The Settlement of Disputes by Compromise in 11th Century France ». American journal of legal history, 22, pp. 281-308.

Winzer, Ulrich (1989). «Cluny und Mâcon im 10. Jahrhundert ». Frühmittelalterliche Studien, 23, pp. 154-202.

Youngs, Deborah (2005). «Cultural Networks » en Radulescu, Raluca y Truelove, A. éds. Gentry Culture in Late Medieval England. Manchester, Manchester University Press, pp. 119-133.

Ysebaert, Walter (2005). «Medieval Letter-Collections as a Mirror of Circles of Friendship? The Example of Stephen of Tournai, 1128-1203». Revue belge de philologie et d'histoire, 83/2, pp. 285-300. 
Ysebaert, Walter (2007). «The Power of personal Networks: Clerics as political Actors in the Conflict between Capetian France and the County of Flanders during the last Decade of the Twelfth Century » en Bolton, Brenda y Meek, C. éds. Aspects of Power and Authority in the Middle Ages. Turnhout: Brepols, pp. 165-184.

Ysebaert, Walter (2009). «Medieval Letters and Letter Collections as historical Sources: methodological Questions and Reflections and research Perspectives (6th14th Centuries) ». Studi medievali, 50, pp. 41-73.

Zimmermann, Harald. éd. (1984). Papsturkunden, I. 896-1046. Vienne: Verlag der Oesterreichischen Akademie der Wissenschaften. 